\title{
Habitat affinities of 228 boreal Finnish spiders: a literature review
}

\author{
Katja Matveinen-Huju
}

Matveinen-Huju, K. 2004: Habitat affinities of 228 boreal Finnish spiders: a literature review. - Entomol. Fennica 15: 149-192.

Information about the habitat affinities of spiders is necessary in ecological studies. I focused on two factors in habitats of spiders: light intensity and moisture. First, the habitats were classified according to these factors. Canopy cover and tree species composition were used to indicate the amount of sunlight reaching the ground. Habitat moisture was determined indirectly from the vegetation. Second, the spider species were classified according to what kind of a habitat they were found in the literature. This paper updates and continues Huhta's (1971) classification, including 228 boreal spider species, based on Finnish literature from boreal region.

K. Matveinen-Huju, Department of Biological and Environmental Sciences, P. O. Box 65, FI-00014 University of Helsinki, Finland; E-mail: katja.matveinen @.helsinki.fi

Received 8 April 2003, accepted 21 January 2004

\section{Introduction}

In ecological studies, it is useful to know the autecology of the species studied (ShraderFrechette \& McCoy 1993). This information can be used as a basis for hypothesis testing. Classification of the species according to their habitat affinities is common for arthropods (e.g. Huhta 1971, Niemelä \& Halme 1992, Koivula 2001). However, often classifications are quite rough (forest species, open habitat species, and generalists), and e.g. moisture is usually not taken into account. Huhta (1971) published a habitat-affinity classification for 198 spiders. Here, I update and continue this classification, emphasizing Finnish literature whenever it is available for the focal species. Species may occur in different habitats in different parts of their range because suitable microclimatic conditions may vary among types of habitat (e.g. Huhta 1971), and consequently the Central European literature may not be applicable to Finland (Huhta 1971, Lehtinen et al. 1979). The updated classification now covers 228 of the ca. 620 species found in Finland (Marusik \& Koponen 2000). The species chosen for this literature review are such that can be caught with pitfall traps. The species list is not comprehensive, but contains species that I have collected in my ecological studies (K. Matveinen-Huju, unpublished data).

The nomenclature follows Platnick (2003). Other names used in the publications reviewed are given in parentheses after each species; authors for these other names are given only when they differ from the authors of the names used in Platnick (2003).

\section{Habitat classification}

The occurrence of most spiders is strictly limited by physical conditions, such as temperature, hu- 
midity, wind, and light intensity, and by biological factors, such as vegetation type, food supply, competition and predation (Foelix 1982). I concentrated on light intensity and moisture, because I assumed these factors to be among the most important abiotic factors characterizing the habitats of spiders.

\subsection{Classification of habitats}

Light intensity varies with the amount of radiation reaching the ground layer. The amount of radiation reaching the ground depends on the density of canopy cover, and tree species composition (Geiger 1965). In Norway spruce (Picea abies) stands, $4 \%-40 \%$ of the radiation reaches the ground, whereas in birch (Betula spp.) or Scots pine (Pinus sylvestris) stands the amount is higher: for birch $20 \%-30 \%$ and for pine $22 \%-$ $40 \%$. For deciduous trees, the amount of radiation reaching the ground varies with the season: in the summer deciduous forests may be as dark as spruce forests, but when there are no leaves about $50 \%$ of the radiation reaches the ground (Geiger 1965). Here, I considered deciduous forests as light forests, because the abundance/activity peaks of many species are in spring and autumn (Huhta 1971, Itämies \& Ruotsalainen 1984, Niemelä et al. 1994).

It is more difficult to find accurate information about the moisture levels near the ground. I used a rule of thumb based on vegetation: forests with lichens at the bottom layer are dry, those with forest mosses, such as Hylocomium splendens, are medium-moist, and those with Sphagnum mosses are moist. I considered clearcuts as dry, and groves as medium-moist habitat, even though there might be considerable variation within them.

The habitat classes are as follows. The classes used for light intensity are mostly the same as in Huhta (1971), but for moisture the class boundaries probably differ.

Light intensity

$\mathrm{A}=$ Open habitats (e.g. clear-cuts, meadows, fields, open bogs)

$\mathrm{B}=$ Semi-open habitats (e.g. light forests, forest edges, pine bogs, bushes)
$\mathrm{C}=$ Shady habitats (spruce forests, spruce mires)

Moisture

$1=$ Dry habitats (e.g. clear-cuts, dry meadows, forests with a ground layer of lichens)

$2=$ Medium-moist habitats (e.g. meadows of medium humidity, forests with a ground layer of forest mosses, like Hylocomium splendens, and groves)

$3=$ Moist habitats (e.g. bogs, mires, moist meadows, forests with a ground layer of Sphagnum mosses)

\subsection{Definition of a species' habitat affinity}

A species was classified according to its occurrence in different habitats, using above levels from $\mathrm{A}$ to $\mathrm{C}$ and 1 to 3 . The species indifferent towards light intensity were noted as $\mathrm{ABC}$, and the species indifferent towards moisture as 123 . Note that Huhta (1971) used D instead of ABC and 4 instead of 123.

I concentrated on published studies done within the hemiboreal and boreal forest zones in Finland, cited in the text for each species. As my focus was on boreal zone, I did not consider studies done in the northern parts of Finland. One should thus note that a given species might be found in different habitats in Lapland, compared to the boreal regions of Finland. For example, Maro sublestus is more eurytopic in Lapland than in the boreal region (Saaristo 1971). I also used one field guide from Central Europe (Heimer \& Nentwig 1991), because it contained most of the reviewed species, and a selection of publications from Sweden (Holm 1947, Holm \& Kronestedt 1970, Kronestedt 1990). However, for the actual classifications I ignored these publications if they were not consistent with the Finnish studies.

Animals move and can be occasionally found in habitats where they do not live or breed. Therefore, it was difficult to know whether the findings were from the preferred habitats or represented occasional ones. Whenever possible (Palmgren 1964, 1977a, Huhta 1965, 1971), I calculated the percentages of individuals found in each habitat type, and the focal species was considered to have an affinity for a certain habitat class if more than 
$75 \%$ of the individuals were caught there. More weight was put in those studies where the focal species was caught abundantly. The literature used in this review for 228 spider species is presented in section 3, and the habitat-affinity classes, based on this literature, are listed in Appendix 1.

\section{Descriptions of the habitat affinities of 228 spider species}

From now on, if I report a species being caught 'near the ground', it means in the ground-layer and/or in the lowest strata of the vegetation. With 'dryish' I mean dry habitats and the driest habitat types in the medium-moist class. The forest types and their abbreviations follow Cajander (1949).

\subsection{Araneidae}

Araneus diadematus Clerck, 1757

Araneus diadematus lives in trees and bushes (especially in conifers) (Lehtinen \& Kleemola 1962, Palmgren 1972, 1974b, 1977a, Koponen 1996). It has more rarely been caught near the ground in forests (e.g. rocky pine forests, VT, MT, hazel groves) (Huhta 1971, Palmgren 1972, 1977a, Biström \& Väisänen 1988), meadows (Palmgren 1977a), Ledum bogs (Palmgren 1977a), roadsides or cleared forests (Palmgren 1977a), and in walls of wooden houses or in firewood piles (Palmgren 1977a). According to Heimer and Nentwig (1991), the species lives in forest edges and gardens.

Araneus nordmanni (Thorell, 1870)

Araneus nordmanni has been captured mostly in spruce forests and on spruce trees (Palmgren 1974b, 1977a, Biström \& Väisänen 1988, Väisänen \& Biström 1990); according to Heimer and Nentwig (1991), it lives in tree crowns. However, Lehtinen et al. (1979) included A. nordmanni in mire fauna.

\section{Araneus quadratus Clerck, 1757}

Araneus quadratus lives in meadows, especially moist ones (Palmgren 1972, 1974b, 1977a, Heimer \& Nentwig 1991), and in other moist open biotopes, such as shores and bogs (e.g. MyricaMolinia bogs) (Palmgren 1972, 1974b). It has also been caught in light forests (e.g. rocky pine forests), roadsides or cleared forests, and Ledum bogs (Palmgren 1974b, 1977a).

\section{Araneus sturmi (Hahn, 1831) (Atea sturmi)}

Araneus sturmi lives in trees and bushes (especially pines) (Palmgren 1964, 1972, 1974b, 1977a, Lehtinen et al. 1979, Heimer \& Nentwig 1991). It has more rarely been captured near forest ground (e.g. Calluna and Cladonia in light pine forests, Vaccinium myrtillus, VT, MT) (Palmgren 1972, 1974b, Biström \& Väisänen 1988), peatlands (e.g. open bogs, Ledum bogs) (Palmgren 1972, 1977a), meadows (Palmgren 1972, 1977a), and roadsides or cleared forests (Palmgren 1977a).

\section{Cercidia prominens (Westring, 1851)}

Cercidia prominens lives in open or semi-open, dryish habitats near the ground (Palmgren 1972, 1974b). It has been found in forests (e.g. rocky pine forests, VT, mixed forests; also MT, spruce mires) (Palmgren 1964, 1972, 1977a, Biström \& Väisänen 1988, Heimer \& Nentwig 1991), bogs (Ledum bogs, Myrica-Molinia bogs; with the higher parts generally dry) (Palmgren 1972, 1977a), meadows (e.g. dry meadows, near ditches) (Palmgren 1972, 1977a, Heimer \& Nentwig 1991), small islands (Palmgren 1972), and roadsides or cleared forests (Palmgren 1977a).

Cyclosa conica (Pallas, 1772)

Cyclosa conica lives mainly in trees (Heimer \& Nentwig 1991), predominantly in spruces and very rarely in pines and junipers (e.g. MT, OMT, spruce mires) (Palmgren 1964, 1972, 1974b, 1977a). It has also been encountered in the lower strata of forests (e.g. moss, Vaccinium myrtillus, Calluna) (Palmgren 1964, 1972, 1974b, 1977a, Huhta 1971, Pajunen et al. 1995). A few specimens have been found in Ledum bogs, too (Palmgren 1977a).

Gibbaranea omoeda (Thorell, 1870) (Araneus omoedus)

Gibbaranea omoeda lives predominantly in spruces (e.g. MT, spruce mires) (Palmgren 1972, 
1974b, 1977a, Lehtinen et al. 1979). It has also been caught in other coniferous trees (Palmgren 1977a, Heimer \& Nentwig 1991), near the ground in forests (e.g. rocky pine forests, VT, MT, OMT, mixed forests) (Huhta 1971, Palmgren 1977a, Palmgren \& Biström 1979, Biström \& Väisänen 1988, Pajunen et al. 1995). One individual has been reported even in a Ledum bog (Palmgren 1977a).

Hypsosinga sanguinea (C. L. Koch, 1844) (Singa sanguinea)

Hypsosinga sanguinea has been caught in forests; mainly light ones (e.g. CT, rocky pine forests, mixed forests; but also MT, junipers) (Huhta 1965, 1971, Palmgren 1972, 1974b, 1977a, Biström \& Väisänen 1988, Pajunen et al. 1995). It has also been caught in peatlands (Ledum bogs, open bogs), and meadows (Palmgren 1977a). According to Heimer and Nentwig (1991), $H$. sanguinea lives in warm, sunny habitats.

\subsection{Clubionidae}

Clubiona caerulescens L. Koch, 1867 (Clubiona coerulescens)

Clubiona caerulescens was caught in forests (e.g. mixed forests, MT with not very closed growth, deciduous trees and bushes; also spruce forests) (Palmgren 1943, 1964, 1977a, Heimer \& Nentwig 1991), and Ledum bogs (Palmgren 1977a).

\section{Clubiona kulczynskii Lessert, 1905}

Clubiona kulczynskii has been caught in forests (e.g. spruce or spruce-dominated forests, mixed forests) (Palmgren 1964, Koponen 1995, Pajunen et al. 1995). Singletons have been found near a spring (Palmgren 1943) and in a moist meadow (Palmgren 1972). According to Heimer and Nentwig (1991), however, C. kulczynskii is a species of raised bogs.

\section{Clubiona lutescens Westring, 1851}

Clubiona lutescens has mainly been caught in light forests (e.g. deciduous forests, mixed forests, birch-mixed mires, forest edges; more rarely shady forests) (Palmgren 1943, 1964, 1972, 1977a, Lehtinen \& Kleemola 1962, Lehtinen et al. 1979). It has also been caught in moist mead- ows (e.g. near ditches, shore meadows; only one individual in dry ones) (Palmgren 1964, 1972, 1977a). However, according to Heimer and Nentwig (1991), C. lutescens lives within shoreline vegetation and peatlands.

\section{Clubiona neglecta O. P-Cambridge, 1862}

Clubiona neglecta has been caught mostly in meadows, mainly dry ones (Palmgren 1972, 1977a), and meadow-like semi-open vegetation on sand (Palmgren 1972). It has also been found in edges of brooks in spruce or mixed forests (Palmgren 1977a), and in deciduous bushes and herbs (Palmgren 1943). According to Heimer and Nentwig (1991), it lives in moist habitats in trees and bushes, and on shores under stones.

\section{Clubiona subsultans Thorell, 1875}

Clubiona subsultans has been caught mostly in forests, in some studies especially in coniferous trees, and among them especially in spruces (e.g. CT, coastal Pineta, VT, MT, OMT, mixed forests, hazel groves, peaty forests) (Palmgren 1943, 1972, 1977a, Huhta 1965, 1971, Lehtinen et al. 1979, Palmgren \& Biström 1979, Biström \& Väisänen 1998, Heimer \& Nentwig 1991, Pajunen et al. 1995). It has more rarely been caught in bogs (Ledum bogs, Myrica-Molinia bogs) (Palmgren 1972), and in meadows (Palmgren 1977a).

\section{Clubiona subtilis L. Koch, 1867}

Clubiona subtilis lives in moist habitats (Heimer \& Nentwig 1991): bogs (mainly Myrica-Molinia bogs, also open ones, shore bogs) (Palmgren 1943, 1972), and moist meadows (Palmgren 1972). It has also rarely been caught in dry meadows (Palmgren 1972, 1977a).

\section{Clubiona trivialis C. L. Koch, 1843}

Clubiona trivialis is most commonly associated with moderate tree cover and dryish habitats. It has been found in light forests (e.g. coastal Pineta, CT, VT, mixed forests, coniferous trees) (Lehtinen \& Kleemola 1962, Huhta 1965, 1971, Palmgren 1972, 1977a) and Ledum bogs (less in Myrica-Molinia bogs) (Palmgren 1972). It has more occasionally been caught in meadows, at least dry ones (Palmgren 1972, 1977a), and in skerries (Palmgren 1972). 


\subsection{Corinnidae}

Phrurolithus festivus (C. L. Koch, 1835)

Phrurolithus festivus has been caught in light forests (e.g. hazel groves, mixed forests, CT, VT, a forest fringe at a shore, overhanging grass in scarps; more rarely MT, junipers) (Palmgren 1972, 1977a, Biström \& Väisänen 1988, Heimer \& Nentwig 1991, Pajunen et al. 1995), peatlands (e.g. open bogs, Myrica-Molinia bogs, pine bogs) (Palmgren 1972, Koponen et al. 2001), meadows (mostly dry ones) (Palmgren 1972, 1977a), lawns and heaths (Heimer \& Nentwig 1991, Koponen 2000), skerries (Palmgren 1972), shores (Lehtinen \& Kleemola 1962, Heimer \& Nentwig 1991, Koponen 2000), dry open habitats (Lehtinen et al. 1979), under Cladonia on rocks (Palmgren 1943), and clear-cuts (Huhta 1971).

\subsection{Dictynidae}

Dictyna arundinacea (Linnaeus, 1758)

Dictyna arundinacea is mostly associated with sites of moderate tree cover, but with varying moisture. It has been caught in light pine forests, mostly dry ones (e.g. rocky pine forests, VT, forest edges) (Palmgren 1964, 1972, 1977a, 1977b, Biström \& Väisänen 1988, Heimer \& Nentwig 1991), peatlands (e.g. open bogs, MyricaMolinia bogs, Ledum bogs) (Palmgren 1972, 1977a), and meadows (Palmgren 1964, 1977a, Heimer \& Nentwig 1991). It lives mainly near the ground and - more rarely - in trees, e.g. junipers, pines and spruces (Palmgren 1964, 1972, 1977a).

Dictyna pusilla Thorell, 1856

Dictyna pusilla has most frequently been caught in coniferous trees (junipers, pines, spruces) (Lehtinen \& Kleemola 1962, Palmgren 1972, 1977a, 1977b). It has also occasionally been captured in pine and spruce forests near the ground (Huhta 1971, Palmgren 1972, 1977a, 1977b), in Ledum bogs (Palmgren 1977a), and in meadows (Palmgren 1977a). According to Heimer and Nentwig (1991), the species lives in herbs, bushes and trees in sunny habitats.
Mastigusa arietina (Thorell, 1871) (Tuberta arietina, Tetrilus arietinus)

Mastigusa arietina has mostly been found in ant nests (Formica rufa coll., Lasius fuliginosus) at least in dark spruce forests (Palmgren 1972, 1977b, Heimer \& Nentwig 1991). According to Heimer and Nentwig (1991), it lives also under bark. Huhta (1971) caught one individual in a burnt-over area.

\subsection{Gnaphosidae}

Drassodes pubescens (Thorell, 1856)

Drassodes pubescens has been found in forests, mainly dry and light ones (e.g. rocky pine forests, CT, VT, mixed forests; more rarely spruce mires) (Palmgren 1964, 1972, 1977a, Huhta 1971, Heimer \& Nentwig 1991, Pajunen et al. 1995), but also in dry to medium-moist meadows (Huhta 1971, Palmgren 1972, 1977a), grasslands and heaths (Heimer \& Nentwig 1991), clear-cuts and burnt-overs (Huhta 1971), shores (Lehtinen \& Kleemola 1962), and peatlands (e.g. open bogs, Calluna bogs, Myrica-Molinia bogs, Ledum bogs, Alnus swamps, Phragmites fens, a peat harvesting area) (Koponen 1968, 1979, 2002a, 2002b, Palmgren 1972, 1977a, Heimer \& Nentwig 1991, Koponen et al. 2001).

Drassyllus praeficus (L. Koch, 1866) (Zelotes praeficus)

According to Heimer and Nentwig (1991), Drassyllus praeficus lives in dry and light sites, e.g. rocky habitats and lawns. Most of the Finnish findings have been in shores and heaths (Koponen 2000). Other findings include fen-like Alnetum (Palmgren 1972), a Myrica-Sesleria bog (Palmgren 1972), a spruce-pine forest of VT (Palmgren 1972), grass on rocks (Palmgren 1972), a very dry sublapidicol (Palmgren 1964), and dry open habitats (Lehtinen et al. 1979).

Drassyllus pusillus (C. L. Koch, 1833) (Zelotes pusillus)

According to Heimer and Nentwig (1991), Drassyllus pusillus lives e.g. in forests, meadows, heaths, and sand. It has been caught in peatlands [e.g. open bogs; in Lithuania also pine bogs; a xerophilous mire species in Koponen (1968)] (Koponen 1968, Koponen et al. 2001, Koponen 
2002b), dry heaths (Koponen 2000), clear-cuts and burnt-overs (Huhta 1971), forests (Pajunen et al. 1995), and under Cladonia on rocks (Palmgren 1943).

\section{Gnaphosa bicolor (Hahn, 1833)}

Gnaphosa bicolor has been caught mostly in light forests (CT, rocky Pineta, VT, mixed forests, old forests; more rarely shady forests) (Palmgren 1943, 1964, 1972, 1977a, Huhta 1965, 1971, Heimer \& Nentwig 1991, Koponen 1995, Pajunen et al. 1995), but it has also been abundantly found in clear-cuts and burnt-overs (Huhta 1965, 1971). G. bicolor has also been caught in grass ribbons on small islands (Palmgren 1972), Myrica-Molinia bogs (Palmgren 1972), meadows (Palmgren 1964, Huhta 1971), very dry sublapidicol (Palmgren 1964), and dry open habitats (Lehtinen et al. 1979). Other habitat types in Heimer and Nentwig (1991) include rocky steppes.

\section{Gnaphosa microps Holm, 1939}

Gnaphosa microps has been caught mostly in peatlands, such as open bogs (Lehtinen et al. 1979, Heimer \& Nentwig 1991, Koponen et al. 2001, Koponen 2002a, 2002b), but one individual has also been found in a clear-cut (Huhta 1965). According to Palmgren (1943), G. microps is a rare northern species. Other habitats in Heimer and Nentwig (1991) include light heather-birch forests and meadows.

\section{Gnaphosa montana (L. Koch, 1866)}

The few findings of Gnaphosa montana have been from forests (e.g. under the bark of trees, VT) (Palmgren 1943, 1972, Huhta 1971, Heimer \& Nentwig 1991, Pajunen et al. 1995), clear-cuts and burnt-overs (Huhta 1971), very dry sublapidicol (Palmgren 1964), the outer walls and inside a house (Palmgren 1977a), and dry open habitats (Lehtinen et al. 1979).

\section{Haplodrassus cognatus (Westring, 1861)}

The few findings of Haplodrassus cognatus have mostly been from trees (under bark, in stems; e.g. oaks) (Palmgren 1943, 1972, 1977a, Lehtinen \& Kleemola 1962, Koponen 1996). According to Heimer and Nentwig (1991), however, the species lives within leaf litter in forests; indeed, Leh- tinen and Kleemola (1962) caught one female among litter.

Haplodrassus moderatus (Kulczyn'ski, 1897) Haplodrassus moderatus has been caught in more or less open peatlands (e.g. open bogs, Myrica-Molinia bogs, fens; in Heimer \& Nentwig (1991) also peaty forests) (Palmgren 1972, Koponen 1978, 2002a, 2002b, Lehtinen et al. 1979, Heimer \& Nentwig 1991, Koponen et al. 2001), drift-sand shores and shore meadows (Palmgren 1943), and other medium-moist to moist meadows (only rarely dry ones) (Palmgren 1972, 1977a, Heimer \& Nentwig 1991), fields (Palmgren 1943), and under loose bark of fence stakes (Palmgren 1943).

Haplodrassus signifer (C. L. Koch, 1839)

Haplodrassus signifer has mostly been caught in clear-cuts and burnt-overs (Huhta 1971), but it has also been found in light forests (e.g. hazel groves, mixed forests, coastal Pineta, VT, rocky pine forests; rarely shady ones) (Huhta 1971, Palmgren 1972, 1977a, Lehtinen et al. 1979, Biström \& Väisänen 1988, Heimer \& Nentwig 1991, Koponen \& Niemelä 1994, Koponen 1995, Pajunen et al. 1995), peatlands [e.g. open bogs, Myrica-Molinia bogs, pine bogs; a xerophilous mire species according to Koponen (1968)] (Palmgren 1972, 1977a, Koponen et al.2001, Koponen 2002a, 2002b), meadows (Palmgren 1943, 1972, Huhta 1971), lawns and heaths (Heimer \& Nentwig 1991), dry open sublapidicol (Palmgren 1977a), Pleurozium on skerries (Palmgren 1972), and rocks (Palmgren 1943).

\section{Haplodrassus silvestris (Blackwall, 1833)}

Most of the few findings of Haplodrassus silvestris have been in forests (a forest fringe at a shore, birch forests or birch-mixed stands of OMT) (Palmgren 1977a, Heimer \& Nentwig 1991). Two individuals have been reported in meadows (Huhta 1971, Palmgren 1977a). Other habitat types in Heimer and Nentwig (1991) include dry lawns and bogs.

\section{Haplodrassus soerenseni (Strand, 1900)}

Haplodrassus soerenseni seems to be a forest species (e.g. CT, rocky pine forests, VT, mixed forests, MT) (Huhta 1965, 1971, Palmgren 1972, 
Palmgren \& Biström 1979, Biström \& Väisänen 1988, Koponen 1995, Heimer \& Nentwig 1991, Pajunen et al. 1995). It has also been caught in peatlands (e.g. open bogs, pine bogs) (Heimer \& Nentwig 1991, Koponen et al. 2001), meadows (Huhta 1971, Palmgren 1977a), and clear-cuts and burnt-overs (Huhta 1971).

\section{Micaria aenea Thorell, 1871}

Micaria aenea has been found in forests (e.g. VT, overhanging grass in rock scarps) (Huhta 1971, Palmgren 1977a, Pajunen et al. 1995), clear-cuts and burnt-overs (Huhta 1971), meadows (Huhta 1971), and shores (Palmgren 1943).

\section{Micaria pulicaria (Sundevall, 1831)}

In most studies Micaria pulicaria has mainly been caught in open habitats: clear-cuts and burnt-overs (Huhta 1971), dry to moist meadows (Palmgren 1943, 1972, 1977a, Huhta 1971), shores (Palmgren 1943, 1964, 1972), treeless skerries (Palmgren 1972), open peatlands (Myrica-Molinia bogs, open bogs) (Palmgren 1972, 1977a), and roads (Palmgren 1943). However, Palmgren (1977a) caught it in light forests (e.g. rocky pine forests, a forest fringe at a shore, overhanging moss in scarps) as abundantly as in open habitats, and Pajunen et al. (1995) caught a few individuals in forests. Heimer and Nentwig (1991) state that M. pulicaria lives in well-lit habitats.

\section{Micaria silesiaca L. Koch, 1875}

Micaria silesiaca has been caught in dry open habitats (e.g. caves, among loose rocks) (Lehtinen et al. 1979), dry heaths (Koponen 2000), burnt-overs (Huhta 1971), and forests (Pajunen et al. 1995).

\section{Zelotes clivicola (L. Koch, 1870) (Zelotes clivicolus)}

Zelotes clivicola has been caught in forests (e.g. CT, VT) (Huhta 1965, 1971, Palmgren 1972, 1977a, Heimer \& Nentwig 1991, Koponen \& Niemelä 1994, Pajunen et al. 1995), peatlands (e.g. Myrica-Molinia bogs) (Palmgren 1972, Heimer \& Nentwig 1991), rocky habitats (Palmgren 1964), meadows (Huhta 1971), and heaths (Heimer \& Nentwig 1991), but most abundantly in clear-cuts and burnt-overs (Huhta 1971).
Zelotes latreillei (Simon, 1878)

Zelotes latreillei has been captured in light forests (e.g. old pine forest, VT, under loose bark) (Palmgren 1943, 1972, 1977a, Huhta 1971, Heimer \& Nentwig 1991, Koponen 1995, Pajunen et al. 1995), under stones and lichens (Palmgren 1943, Lehtinen \& Kleemola 1962), peatlands [e.g. pine bogs, open bogs; a xerophilous mire species in Koponen (1968)] (Koponen 1968, Heimer \& Nentwig 1991, Koponen et al. 2001, Koponen 2002b), meadows (Huhta 1971), dry open sublapidicol (Palmgren 1964, 1977a), and clearcuts and burnt-overs (Huhta 1971).

Zelotes petrensis (C. L. Koch, 1839)

Zelotes petrensis has been found in light forests (e.g. a polluted dry pine forest with almost no vegetation) (Palmgren 1943, 1977a, Heimer \& Nentwig 1991, Koponen \& Niemelä 1994, 1995), on rocks in shores (Palmgren 1943), dry meadows (Palmgren 1977a), heaths and lawns (Heimer \& Nentwig 1991), clear-cuts (Huhta 1971), and dry open habitats (Lehtinen et al. 1979).

\section{Zelotes subterraneus (C. L. Koch, 1833)}

Zelotes subterraneus was found in shores (Palmgren 1943, 1972, Lehtinen \& Kleemola 1962, Koponen 2000), open rocks (Palmgren 1972), very dry sublapidicol (Palmgren 1964), dry open habitats (Lehtinen et al. 1979), and forests (e.g. rocky forests, coastal Pineta, VT, mixed forests, overhanging grass in scarps, stems of pines, a forest fringe at a shore; also MT) (Palmgren 1943, 1972, 1977a, Palmgren \& Biström 1979, Heimer \& Nentwig 1991, Koponen 1995). Other habitats mentioned in Heimer and Nentwig (1991) are heaths, lawns and bogs.

\subsection{Hahniidae}

Cryphoeca silvicola (C. L. Koch, 1834)

Cryphoeca silvicola has commonly been found in shady forests, both in trees and near the ground (MT, OMT, less often spruce mires) (Palmgren 1964, 1972, 1977a, 1977b, Huhta 1965, 1971, Palmgren \& Biström 1979, Biström \& Väisänen 1988, Väisänen \& Biström 1990, Koponen 1995, 1999, Pajunen et al. 1995). It has more rarely oc- 
curred in light forests (VT, coastal Pineta, mixed forests, hazel groves) (Huhta 1965, 1971, Palmgren 1972, 1977b, Biström \& Väisänen 1988, Koponen 1995, Pajunen et al. 1995), peatlands (Koponen 1978), and clear-cuts (Huhta 1965, 1971). Heimer and Nentwig (1991) did not separate the types of coniferous forests.

\section{Hahnia nava (Blackwall, 1841)}

Hahnia nava has been caught in light forests (e.g. CT, spruce-pine forests, coastal Pineta, rocky pine forests) (Palmgren 1964, 1972, 1977b, Pajunen et al. 1995), but also in meadows (most rarely moist ones) (Palgmren 1972, 1977b), islands and skerries (e.g. in grass ribbons, Pleurozium) (Palmgren 1972), and very dry sublapidicol (Palmgren 1964).

Hahnia ononidum Simon, 1875 (Hahnia mengei Chyzer \& Kulczyn'ski, 1897)

Hahnia ononidum seems to be a forest species (mainly not very dry ones, e.g. MT, VT, mixed spruce-pine forest; but also rocky pine forest, CT) (Huhta 1965, 1971, Palmgren 1972, 1977b, Palmgren \& Biström 1979, Biström \& Väisänen 1988, Heimer \& Nentwig 1991, Pajunen et al. 1995), although Huhta (1971) caught it quite abundantly also in clear-cuts.

\section{Hahnia pusilla C. L. Koch, 1841}

Moisture seems to be more important for Hahnia pusilla than the light intensity (Palmgren 1972). According to Palmgren (1977b), the species can be found in drier habitats mainly in spring and autumn (Palmgren 1977b). H. pusilla has been caught in different types of peatlands (e.g. open bogs, Myrica-Molinia bogs, Ledum bogs, spruce mires) (Palmgren 1964, 1972, 1977a, 1977b, Koponen 1978, Lehtinen et al. 1979), but it has also been captured in forests (e.g. hazel groves, MT, VT, dry pine forests, coastal Pineta, oaks) (Palmgren 1964, 1972, 1977a, 1977b, Huhta 1965, Biström \& Väisänen 1988, Väisänen \& Biström 1990, Pajunen et al. 1995, Koponen 1996). A few findings have been from clear-cuts (Huhta 1971), medium-moist to moist meadows (Palmgren 1972), and very dry sublapidicol (Palmgren 1964).

\subsection{Linyphiidae}

Abacoproeces saltuum (L. Koch, 1872)

Abacoproeces saltuum has mostly been found in light forests (e.g. a forest fringe at a shore, VT, coastal Pineta, mixed forests; rarely in the driest forest types) (Huhta 1965, 1971, Palmgren 1972, 1977a, Koponen 1995, Pajunen et al. 1995). It has more rarely been caught in shady forests (e.g. MT) (Palmgren 1977a, Palmgren \& Biström 1979), near meadow ditches (Palmgern 1977a), and rocks (Lehtinen \& Kleemola 1962, Palmgren 1972, 1976). A. saltuum has an affinity for airy ground structure (Palmgren 1976, 1977a), and it has been caught within mosses and grasses (Palmgren 1972, 1976).

Agnyphantes expunctus (O. P-Cambridge, 1875) (Lepthyphantes expunctus)

Agnyphantes expunctus has mostly been caught in trees, at least spruce (Palmgren 1964, 1977a, Heimer \& Nentwig 1991). It has also been caught in the lower strata of forests (e.g. old spruce forests, spruce-deciduous mixed forest, forest edges) (Palmgren 1964, Koponen 1995). A. expunctus is a northern species (Palmgren 1977a).

Agyneta cauta (O. P-Cambridge, 1902)

Agyneta cauta has been caught in forests (e.g. CT, VT, MT, OMT, mixed forests, hazel groves) (Huhta 1965, 1971, Palmgren 1972, 1975, 1977a, Heimer \& Nentwig 1991, Koponen 1995, Pajunen et al. 1995), and peatlands (e.g. spruce mires, Ledum bogs, Myrica-Molinia bogs, open bogs) (Palmgren 1964, 1972, 1975, 1977a, Koponen 1978, 2002a, 2002b, Heimer \& Nentwig 1991, Koponen et al. 2001). It has also been caught in meadows (Palmgren 1964, Huhta 1965, 1971), sandy shores (Palmgren 1964), and clear-cuts and burnt-overs (Huhta 1965, 1971).

Agyneta conigera (O. P-Cambridge, 1863) Agyneta conigera has been characterised as being a forest species, being caught mostly in coniferous forests (e.g. CT, VT, coastal Pineta, MT, OMT, old forests, hazel groves) (Palmgren 1964, 1972, 1977a, Huhta 1965, 1971, Palmgren \& Biström 1979, Heimer \& Nentwig 1991, Koponen 1995, 1999, Pajunen et al.1995). Some of the findings have been from peatlands (e.g. pine 
bogs, open bogs, Myrica-Molinia bogs, spruce mires) (Palmgren 1972, Koponen et al. 2001), meadows and shore meadows (Huhta 1971, Palmgren 1972, 1977a), edges of quagmires and brooks (Palmgren 1977a), clear-cuts (Huhta 1971), and rocky shelves (Palmgren 1972). It can be caught in moss (Heimer \& Nentwig 1991), “förna", or grass (Palmgren 1975), but it may also ascend higher (Palmgren 1972, 1975, 1977a).

Agyneta olivacea (Emerton, 1882)

The biology of Agyneta olivacea is insufficiently known (Heimer \& Nentwig 1991). It has been found in forests (e.g. an old dense spruce forest, a mixed forest of birch, pine and spruce) (Koponen 1995, Pajunen et al.1995).

Agyneta ramosa Jackson, 1912

Agyneta ramosa has mainly been caught in different types of forest (especially moss in coniferous forests, e.g. VT, coastal Pineta, MT, OMT, spruce mires, mixed forests, hazel groves) (Huhta 1971, Palmgren 1972, 1977a, Lehtinen et al. 1979, Palmgren \& Biström 1979, Koponen 1995, 1999 , Pajunen et al. 1995). Some individuals have been caught in peatlands (e.g. open bogs) (Palmgren 1972, 1977a, Koponen 1978, Heimer \& Nentwig 1991), and clear-cuts (Huhta 1965, 1971). Another habitat type in Heimer and Nentwig (1991) was trees.

Agyneta subtilis (O. P-Cambridge, 1863)

Agyneta subtilis has mainly been found in different types of forest (e.g. CT, VT, MT, OMT, spruce mires, old forests; also deciduous forests) (Palmgren 1964, 1972, 1975, 1977a, Huhta 1965, 1971, Palmgren \& Biström 1979, Heimer \& Nentwig 1991, Koponen 1995, 1999, Pajunen et al. 1995). Some individuals have also been caught in clearcuts (Huhta 1965, 1971), Ledum bogs, open bogs, and moist meadows (Palmgren 1972, 1975, 1977a, Heimer \& Nentwig 1991).

Allomengea scopigera (Grube, 1859)

Allomengea scopigera has mostly been found in moist sites: shore and fen-like Alneta (Palmgren 1972, 1975, Lehtinen et al.1979), shores (Palmgren 1972, 1975), moist meadows (Palmgren 1972, 1975, 1977a), near ditches in forests (Palmgren 1977a), edges of quagmires or brooks
(Palmgren 1977a), and peatlands (e.g. MyricaMolinia bogs) (Palmgren 1972, Koponen 1978, Heimer \& Nentwig 1991). However, it has also been caught in spruce forests of OMT (Huhta 1971), and in mixed forests (Palmgren 1964).

Anguliphantes angulipalpis (Westring, 1851) (Lepthyphantes angulipalpis)

Anguliphantes angulipalpis has mainly been caught in forests (e.g. fen-like and shore Alneta, deciduous forests, mixed forests, a forest fringe at a shore, coastal Pineta, VT, dry pine forests, MT, spruce mires, junipers) (Palmgren 1964, 1972, 1975, 1977a, Huhta 1971, Lehtinen et al. 1979, Palmgren \& Biström 1979). Some individuals have also been captured in clear-cuts (Huhta 1971), edges of fields (Palmgren 1972, 1975), grass ribbons in small islands (Palmgren 1972), and meadows (Palmgren 1977a). A. angulipalpis lives within litter (Heimer \& Nentwig 1991).

\section{Asthenargus paganus (Simon, 1884)}

Asthenargus paganus has mainly been caught in forests (especially spruce forests, mixed forests with spruce, or spruce mires) (Palmgren 1964, 1976, 1977a, Biström \& Väisänen 1988, Heimer \& Nentwig 1991, Koponen 1995, 1999, Pajunen et al. 1995). Lehtinen et al. (1979) caught $A$. paganus in a bog, but stated that it inhabits mires only in peripheral locations. It is an eastern species (Palmgren 1977a).

Bathyphantes gracilis (Blackwall, 1841)

Bathyphantes gracilis has been caught in moist habitats: meadows (more rarely dry to mediummoist ones) (Huhta 1971, Palmgren 1972, 1977a, Heimer \& Nentwig 1991), and peatlands (Sphagnum in small depressions in semi-open forest, spruce mires, open bogs, Myrica-Molinia bogs, fen-like Alneta) (Koponen 1968, 1978, 2002a, 2002b, Palmgren, 1972, 1977a, Lehtinen et al. 1979, Koponen et al. 2001). It has also been caught in smaller numbers in clear-cuts (Huhta 1971), and forests (Coryleta, MT, mixed forests) (Palmgren 1972, 1977a, Heimer \& Nentwig 1991).

Bathyphantes nigrinus (Westring, 1851)

The most typical habitat of Bathyphantes nigrinus varies among different studies: hazel 
groves (Palmgren 1972, 1975), bogs with shrubs (Myrica, Ledum, small birches etc.) and some cover of scattered trees (Palmgren 1972, 1975), moist meadows (Palmgren 1977a), and spruce mires (Palmgren 1977a, Heimer \& Nentwig 1991). B. nigrinus was also caught in dry to medium-moist meadows (Palmgren 1964, 1972, 1977a), other types of forests (e.g. MT, mixed forests, forest edges) (Palmgren 1964, 1972, 1977a), and roadsides or cleared forests (Palmgren 1977a).

\section{Bathyphantes parvulus (Westring, 1851)}

The habitat distribution of Bathyphantes parvulus resembles that of $B$. gracilis (Palmgren 1972, Heimer \& Nentwig 1991): moist to medium-moist meadows (more rarely dry ones) (Palmgren 1964, 1972, 1975, 1977a, Huhta 1971, Lehtinen et al. 1979, Heimer \& Nentwig 1991), and peatlands (e.g. open bogs, Myrica-Molinia bogs, Alnus swamps, Phragmites fens, Calluna bogs, a peat harvesting area, Sphagnum in birchmixed forest and depressions) (Palmgren 1972, 1977a, Koponen 1979, 2002b, Lehtinen et al. 1979). It has also been caught in clear-cuts (Huhta 1971), treeless skerries and forests (e.g. pinebirch forests) (Palmgren 1972, 1977a, Pajunen et al. 1995). Other habitat types mentioned in Heimer and Nentwig (1991) were forests.

Bolephthyphantes index (Thorell, 1856) (Bolyphantes index)

Bolephthyphantes index has been found in coniferous forests (e.g. Sphagnum in small depressions in semi-open forest, rocky pine forests, VT, MT; also junipers, spruces) (Palmgren 1964, 1977a, Huhta 1971, Biström \& Väisänen 1988, Pajunen et al. 1995), and peatlands (Ledum bogs, open bogs, Betula nana) (Palmgren 1972, 1975, 1977a). However, according to Heimer and Nentwig (1991), B. index lives e.g. in tree roots and clefts of rocks.

Bolyphantes alticeps (Sundevall, 1833)

Bolyphantes alticeps has mainly been caught in forests (e.g. CT, coastal Pineta, mixed forests, VT, forest edges, spruce forests, spruce mires, hazel groves) (Lehtinen \& Kleemola 1962, Palmgren 1964, 1972, 1975, 1977a, Huhta 1965, 1971, Heimer \& Nentwig 1991), but sometimes also quite abundantly in meadows (Palmgren 1964, 1972, 1977a, Huhta 1971, Heimer \& Nentwig 1991). It has also been captured in peatlands (Myrica-Molinia bogs, Ledum bogs) (Palmgren 1972, 1977a) and clear-cuts (Huhta 1971).

\section{Bolyphantes luteolus (Blackwall, 1833)}

Bolyphantes luteolus has been caught in light pine stands (e.g. coastal Pineta) (Palmgren 1972, 1975), Elymus arenarius on sandy beaches (Palmgren 1972, 1975), small islands and skerries (Palmgren 1972, 1975), dry meadows (Palmgren 1972, 1975), and bogs (e.g. open bogs) (Koponen 1978, Koponen 2002b).

Centromerus arcanus (O. P-Cambridge, 1873) Centromerus arcanus has been caught in forests (e.g. CT, coastal Pineta, VT, MT, OMT, mixed forests, spruce mires, hazel groves) (Palmgren 1964, 1972, 1975, 1977a, Huhta 1965, 1971, Palmgren \& Biström 1979, Biström \& Väisänen 1988, Väisänen \& Biström 1990, Heimer \& Nentwig 1991, Koponen 1995, 1999, Pajunen et al. 1995), but the catches in clear-cuts and burntovers have also been reported high (Huhta 1971), and it has also been regular in peatlands (e.g. Alnus swamps, Phragmites fens, Calluna bogs, a peat harvesting area, spruce mires, Ledum bogs, Myrica-Molinia bogs, open bogs) (Palmgren 1964, 1972, 1975, 1977a, Koponen 1978, 1979, 2002a, 2002b, Lehtinen et al. 1979, Koponen et al. 2001). Few findings exist in dry to moist meadows, sandy shores, treeless skerries, and coniferous trees (Palmgren 1964, 1972, 1975, 1977a).

Centromerus sylvaticus (Blackwall, 1841)

Centromerus sylvaticus has been found in forests (e.g. CT, coastal Pineta, VT, mixed forests, hazel groves; rarely spruce forests of MT, OMT) (Palmgren 1964, 1972, 1975, 1977a, Huhta 1971, Heimer \& Nentwig 1991, Pajunen et al. 1995), dry to moist meadows (Huhta 1971, Palmgren 1972, 1975, 1977a), clear-cuts and burnt-overs (Huhta 1971), and peatlands (e.g. open bogs, Myrica-Molinia bogs, Ledum bogs) (Palmgren 1972, 1977a).

Ceratinella brevis (Wider, 1834)

Ceratinella brevis is rather eurytopic, although it 
shuns the wettest and driest habitats (Palmgren 1972, 1976, Heimer \& Nentwig 1991). It has been caught in forests (e.g. CT, coastal Pineta, VT, mixed forests, hazel groves; more rarely OMT, spruce mires) (Lehtinen \& Kleemola 1962, Huhta 1965, 1971, Palmgren 1972, 1976, 1977a, Pajunen et al. 1995), peatlands (e.g. spruce mires, Ledum bogs with low tree stratum, MyricaMolinia bogs, open bogs) (Palmgren 1972, 1977a), dry to medium-moist meadows (Huhta 1971, Palmgren 1972, 1976), skerries and small islands (Palmgren 1972), and most rarely junipers (Palmgren 1977a), and burnt-overs (Huhta 1971). It lives within mosses and litter (Palmgren 1976).

Ceratinella scabrosa (O. P-Cambridge, 1871) Ceratinella scabrosa has been found in forests (e.g. hazel groves, near ditches in deciduous or mixed forests, also Sphagnum in spruce mires) (Palmgren 1972, 1976, 1977a, Heimer \& Nentwig 1991, Pajunen et al. 1995).

Cnephalocotes obscurus (Blackwall, 1834) Cnephalocotes obscurus has been caught in light forests (e.g. CT, VT, coastal Pineta, mixed forests) (Huhta 1965, 1971, Palmgren 1972, 1976, Pajunen et al. 1995), dry to medium-moist meadows (rarely moist ones) (Palmgren 1964, 1972, 1976, 1977a, Huhta 1971), clear-cuts and burntovers (Huhta 1971), and peatlands (e.g. Ledum bogs, Myrica-Molinia bogs, open bogs, birchmixed mires) (Palmgren 1964, 1972, 1977a, Koponen 2002a). It has more rarely been found in shady forests (e.g. spruce forests, spruce mires) (Palmgren 1964, 1977a, Pajunen et al. 1995) that it shuns (Palmgren 1972). According to Heimer and Nentwig (1991), C. obscurus lives in light and moist habitats.

\section{Dicymbium tibiale (Blackwall, 1836)}

The optimal habitat of Dicymbium tibiale seems to be forest (especially OMT; other types reported include hazel groves, MT, mixed forests, spruce and birch-mixed mires; most rarely VT) (Palmgren 1964, 1972, 1976, 1977a, Huhta 1965, 1971, Biström \& Väisänen 1988, Pajunen et al. 1995), but it has also been caught abundantly in clear-cuts and burnt-overs (Huhta 1965, 1971). It has more rarely been found in meadows (Huhta
1971, Palmgren 1972, 1977a), open bogs (Palmgren 1977a), and treeless skerries (Palmgren 1972).

Diplocentria bidentata (Emerton, 1882)

Diplocentria bidentata is a forest species. The optimum seems to be in spruce forests and mixed forests with spruce (MT, OMT, also spruce mires) (Palmgren 1964, 1972, 1976, 1977a, Huhta 1965, 1971, Palmgren \& Biström 1979, Biström \& Väisänen 1988, Väisänen \& Biström 1990, Koponen 1995, Pajunen et al. 1995), although it has also been caught quite abundantly in light forests (e.g. CT, rocky pine forests, coastal Pineta, VT) (Palmgren 1972, 1977a, Biström \& Väisänen 1988, Väisänen \& Biström 1990, Koponen 1995, Pajunen et al. 1995), and clear-cuts and burntovers (Huhta 1965, 1971). It has more rarely been caught in peatlands (Koponen 1978), and meadows (Palmgren 1964, 1977a). According to Heimer and Nentwig (1991), D. bidentata lives under mosses and stones.

Diplocentria rectangulata (Emerton, 1915) (Microcentria rectangulata, Microcentria pusilla Schenkel, 1925)

Diplocentria rectangulata has been caught in forests (especially shady spruce forests, e.g. MT, HMT; other types include: VT, mixed forests, overhanging moss in dense scarps) (Palmgren 1964, 1976, 1977a, Huhta 1965, 1971, Palmgren \& Biström 1979, Biström \& Väisänen 1988, Pajunen et al. 1995), peatlands (e.g. edges of Ledum bogs, also open bogs) (Palmgren 1976, 1977a, Koponen 1978, 2002a), and clear-cuts (Huhta 1965, 1971).

Diplocephalus latifrons (O. P-Cambridge, 1863) Diplocephalus latifrons seems to have an affinity for spruce forests of OMT (Huhta 1965, 1971, Palmgren 1976). It has also been caught in light forests (e.g. deciduous and mixed forests) (Lehtinen et al. 1979, Pajunen et al. 1995), meadows (Huhta 1971), and clear-cuts (Huhta 1971). According to Heimer and Nentwig (1991), it lives in many kinds of habitat, especially in forests, and is absent only in the driest habitats.

Diplocephalus picinus (Blackwall, 1841)

The most typical habitat of Diplocephalus pici- 
nus seems to be leaf litter of deciduous forests (e.g. hazel groves, fen-like Alneta, shore Alneta, deciduous-mixed forests of fern type) (Lehtinen \& Kleemola 1962, Palmgren 1972, 1976, 1977a, Heimer \& Nentwig 1991). A few individuals have been caught within mosses or overhanging vegetation (Palmgren 1977a). It has rarely been found in other types of forest (e.g. MT, OMT, coastal Pineta) (Palmgren 1964, 1977a, Palmgren \& Biström 1979, Huhta 1971). One individual has been reported in a meadow (Huhta 1971).

\section{Diplostyla concolor (Wider, 1834)}

Diplostyla concolor has been captured in forests (e.g. groves, VT, MT, OMT, mixed forests, a forest fringe at shore; also spruce mires) (Palmgren 1975, 1977a, Heimer \& Nentwig 1991, Koponen 1995, Pajunen et al. 1995), meadows (especially under heaps of hay in meadow edges) (Huhta 1971, Palmgren 1975, 1977a), clear-cuts and burnt-overs (Huhta 1971), bogs (Palmgren 1975), and rocks (Palmgren 1975, 1977a). Other habitat types in Heimer and Nentwig (1991) include gardens and shady shores.

\section{Dismodicus bifrons (Blackwall, 1841)}

Dismodicus bifrons has been caught in two different habitats: meadows, mainly moist ones (Palmgren 1972, 1976, 1977a), and light forests (e.g. VT, not very closed MT, mixed forests, forest edges, also in Sphagnum and other moister places) (Palmgren 1964, 1977a, Huhta 1971). A few individuals have also been caught in roadsides or cleared forests (Palmgren 1977a), sandy shores (Palmgren 1964), and Ledum bogs (Palgmren 1977a). According to Heimer and Nentwig (1991), D. bifrons lives in bushes and trees in different habitats.

\section{Dismodicus elevatus (C. L. Koch, 1838)}

Dismodicus elevatus has been caught mainly in forests (e.g. rocky pine forests, VT, spruce forests, deciduous-mixed fern type forests, birch forests) (Palmgren 1972, 1976, 1977a, Lehtinen et al. 1979, Biström \& Väisänen 1998, Koponen 1995), and most abundantly there in coniferous trees (pines, spruces; more rarely junipers) (Palmgren 1972, 1976, 1977a, Heimer \& Nentwig 1991). According to Palmgren (1972, 1976), it apparently overwinters in trees. It has more rarely been caught in Ledum bogs (Palmgren 1977a), fields (Palmgren 1976), meadows (Palmgren 1964, 1972, 1976, 1977a), and roadsides or cleared forests (Palmgren 1977a).

\section{Drapetisca socialis (Sundevall, 1833)}

Drapetisca socialis has been caught in forests (e.g. coastal Pineta, rocky Pineta, VT, MT, OMT, mixed forests, hazel groves) (Huhta 1971, Palmgren 1972, 1977a, Biström \& Väisänen 1998). It lives mainly in trees (e.g. junipers, pines, spruces, oaks) (Palmgren 1972, 1975, 1977a, Heimer \& Nentwig 1991, Koponen 1996, Koponen et al. 1997), but it has also been found near the ground in forests (Huhta 1971, Palmgren 1972). The findings near the ground may be related to overwintering; according to Heimer and Nentwig (1991), D. socialis lives in trees but can be found on the ground in late autumn. Some individuals have been caught even in meadows (Palmgren 1972).

Entelecara congenera (O. P-Cambridge, 1879) Entelecara congenera seems to be a forest species (e.g. rocky pine forests, CT, VT, spruce forests) (Palmgren 1972, 1977a, Lehtinen et al. 1979, Biström \& Väisänen 1988). It has most abundantly been caught in trees (pines, spruces, junipers) (Palmgren 1964, 1972, 1976, 1977a, Heimer \& Nentwig 1991), and more rarely near the ground (e.g. in Calluna) (Palmgren 1972, 1976, 1977a). It has also been caught in peatlands (e.g. Ledum bogs, Myrica-Molinia bogs) (Palmgren 1972, 1977a) and meadows (Palmgren 1977a).

\section{Entelecara erythropus (Westring, 1851)}

Palmgren (1977a) caught one individual of Entelecara erythropus under the bark of a decaying birch, and one on the ground in a meadow of medium humidity. According to Heimer and Nentwig (1991), it lives within mosses and grasses.

\section{Erigone atra Blackwall, 1833}

Erigone atra seems to have an affinity for open habitats: moist meadows and shore meadows (rarely drier ones) (Palmgren 1972, 1976, 1977a, Huhta 1971), shores (Palmgren 1976), peatlands (e.g. open bogs, Ledum bogs) (Palmgren 1972, 
1977a, Koponen 2002a), and clear-cuts and burnt-overs (Huhta 1965, 1971). It has also been caught in light forests (e.g. a polluted dry pine forest with almost no vegetation, CT, thinned pine forests) (Huhta 1965, 1971, Koponen \& Niemelä 1994, 1995). E. atra is a true pioneer species (Huhta 1971, Koponen \& Niemelä 1994, 1995). However, according to Heimer and Nentwig (1991), it lives in many kinds of habitat, lacking only from the driest ones.

\section{Erigone dentipalpis (Wider, 1834)}

Erigone dentipalpis has an affinity for open habitats: small skerries (especially in grass tufts or ribbons and in beds of Matricaria, Sedum acre, and Allium schoenoprasum) (Palmgren 1972), moist gravelly shores and wrack beds (Lehtinen \& Kleemola 1962), meadows (Huhta 1971, Palmgren 1972, 1977a), more rarely clear-cuts and burnt-overs (Huhta 1965, 1971). It has also been found in Ledum bogs (Palmgren 1977a) and rocky pine forests in Cladonia (Palmgren 1972). It is a pioneer species (Huhta 1971). However, according to Heimer and Nentwig (1991), E. dentipalpis does not have any special habitat affinity.

\section{Erigonella hiemalis (Blackwall, 1841)}

Erigonella hiemalis has been found in dry to moist meadows (Palmgren 1964, 1972, 1976, 1977a, Huhta 1971), clear-cuts and burnt-overs (Huhta 1971), skerries (Palmgren 1972, 1976), and forests, mainly moist to fairly moist types (e.g. a forest fringe at a shore, edges of brooks in forests, spruce mires, hazel groves, mixed forests with birch) (Palmgren 1964, 1972, 1977a, Heimer \& Nentwig 1991, Pajunen et al. 1995).

\section{Gonatium rubellum (Blackwall, 1841)}

Gonatium rubellum has mainly been caught in medium-moist forests (e.g. VT, MT, OMT, mixed forests, forest edges; also spruce mires) (Palmgren 1964, 1972, 1976, 1977a, Huhta 1965, 1971, Biström \& Väisänen 1998, Heimer \& Nentwig 1991). The majority of individuals has been caught in Vaccinium myrtillus (Palmgren 1972, 1977a). A few individuals has been caught in clear-cuts (Huhta 1965, 1971, Palmgren 1977a), overhanging grass at meadow ditches (Palmgren 1977a), Ledum bogs (Palmrgen 1977a), and skerries (Palmgren 1972).

Gongylidiellum latebricola (O. P-Cambridge, 1871)

The most typical habitat of Gongylidiellum latebricola is spruce mire (Palmgren 1964, 1972, 1976, 1977a). It has also been caught in other types of covered peatlands (e.g. Myrica-Molinia bogs, Ledum bogs, birch-mixed mires; more rarely open bogs) (Palmgren 1964, 1972, 1976, 1977a). It has also very rarely been found in dry to moist meadows (Palmgren 1964, 1972, 1976, 1977a) and medium-moist forests (VT, MT) (Huhta 1971, Palmgren 1977a, Heimer \& Nentwig 1991).

Gongylidiellum murcidum Simon, 1884

Gongylidiellum murcidum seems to be a stenotopic open-habitat species in the Finnish studies, although Heimer and Nentwig (1991) considered it as a forest species. Most G. murcidum specimens have been caught in meadows, rarely dry ones (Palmgren 1964, 1972, 1976, 1977a, Huhta 1971), and bogs, mainly open ones (Palmgren 1964, 1972, 1976). It has more rarely been found in sandy shores (Palmgren 1964) and light forests (in Sphagnum, a thinned pine stand) (Huhta 1965, 1971, Palmgren 1977a, Pajunen et al. 1995).

Gongylidium rufipes (Linnaeus, 1758)

Gongylidium rufipes has mostly been caught in forests (e.g. deciduous trees, hazel groves, moist depressions in forests, mixed forests, forest edges, VT, rocky pine stands; also spruce forests, spruce mires) (Lehtinen \& Kleemola 1962, Palmgren 1964, 1972, 1976, 1977a, Biström \& Väisänen 1988). However, it has also been caught in dry to moist meadows, sometimes abundantly (Palmgren 1964, 1972, 1977a). It has rarely been found in roadsides or cleared forests (Palmgren 1977a), and Ledum bogs (Palmgren 1972, 1977a). According to Lehtinen and Kleemola (1962), G. rufipes lives even within wet, acidic litter where other spiders are absent. Heimer and Nentwig (1991) stated that it has an affinity for moist habitats. 
Helophora insignis (Blackwall, 1841)

Helophora insignis has been caught mostly in forests (e.g. hazel groves, rocky pine forests, VT, coastal Pineta, MT, OMT, spruce mires, mixed forests, forest edges, coniferous trees, oaks) (Palmgren 1964, 1972, 1975, 1977a, Huhta 1965, 1971, Palmgen \& Biström 1979, Biström \& Väisänen 1988, Heimer \& Nentwig 1991, Koponen 1996), but it has also been found quite abundantly in moist meadows (Palmgren 1972, 1977a). It has also been caught in Ledum bogs (Palmgren 1972, 1977a).

\section{Hilaira herniosa (Thorell, 1875)}

Hilaira herniosa seems to be a forest species, being most often caught in spruce forests (e.g. HMT, spruce mires) (Palmgren 1964, 1975, 1977a, Huhta 1965, 1971, Koponen 1995, 1999). Some individuals have also been caught in pine forests and mixed forests (Huhta 1965, Koponen 1995, 1999), clear-cuts (Huhta 1971), and peatlands (Palmgren 1964, Koponen 1978). According to Heimer and Nentwig (1991), $H$. herniosa lives within moist mosses. It is a northern species (Koponen1999).

Incestophantes kochiellus (Strand, 1900) (Lepthyphantes kochiellus)

Incestophantes kochiellus has been caught only in forests (e.g. spruce forests) (Palmgren 1975, Palmgren \& Biström 1979, Pajunen et al. 1995).

Lepthyphantes antroniensis Schenkel, 1933 (Lepthyphantes exiguus Holm, 1939)

Lepthyphantes antroniensis has mainly been caught in forests (e.g. VT, MT, HMT, old spruce, pine and mixed forests, a forest fringe at a shore) (Huhta 1965, 1971, Palmgren 1975, 1977a, Palmgren \& Biström 1979, Biström \& Väisänen 1988, Heimer \& Nentwig 1991, Koponen 1995, 1999, Pajunen et al. 1995). It has also been caught in peatlands (Koponen 1978), and in a clear-cut (Huhta 1971). L. antroniensis is a northern species (Palmgren 1977a, Koponen 1999).

\section{Lophomma punctatum (Blackwall, 1841)}

Lophomma punctatum lives in moist habitats (Heimer \& Nentwig 1991): peatlands (e.g. open bogs, fen-like Alneta, peaty shores, Sphagnum in forests) (Lehtinen \& Kleemola 1962, Palmgren
1972, 1976, 1977a), and moist meadows and within overhanging grass of meadow ditches (Palmgren 1977a). A couple of individuals have been found in spruce branches at forest edges (Palmgren 1977a).

\section{Macrargus boreus Holm, 1968}

Macrargus boreus has mainly been caught in light forests (e.g. VT, a forest fringe at shore, mixed forests, also rocky pine forests) (Huhta 1971, Palmgren 1977a, Biström \& Väisänen 1988), but some specimens have also been found in medium-moist to moist meadows (Palmgren 1977a).

Macrargus carpenteri (O. P-Cambridge, 1894) Macrargus carpenteri has been caught in light forests (e.g. CT, rocky pine forests, VT, coastal Pineta, mixed forests; also spruce forests) (Palmgren 1964, 1972, 1975, 1977a, Huhta 1971, Biström \& Väisänen 1988, Heimer \& Nentwig 1991, Koponen 1995, Pajunen et al. 1995), dry open habitats (Lehtinen et al. 1979), dry meadows (Palmgren 1972, 1975, 1977a), grass ribbons on small islands (Palmgren 1972), burnt-overs (Huhta 1971), and peatlands (open bogs, pine bogs) (Palmgren 1977a, Koponen et al. 2001, Koponen 2002a, 2002b).

Macrargus multesimus (O. P-Cambridge, 1875) The only information about the habitat of Macrargus multesimus is in Palmgren (1964): one individual was trapped in a pine or pine-dominated dry forest. It seems to be a northern species (Palmgren 1975).

\section{Macrargus rufus (Wider, 1834)}

Macrargus rufus seems to be a forest species, with the optimum being in spruce forests (e.g. CT, coastal Pineta, VT, MT, OMT, spruce mires, hazel groves, mixed forests) (Lehtinen \& Kleemola 1962, Palmgren 1964, 1972, 1975, 1977a, Huhta 1965, 1971, Palmgren \& Biström 1979, Biström \& Väisänen 1988, Väisänen \& Biström 1990, Heimer \& Nentwig 1991, Koponen 1995, 1999 , Pajunen et al. 1995). Huhta $(1965,1971)$ caught it quite abundantly in clear-cuts and burnt-overs, but not as abundantly as in forests. It has also been caught in peatlands (e.g. Ledum bogs, MyricaMolinia bogs) (Palmgren 1972, 1977a, Koponen 
1978), moist meadows (Palmgren 1972), and sandy shores (Palmgren 1964).

Maro lehtineni Saaristo, 1971

Maro lehtineni has been captured in forests (OMT, conifer-dominated forest, spruce forests) (Huhta 1971, Saaristo 1971, Palmgren 1975, Heimer \& Nentwig 1991), and clear-cuts (Huhta 1965, 1971).

\section{Maro lepidus Casemir, 1961}

Maro lepidus seems to have an affinity for moist habitats: forested and open peatlands (e.g. Ledum bogs, Myrica-Molinia bogs, open bogs, Alnus swamps, Phragmites fens, spruce mires, Sphagnum in forests) (Palmgren 1964, 1972, 1975, 1977a, Saaristo 1971, Koponen 1978, 1979, 2002a, 2002b, Heimer \& Nentwig 1991), but it has also been found in moist meadows (Palmgren 1972, 1975).

\section{Maro sublestus Falconer, 1915}

Also Maro sublestus seems to have an affinity for moist habitats, as it has mainly been caught among Sphagnum (e.g. Myrica-Molinia bogs, open bogs, spruce mires, birch-mixed mires, small depressions in forests) (Saaristo 1971, Palmgren 1972, 1975, 1977a, Koponen 2002b). In addition, almost all of the findings have been from shady habitats (e.g. the above mentioned forests with Sphagnum, but also other kinds of 'not too dry' forests) (Palmgren 1964, 1975, 1977a, Saaristo 1971, Heimer \& Nentwig 1991).

\section{Maso sundevalli (Westring, 1851)}

Maso sundevalli has been found mostly in forests (e.g. VT, coastal Pineta, MT, OMT, spruce mires, mixed forests, forest edges, hazel groves; more rarely CT, coniferous trees) (Palmgren 1964, 1972, 1976, 1977a, Huhta 1965, 1971, Palmgren \& Biström 1979, Biström \& Väisänen 1988, Heimer \& Nentwig 1991, Koponen 1995, Pajunen et al. 1995), but the abundance has also been fairly high in clear-cuts and burnt-overs (Huhta $1965,1971)$. It has also rarely been caught in peatlands (e.g. Ledum bogs, Myrica-Molinia bogs, open bogs) (Palmgren 1972, 1977a), meadows (Palmgren 1964, 1972, 1977a), islands and skerries (Palmgren 1972), sandy shores (Palm- gren 1964, 1972), and roadsides or cleared forests (Palmgren 1977a).

Meioneta affinis (Kulczyn'ski, 1898) [Meioneta beata (O. P.-Cambridge, 1906)]

The findings of Meioneta affinis have been concentrated in open habitats: dry to moist meadows (Huhta 1971, Palmgren 1972, 1975, 1977a), peatlands (e.g. Myrica-Molinia bogs, open bogs; more rarely Ledum bogs, edges of open bogs) (Palmgren 1964, 1972, 1975, 1977a, Koponen et al. 2001, Koponen 2002a), semi-open grass vegetation on sand (Palmgren 1972), and clear-cuts and burnt-overs (Huhta 1971). Some individuals were also caught in forests (e.g. VT, dry pine forests, spruce-pine forests) (Huhta 1971, Palmgren 1977a, Biström \& Väisänen 1988, Pajunen et al. 1995). According to Heimer and Nentwig (1991) M. affinis lives within mosses and grasses in relatively dry habitats.

\section{Meioneta gulosa (L. Koch, 1869)}

Meioneta gulosa has been caught mainly in clearcuts and burnt-overs (Huhta 1965, 1971). A few individuals have also been captured in forests (a thinned pine forest, pine forests with Cladonia, spruce-pine forests, MT) (Palmgren 1964, Huhta 1971, Palmgren \& Biström 1979, Biström \& Väisänen 1988). However, according to Heimer and Nentwig (1991), M. gulosa lives in meadows.

\section{Meioneta rurestris (C. L. Koch, 1836) (Agyneta rurestris)}

Meioneta rurestris seems to live in open habitats (e.g. clear-cuts and burnt-overs, dry meadows; also shores, open peatlands) (Huhta 1965, 1971, Palmgren 1972, 1975, 1977a, Heimer \& Nentwig 1991), but also in light forests (e.g. rocky pine forests, forest edges, MT, OMT, VT, a polluted dry pine forest with almost no vegetation) (Huhta 1971, Palmgren 1964, 1972, 1975, Biström \& Väisänen 1988, Heimer \& Nentwig 1991, Koponen \& Niemelä 1994, 1995). It is a pioneer species (Koponen \& Niemelä 1994, 1995).

Micrargus apertus (O. P-Cambridge, 1871)

Micrargus apertus has been caught only in forests (e.g. dark coniferous forests with Sphagnum and Mnium, spruce mires, Sphagnum in small depressions in forests, MT, but also quite light and 
dry forests) (Palmgren 1976, 1977a, Palmgren \& Biström 1979, Pajunen et al. 1995).

Micrargus herbigradus (Blackwall, 1854)

Micrargus herbigradus is eurytopic (Huhta 1971, Palmgren 1972). It has been caught in dry to moist meadows (Palmgren 1964, 1972, 1976, 1977a), clear-cuts (Huhta 1971), small islands and skerries (Palmgren 1972), forests (e.g. VT, MT, OMT, mixed forests, edges of brooks in forests, birch-mixed mires, spruce mires; rarely spruces) (Palmgren 1964, 1972, 1976, 1977a, Huhta 1965, 1971, Heimer \& Nentwig 1991, Koponen 1995, Pajunen et al. 1995), and peatlands (e.g. Ledum bogs, Myrica-Molinia bogs, open bogs) (Palmgren 1964, 1972, 1976, 1977a, Koponen 1978, Koponen et al. 2001).

Microlinyphia pusilla (Sundevall, 1830) (Linyphia pusilla)

Microlinyphia pusilla has an affinity for moist open habitats (Palmgren 1975, Heimer \& Nentwig 1991). It has been caught in meadows, mostly moist ones (Huhta 1971, Palmgren 1975, 1977a), clear-cuts and burnt-overs (Huhta 1965, 1971), peatlands (Ledum bogs, open bogs, quagmires) (Palmgren 1975, 1977a), but more rarely in forests (e.g. rocky pine forests, thinned pine forests, VT, a forest fringe at a shore, Sphagnum in forests, OMT) (Huhta 1965, 1971, Palmgren 1977a, Biström \& Väisänen 1988).

\section{Microneta viaria (Blackwall, 1841)}

Microneta viaria has mainly been caught in forests (e.g. VT, MT, OMT, mixed forests, forest edges, hazel groves, deciduous forests, fen-like and shore Alneta, a forest fringe at a shore, overhanging grass of scarps) (Lehtinen \& Kleemola 1962, Palmgren 1964, 1972, 1975, 1977a, Huhta 1965, 1971, Lehtinen et al. 1979, Palmgren \& Biström 1979, Biström \& Väisänen 1988, Koponen 1995, Pajunen et al. 1995). It was also collected in peatlands (e.g. Myrica-Molinia bogs, Alnus swamps, a peat-harvesting area, spruce mires) (Palmgren 1972, 1975, Koponen 1978, 1979), and some individuals even in semi-open grass vegetation on sand (Palmgren 1972), meadows (Huhta 1971, Palmgren 1977a), and burnt-overs (Huhta 1971). M. viaria lives within leaf litter (Palmgren 1972, Heimer \& Nentwig 1991).
Minicia marginella (Wider, 1834)

Minicia marginella has mainly been found in open habitats: open peatlands (e.g. MyricaMolinia bogs, open bogs, eutrophic fens) (Palmgren 1964, 1972, 1976, 1977a, Lehtinen et al. 1979, Koponen 2002a, 2002b), meadows, mostly dry ones (Palmgren 1976, 1977a), semi-open grass vegetation on sand (Palmgren 1972), and clear-cuts and burnt-overs (Huhta 1971). It has also been collected in Ledum bogs (Palmgren 1977a), overhanging mosses of dense scarps (Palmgren 1977a), and forests (e.g. VT) (Biström \& Väisänen 1988, Pajunen et al. 1995). According to Heimer and Nentwig (1991), it is associated with warm habitats.

Minyriolus pusillus (Wider, 1834)

Minyriolus pusillus lives in forests (e.g. CT, rocky pine forests, VT, coastal Pineta, MT, OMT, overhanging mosses of dense scarps, mixed forests, spruce mires; more rarely hazel groves, junipers) (Lehtinen \& Kleemola 1962, Palmgren 1964, 1972, 1976, 1977a, Huhta 1965, 1971, Lehtinen et al. 1979, Palmgren \& Biström 1979, Biström \& Väisänen 1988, Väisänen \& Biström 1990, Heimer \& Nentwig 1991, Koponen 1995, Pajunen et al. 1995). It has also been caught in other habitats, but not as abundantly as in forests: clear-cuts and burnt-overs (Huhta 1965, 1971), dry to moist meadows (Palmgren 1964, 1972, 1976, 1977a), islands and skerries (Palmgren 1972), and peatlands (e.g. Ledum bogs, MyricaMolinia bogs) (Palmgren 1972, 1976, 1977a). Palmgren (1972, 1977a) stressed the importance of dry ground and a lush moss carpet.

Moebelia penicillata (Westring, 1851) (Entelecara penicillata)

Moebelia penicillata lives in trees (pines, spruces, junipers, birches, oaks) (Palmgren 1964, 1972, 1976, 1977a, Heimer \& Nentwig 1991, Koponen 1996, Koponen et al. 1997). According to Palmgren (1972), it apparently hibernates on the ground. It has also been caught in VT (Biström \& Väisänen 1988) and within dwarf shrubs in a Ledum bog (Palmgren 1977a).

Neriene clathrata (Sundevall, 1830) (Linyphia clathrata)

Neriene clathrata has been caught in forests (e.g. 
VT, coastal Pineta, moist depressions, a forest fringe at a shore, mixed forests, birch forests, hazel groves; more rarely shady forests, e.g. overhanging moss in dense scarps, MT, OMT) (Huhta 1971, Palmgren \& Biström 1979, Biström \& Väisänen 1988, Koponen 1995, Pajunen et al. 1995) but also in meadows (especially overhanging grasses of meadow ditches) (Palmgren 1977a). It has also been captured in peatlands (e.g. Ledum bogs, Myrica-Molinia bogs) (Palmgren 1972, 1977a), and clear-cuts (Huhta 1965, 1971). According to Heimer and Nentwig (1991), N. clathrata lives within lower vegetation near the ground.

\section{Neriene montana (Clerck, 1757) (Linyphia montana)}

According to Palmgren (1975), the main habitat of Neriene montana is shady forest. It has been caught e.g. under bark of deciduous trees, within overhanging vegetation of scarps, MT, junipers, spruces, and interstitices between boulders and rock clefts (Lehtinen \& Kleemola 1962, Palmgren 1972, 1975, 1977a, Biström \& Väisänen 1988).

\section{Neriene peltata (Wider, 1834) (Prolinyphia peltata)}

Neriene peltata has mainly been caught in forests, especially in coniferous trees (most abundantly in spruce), and in Vaccinium myrtillus (e.g. VT, MT, OMT, mixed forests, forest edges, spruce mires; rarely hazel groves) (Palmgren 1964, 1972, 1975, 1977a, Huhta 1971, Lehtinen et al. 1979, Biström \& Väisänen 1988, Heimer \& Nentwig 1991, Pajunen et al. 1995). It has also been found in peatlands (e.g. spruce mires, Ledum bogs) (Palmgren 1964, 1977a, Lehtinen et al. 1979), and meadows (Palmgren 1964, 1977a).

Neriene radiata (Walckenaer, 1842) [Neriene marginata (C. L. Koch, 1834)]

Neriene radiata has an affinity for semi-open habitats (Heimer \& Nentwig 1991): light forests (e.g. CT, rocky pine forests, VT, forest edges, scarps; rarely MT) (Palmgren 1964, 1972, 1975, 1977a), and Ledum bogs (Palmgren 1972, 1975, 1977a). It has been especially abundant in Calluna, Vaccinium myrtillus and other dwarf shrubs, and junipers (Palmgren 1975, 1977a). It has also rarely been found in meadows, roadsides or cleared forests, and boulder beds of the feet of cliffs (Palmgren 1977a).

Obscuriphantes obscurus (Blackwall, 1841) (Lepthyphantes obscurus)

Obscuriphantes obscurus seems to be a forest species (e.g. CT, VT, MT, mixed forests, moist depressions in forests; coniferous trees, lower vegetation, and leaf-litter) (Lehtinen \& Kleemola 1962, Palmgren 1964, 1972, 1975, 1977a, Biström \& Väisänen 1988, Heimer \& Nentwig 1991, Koponen 1995, Pajunen et al. 1995). L. obscurus has also been captured in peatlands, e.g. Ledum bogs (Palmgren 1972), medium-moist meadows (Palmgren 1972), roadsides or cleared forests (Palmgren 1977a), and grass ribbons on small islands (Palmgren 1972).

\section{Oedothorax apicatus (Blackwall, 1850)}

Oedothorax apicatus seems to be an open-habitat species (Heimer \& Nentwig 1991): shores (Lehtinen \& Kleemola 1962, Palmgren 1972, 1976), small skerries (Palmgren 1972, 1976) and, more rarely, moist meadows (Palmgren 1972, 1976). Koponen and Niemelä $(1994,1995)$ caught it in a polluted dry pine forest with almost no vegetation. It is a pioneer species (Koponen \& Niemelä 1994, 1995).

Oedothorax gibbosus (Blackwall, 1841) [Oedothorax gibbosus tuberosus (Blackwall, 1841)] Oedothorax gibbosus has been caught in spruce mires, fen-like Alneta, and other types of moist sites within forests (Palmgren 1972, 1976, 1977a), and other types of peatlands (e.g. Ledum bogs, Myrica-Molinia bogs, open bogs) (Palmgren 1972, 1976, 1977a), and moist meadows (Palmgren 1972, 1976, 1977a). A few findings have been from drier habitats: forests (e.g. moss in MT) (Palmgren 1977a, Pajunen et al. 1995), an old burnt-over (Huhta 1971) and a meadow (Huhta 1971). According to Heimer and Nentwig (1991), O. gibbosus lives in moist open habitats.

\section{Oedothorax retusus (Westring, 1851)}

Oedothorax retusus is a shore species (e.g. wrack beds, shore meadows, gulleries, coastal Pineta, a forest fringe at a shore, silty shores of temporary ponds) (Lehtinen \& Kleemola 1962, Palmgren 
1964, 1972, 1976, 1977a, Heimer \& Nentwig 1991, Koponen 2000). It has also been caught in deciduous-mixed fern type forests, spruce mires, overhanging vegetation of meadow ditches, and Myrica-Molinia bogs (Palmgren 1964, 1972, 1977a).

Oreonetides vaginatus (Thorell, 1872)

Oreonetides vaginatus has been found in forests (e.g. spruce mires, old spruce and mixed forests) (Palmgren 1972, 1975, Heimer \& Nentwig 1991, Koponen 1995, Pajunen et al. 1995), and peatlands (Koponen 1978). One individual has been reported in a clear-cut (Huhta 1971).

Oryphantes angulatus (O. P-Cambridge, 1881) (Lepthyphantes angulatus)

In most studies Oryphantes angulatus seems to have an affinity for moist habitats: peatlands [e.g. Alnus swamps, Phragmites fens, Calluna bogs, Myrica-Molinia bogs, open bogs, spruce mires; a hygrophilous mire species in Koponen (1968)] (Palmgren 1964, 1972, 1975, 1977a, Koponen 1968, 1978, 1979, 2002a, 2002b, Heimer \& Nentwig 1991, Koponen et al.2001), and moist meadows (Palmgren 1972, 1975, 1977a). It has also been caught in medium-moist forests (e.g. spruce forests, spruce-pine forests, old mixed and pine forests) (Palmgren 1964, 1972, Koponen 1995, Pajunen et al. 1995), and rarely in dry meadows (Palmgren 1972), and clear-cuts (Huhta 1965, 1971).

Palliduphantes pallidus (O. P-Cambridge, 1871) (Lepthyphantes pallidus)

Palliduphantes pallidus has mostly been captured in forests (e.g. VT, MT, OMT, mixed forests; rarely CT) (Huhta 1971, Palmgren 1972, 1975, 1977a, Biström \& Väisänen 1988, Heimer \& Nentwig 1991, Pajunen et al. 1995), and clearcuts and burnt-overs (Huhta 1971). It has rarely been caught in moist meadows (Palmgren 1972, 1975), and very dry sublapidicol (Palmgren 1964). Other habitat types in Heimer and Nentwig (1991) were caves.

\section{Pelecopsis elongata (Wider, 1834)}

Pelecopsis elongata has mainly been encountered in forests (e.g. MT, OMT, spruce mires; also CT, VT, coastal Pineta) (Palmgren 1964, 1972,
1976, Huhta 1971, Heimer \& Nentwig 1991, Pajunen et al.1995). It has also been caught in Ledum and Myrica-Molinia bogs (Palmgren 1972), small islands (Palmgren 1972), and clearcuts (Huhta 1971). It ascends trees, but lives also in ant nests (Formica spp.) (Palmgren 1972).

Pelecopsis mengei (Simon, 1884) (Trichopterna mengei)

Pelecopsis mengei has been stated as having an affinity for moist habitats (Palmgren 1976, 1977a, Heimer \& Nentwig 1991). Indeed, it has been caught in peatlands, including different types of peaty forests (e.g. spruce mires, birchmixed mires, moist Alnetum) (Palmgren 1972, 1976, 1977a, Koponen 1978). However, it has also been caught in forests with forest mosses (e.g. spruce forests, spruce-dominated forests, mixed forests, VT) (Palmgren 1964, Huhta 1971, Biström \& Väisänen 1988, Koponen 1995, Pajunen et al. 1995). It has also rarely been found in burnt-overs (Huhta 1971), and within the overhanging grasses of a meadow ditch (Palmgren 1977a).

\section{Peponocranium praeceps Miller, 1943}

There are only two published findings of Peponocranium praeceps: in a moist shore meadow, and in a forest meadow (Palmgren 1976).

Pityohyphantes phrygianus (C. L. Koch, 1836) Pityohyphantes phrygianus seems to be a forest species (e.g. rocky pine forests, VT, MT, mixed forests) (Palmgren 1964, 1972, 1975, 1977a, Lehtinen et al.1979, Biström \& Väisänen 1988, Heimer \& Nentwig 1991, Pajunen et al. 1995). Most of the findings have been from coniferous trees (especially spruces, but also junipers, pines) (Palmgren 1964, 1972, 1975, 1977a). It has also been caught in Ledum and Myrica-Molinia bogs (Palmgren 1972, 1977a), meadows (Palmgren 1977a), and roadsides and cleared forests (Palmgren 1977a).

Pocadicnemis pumila (Blackwall, 1841)

Pocadicnemis pumila seems to live in semi-open to open habitats. It has been caught in light forests (e.g. rocky pine forests, CT, VT, coastal Pineta, mixed forests, scarps) (Palmgren 1964, 1972, 1976, 1977a, Huhta 1965, 1971, Palmgren \& Bi- 
ström 1979, Biström \& Väisänen 1988, Koponen 1995, Pajunen et al.1995), clear-cuts and burntovers (Huhta 1965, 1971), medium-moist to moist meadows, more rarely dry ones (Palmgren 1964, 1972, 1976, 1977a, Huhta 1971), and peatlands (e.g. Ledum bogs, Myrica-Molinia bogs, open bogs) (Palmgren 1964, 1972, 1976, 1977a, Koponen 1978, Koponen et al. 2001), but somewhat more rarely in shady forests (e.g. MT, OMT, spruce mires) (Palmgren 1964, 1972, 1977a, Huhta 1965, Koponen 1995, Pajunen et al. 1995). It has an affinity for "airy" structures, like lush mosses and overhanging grasses (Palmgren 1972, 1977a). According to Heimer and Nentwig (1991), P. pumila lives in moist habitats.

Poeciloneta variegata (Blackwall, 1841) [Poeciloneta globosa (Wider, 1834)]

Poeciloneta variegata has mostly been caught in forests (e.g. overhanging grasses and mosses of shady scarps, MT) (Palmgren 1972, 1977a, Palmgren \& Biström 1979, Heimer \& Nentwig 1991). It has also rarely been found in meadows (e.g. overhanging grass at meadow ditches, dry meadows) (Palmgren 1977a), very dry sublapidicol (Palmgren 1964), rocks (Palmgren 1972), and bogs (Palmgren 1972).

Porrhomma campbelli F. O. P-Cambridge, 1894 (Porrhomma fagei Miller \& Kratochvil, 1940) Palmgren (1977a) caught some individuals of Porrhomma campbelli in a little swamp, surrounded by forest and covered by very luxuriant Sphagnum. According to Heimer and Nentwig (1991), it lives under stones.

\section{Porrhomma pallidum Jackson, 1913}

Porrhomma pallidum seems to be a forest species (especially spruce forests, i.e. MT, OMT, spruce mires, but also in VT, mixed forests, hazel groves) (Palmgren 1964, 1972, 1975, 1977a, Huhta 1965, 1971, Palmgren \& Biström 1979, Biström \& Väisänen 1988, Väisänen \& Biström 1990, Heimer \& Nentwig 1991, Koponen 1995 , 1999, Pajunen et al. 1995), but it has also been caught abundantly in clear-cuts and burnt-overs (Huhta 1965, 1971). It has also been reported in peatlands, e.g. Myrica-Molinia bogs (Palmgren 1972, Koponen 1978).
Porrhomma pygmaeum (Blackwall, 1834)

Porrhomma pygmaeum seems to have an affinity for moisture: open peatlands (e.g. MyricaMolinia bogs, open bogs, quagmires) (Palmgren 1964, 1972, 1975, 1977a, Heimer \& Nentwig 1991), moist forested sites (e.g. fen-like Alneta, Sphagnum in small depressions in forests, birchmixed mires, Ledum bogs) (Palmgren 1972, 1977a, Heimer \& Nentwig 1991), and moist shore meadows (rarely other types of meadows) (Palmgren 1964, 1972, 1975, 1977a). A few individuals has been caught in trees and Vaccinium myrtillus in forests (Palmgren 1972, 1977a).

Savignia frontata Blackwall, 1833 (Savignya frontata)

Savignia frontata has mainly been caught in moist habitats (Lehtinen \& Kleemola 1962): shores and close to them (Palmgren 1972, 1976), islands and skerries (Palmgren 1972, 1976), moist meadows (but probably also dry ones) (Huhta 1971, Palmgren 1972, 1977a). It has also more rarely been found in peatlands (e.g. open bogs, Ledum bogs) (Palmgren 1972, 1977a, Koponen 1978), and fen-like Alneta on shores (Palmgren 1972). Only a few individuals have been reported in forests (e.g. OMT, edges of brooks in forests, Sphagnum in small depressions in forests, rocky pine forests, CT) (Huhta 1965, 1971, Palmgren 1972, 1976, 1977a, Pajunen et al.1995), and clear-cuts (Huhta 1965, 1971).

Scotinotylus evansi (O. P-Cambridge, 1894) (Caledonia evansi)

In Southern Finland Scotinotylus evansi has been caught mainly in light forests (e.g. VT, a shaded slope of a small island; also shady ones) (Huhta 1965, 1971, Palmgren 1972, Pajunen et al. 1995). Huhta (1971) caught one individual in a burntover. According to Palmgren (1976), S. evansi lives in moss in the boreal region. However, according to Heimer and Nentwig (1991), it lives in open habitats. It is a northern species (Palmgren 1972).

Semljicola faustus (O. P-Cambridge, 1900) (Eboria fausta, Latithorax faustus)

In Southern and Central Finland (as in Central Europe; Heimer \& Nentwig 1991) Semljicola faustus seems to be a forest species, with an affin- 
ity for spruce forests, especially spruce mires (more rarely light forests, e.g. deciduous forests, mixed forests, VT) (Palmgren 1964, 1972, 1976, 1977a, Huhta 1965, 1971, Pajunen et al. 1995). It has also more rarely been caught in open bogs (Koponen et al. 2001), clear-cuts and burnt-overs (Huhta 1971), and near a meadow ditch (Palmgren 1977a).

Semljicola latus (Holm, 1939) (Latithorax latus) Semljicola latus is a northern species (Huhta 1965, Palmgren 1976, Koponen 1999). It has been found in spruce forests (old spruce-dominated forests, HMT) (Huhta 1965, Koponen 1995, 1999), and one individual was reported in a clear-cut (Huhta 1965).

Silometopus incurvatus (O. P-Cambridge, 1873) Silometopus incurvatus has almost always been caught from sites rich in mosses and lichens in light forests (e.g. CT, VT, spruce-pine forests, a forest fringe at a shore). It has also rarely been caught in MT (Palmgren 1972, 1976, 1977a, Palmgren \& Biström 1979) and semi-open grass vegetation on sand (Palmgren 1972).

\section{Silometopus reussi (Thorell, 1871)}

Silometopus reussi has been caught only in open habitats (Heimer \& Nentwig 1991): treeless skerries (Palmgren 1972), shores (Palmgren 1972, 1976), meadows (Huhta 1971, Palmgren 1976, 1977a), dry sublapidicol (Palmgren 1977a), and burnt-overs (Huhta 1965, 1971).

\section{Sisicus apertus (Holm, 1939)}

Sisicus apertus has been captured in bogs (e.g. Myrica-Molinia bogs, Ledum bogs, pine bogs) (Palmgren 1972, 1975, Lehtinen et al. 1979), small moist depressions covered with willows (Palmgren 1972), spruce mires (Palmgren 1975, 1977a), spruce forests (e.g. MT, HMT) (Huhta 1965, 1971, Palmgren 1977a), thinned pine forests of MT (Huhta 1965, 1971), and clear-cuts (Huhta 1971).

\section{Stemonyphantes lineatus (Linnaeus, 1758)}

Stemonyphantes lineatus has mainly been captured in forests (e.g. overhanging grass and moss in shady scarps, hazel groves, mixed forests, rocky pine forests, CT, VT, MT, forest edges; rarely pines) (Palmgren 1972, 1975, 1977a, Huhta 1965, 1971, Palmgren \& Biström 1979, Heimer \& Nentwig 1991, Pajunen et al.1995), and peatlands (e.g. open bogs, Myrica-Molinia bogs, Ledum bogs) (Palmgren 1972, 1975, 1977a, Koponen 2002b). It has more rarely been caught in meadows (Palmgren 1972, 1977a, Heimer \& Nentwig 1991), clear-cuts and burntovers (Huhta 1971), walls of wooden houses, or firewood piles (Palmgren 1977a). According to Palmgren (1972), the affinity could be described as lush, but airy and fairly moist vegetation in the +/- lowest layers. Other habitats listed in Heimer and Nentwig (1991) were ruderal habitats.

Tallusia experta (O. P-Cambridge, 1871) (Centromerus expertus)

Tallusia experta seems to have an affinity for moist habitats: peatlands (e.g. open bogs, birchmixed mires; more rarely spruce mires; in Lithuania also pine bogs) (Palmgren 1964, 1972, 1975 , 1977a, Koponen 1978, 2002a, 2002b, Koponen et al. 2001), other moist and peaty places in forests (e.g. Sphagnum in small depressions, edges of brooks) (Palmgren 1977a), and moist meadows (also drier ones) (Huhta 1971, Palmgren 1972, 1975, 1977a, Heimer \& Nentwig 1991). Other habitat types mentioned by Heimer and Nentwig (1991) were forest edges.

Tapinocyba insecta (L. Koch, 1869)

Tapinocyba insecta has been captured in light forests (Palmgren 1976), and dry meadows (Palmgren 1964, 1976). Palmgren (1972) found one individual in a gravel shore, but he thought that it was an atypical habitat. According to Heimer and Nentwig (1991), T. insecta lives within mosses and litter of forests.

Tapinocyba pallens (O. P-Cambridge, 1872)

Tapinocyba pallens has mostly been encountered in forests (e.g. CT, VT, MT, OMT, HMT, hazel groves, mixed forests; rarely branches of spruces) (Lehtinen \& Kleemola 1962, Palmgren 1964, 1972, 1976, 1977a, Huhta 1965, 1971, Palmgren \& Biström 1979, Biström \& Väisänen 1988, Väisänen \& Biström 1990, Heimer \& Nentwig 1991, Koponen \& Niemelä 1994, 1995, Koponen 1995 , 1999, Pajunen et al. 1995), but it may also be abundant in clear-cuts and burnt-overs (Huhta 
$1965,1971)$. It has also been caught in peatlands (e.g. spruce mires, birch-mixed mires, Ledum bogs, Myrica-Molinia bogs, open bogs) (Palmgren 1964, 1972, 1977a, Koponen et al. 2001), dry to moist meadows (Palmgren 1964, 1972, 1977a, Huhta 1971), and islands and skerries (Palmgren 1972).

\section{Tapinopa longidens (Wider, 1834)}

Tapinopa longidens has mainly been caught in forests [e.g. VT, MT, OMT, coastal Pineta, old pine forests, hazel groves, mixed forests; more rarely rocky pine forests, CT; in Heimer \& Nentwig (1991) mainly sunny and dry forest edges] (Huhta 1965, 1971, Palmgren 1972, 1975 , 1977a, Palmgren \& Biström 1979, Biström \& Väisänen 1988, Heimer \& Nentwig 1991, Koponen 1995), but the abundance has also been reported as being fairly high in clear-cuts (Huhta 1971). The species has also rarely been collected in meadows (Palmgren 1972, 1975, 1977a), islands and skerries (Palmgren 1972), and MyricaMolinia bogs (Palmgren 1972).

Tenuiphantes alacris (Blackwall, 1853) (Lepthyphantes alacris)

Tenuiphantes alacris has mostly been caught in shady forests (e.g. MT, OMT, spruce mires, also mixed forests with spruce) (Palmgren 1964, 1972, 1975, 1977a, Huhta 1965, 1971, Palmgren \& Biström 1979, Biström \& Väisänen 1988, Väisänen \& Biström 1990, Koponen 1995, 1999, Pajunen et al. 1995), although Palmgren (1977a) caught it quite abundantly even within overhanging grasses of meadow ditches. It has also rarely been found in light forests (e.g. pine-birch forests, coastal Pineta, forest edges) (Palmgren 1964, 1972, 1977a, Biström \& Väisänen 1988, Koponen 1995, Pajunen et al. 1995), leaf-litter (Lehtinen \& Kleemola 1962), peatlands (e.g. Ledum bogs) (Palmgren 1972, Koponen 1978), clearcuts (Huhta 1971), and dry meadows (Palmgren 1964). According to Heimer and Nentwig (1991), T. alacris lives in leaf-litter, but Palmgren (1975) stated that it lives mainly within mosses but also among overhanging vegetation, field layer and low in trees.
Tenuiphantes cristatus (Menge, 1866) (Lepthyphantes cristatus)

Tenuiphantes cristatus has been caught in peatlands (e.g. Alnus swamps, Myrica-Molinia bogs, Ledum bogs, spruce mires, birch-mixed mires; rarely open bogs) (Palmgren 1972, 1975, 1977a, Koponen 1979). It has also rarely been caught in medium-moist to moist meadows (Palmgren 1964, 1972, 1975, 1977a), and medium-moist forests (e.g. hazel groves, MT, VT, mixed forests, coastal Pineta) (Lehtinen \& Kleemola 1962, Palmgren 1972, Biström \& Väisänen 1988, Pajunen et al. 1995). However, according to Heimer and Nentwig (1991), it lives within litter in deciduous forests.

Tenuiphantes mengei (Kulczyński, 1887) (Lepthyphantes mengei)

Tenuiphantes mengei has been most frequently encountered in light forests (e.g. VT, mixed forests, also moist depressions; more rarely rocky pine forests, spruce forests, trees) (Lehtinen \& Kleemola 1962, Palmgren 1964, 1972, 1975, 1977a, Huhta 1965, 1971, Palmgren \& Biström 1979, Biström \& Väisänen 1988, Koponen 1995, Pajunen et al. 1995), but it has also been abundant in clear-cuts and burnt-overs (Huhta 1971). It was also captured in sandy shores (Palmgren 1964, 1972), dry to moist meadows (Palmgren 1972, 1977a), and peatlands (e.g. Ledum bogs, MyricaMolinia bogs, open bogs) (Palmgren 1972, 1977a, Koponen 1978, 2002b). According to Heimer and Nentwig (1991), T. mengei lives within leaf litter and mosses, and under stones.

Tenuiphantes tenebricola (Wider, 1834) (Lepthyphantes tenebricola)

Tenuiphantes tenebricola seems to be a forest species (e.g. CT, VT, MT, OMT, spruce mires, mixed forests, hazel groves, deciduous forests, also coniferous trees) (Lehtinen \& Kleemola 1962, Palmgren 1964, 1972, 1975, 1977a, Huhta 1965, 1971, Lehtinen et al. 1979, Palmgren \& Biström 1979, Biström \& Väisänen 1988, Heimer \& Nentwig 1991, Koponen 1995, 1999, Pajunen et al. 1995). In some studies it has shown indications of an affinity for spruce forests (Huhta 1965, 1971, Palmgren 1972, 1975), but in others it has been equally abundant in spruce and light forests (Palmgren 1977a, Koponen 1995). It has also 
been found in clear-cuts (Huhta 1965, 1971), peatlands (Palmgren 1972, Koponen 1978), and within overhanging grasses of meadow ditches (Palmgren 1977a). T. tenebricola lives commonly among mosses and litter, but can be caught regularly in Vaccinium myrtillus and taller plants (Palmgren 1972, 1975).

Thyreosthenius biovatus (O. P-Cambridge, 1875) Thyreosthenius biovatus has rarely been collected, but most of the findings have been from ant nests (Formica rufa coll.) (Palmgren 1972, 1976, Heimer \& Nentwig 1991). Koponen (1995) caught T. biovatus in old dense spruce forests with thick moss cover.

Thyreosthenius parasiticus (Westring, 1851)

Thyreosthenius parasiticus has been caught in forests (e.g. VT, MT, OMT, under bark of dying or dead birches, stems of deciduous trees) (Palmgren 1964, 1972, 1976, 1977a, Biström \& Väisänen 1988, Väisänen \& Biström 1990, Pajunen et al. 1995), ant nests (Palmgren 1976), and meadows (Palmgren 1977a). According to Heimer and Nentwig (1991), it requires a balanced microclimate but lives otherwise in a variety of habitats.

Tibioploides arcuatus (Tullgren, 1955) (Tibioplus arcuatus)

Tibioploides arcuatus has mainly been collected in light forests (e.g. CT, VT, thinned pine forests, old pine forests) (Huhta 1965, 1971, Palmgren 1975, Biström \& Väisänen 1988, Koponen 1995, Pajunen et al.1995). It has also more rarely been caught in MT (Palmgren 1972, Biström \& Väisänen 1988), and clear-cuts (Huhta 1965, 1971). Koponen (1978), however, caught it in peatlands.

\section{Tibioplus diversus (L. Koch, 1879)}

Tibioplus diversus has solely been caught in forests (e.g. thinned pine forests, HMT, spruce-dominated forests, mixed pine-spruce forests with some birches) (Huhta 1971, Palmgren 1975, Koponen 1995).

Tiso vagans (Blackwall, 1834)

Tiso vagans has most frequently been caught in medium-moist meadows (also dry and moist ones) (Palmgren 1964, 1972, 1976, 1977a), but according to Heimer and Nentwig (1991) it lives in moist, open habitats. A few individuals have been caught in MT (Palmgren 1977a), dunged vegetation in gulleries (Palmgren 1972), and litter (Lehtinen \& Kleemola 1962).

Troxochrota scabra Kulczyński, 1894 [Ceratinops pectinata (Tullgren, 1955)]

Troxochrota scabra has mostly been caught in dryish light forests (e.g. CT, VT, coastal Pineta) (Huhta 1965, 1971, Palmgren 1972, 1976, 1977a, Biström \& Väisänen 1988). It has also rarely been caught in MT forests (Palmgren 1977a, Palmgren \& Biström 1979), islands and skerries (Palmgren 1972, 1976), dry and moist meadows (Palmgren 1972), open and Myrica-Molinia bogs (Palmgren 1972, 1976, 1977a), and clear-cuts and burntovers (Huhta 1971).

Troxochrus nasutus Schenkel, 1925

A few individuals of Troxochrus nasutus have been collected in meadows (Palmgren 1977a), very dense spruce forests of MT (Palmgren 1972), under a barn (Palmgren 1976), and clearcuts (Huhta 1971). However, according to Heimer and Nentwig (1991), T. nasutus lives in moist forests in trees.

Troxochrus scabriculus (Westring, 1851)

Troxochrus scabriculus lives in open or very lightly forested habitats (Palmgren 1972, 1976): treeless or lightly forested islands and skerries, especially gulleries (Palmgren 1972, 1976), semi-open grass vegetation on sand (Palmgren 1972), rocky pine forests (Palmgren 1976, 1977a), other rocky habitats (Lehtinen \& Kleemola 1962, Palmgren 1964), and more rarely in dry to medium-moist meadows (Palmgren 1964, 1972, 1976, 1977a, Huhta 1971). According to Heimer and Nentwig (1991), it lives in open habitats.

Walckenaeria antica (Wider, 1834) (Wideria antica)

Walckenaeria antica has been caught in forests (e.g. rocky pine forests, CT, VT, coastal Pineta, mixed forests, MT, OMT, spruce mires) (Palmgren 1964, 1972, 1976, 1977a, 1982, Huhta 1965, 1971, Palmgren \& Biström 1979, Biström \& Väisänen 1988, Koponen \& Niemelä 1994, 1995 , Koponen 1995, Pajunen et al. 1995), and peatlands [e.g. Alnus swamps, Phragmites fens, 
Calluna bogs, Ledum bogs, Myrica-Molinia bogs, open bogs, quagmires; according to Palmgren $(1976,1982)$ it lives there in the drier parts] (Palmgren 1972, 1976, 1977a, 1982, Koponen 1978, 1979, 2002a, 2002b). W. antica has also been captured in rocky habitats (Palmgren 1972, 1976), meadows (especially dry ones, but also medium-moist to moist) (Huhta 1971, Palmgren 1972, 1976, 1977a, 1982), clear-cuts and burntovers (Huhta 1971, Palmgren 1982), and shores (Palmgren 1982). According to Heimer and Nentwig (1991) and Palmgren (1972, 1976, 1982), W. antica lives in light and dry habitats.

Walckenaeria atrotibialis (O. P-Cambridge, 1878) [Walckenaeria melanocephala O. P.-Cambridge, 1881, Wideria melanocephala (O. P.Cambridge, 1881)]

Walckenaeria atrotibialis seems to have an affinity for moist habitats: peatlands (e.g. spruce mires, birch-mixed mires, Sphagnum in small depressions of forests, Alnus swamps, MyricaMolinia bogs, open bogs; in Lithuania also pine bogs) (Palmgren 1964, 1972, 1976, 1977a, Koponen 1978, 1979, 2002a, Koponen et al. 2001), shores with dense stands of Salix and Phragmites (Palmgren 1976), and rarely moist meadows (Palmgren 1977a). It has also been caught in drier habitats: forests (e.g. pine forests, spruce forests, mixed forests) (Palmgren 1964, 1977a, Huhta 1971, Palmgren \& Biström 1979, Biström \& Väisänen 1988, Koponen \& Niemelä 1994, Koponen 1995, Pajunen et al. 1995), and burnt-overs (Huhta 1971).

Walckenaeria cucullata (C. L. Koch, 1836) (Wideria cucullata)

Walckenaeria cucullata has mainly been caught in forests (e.g. rocky pine forests, CT, VT, coastal Pineta, MT, OMT, mixed forests, hazel groves, spruce mires, overhanging moss in scarps, moist depressions) (Palmgren 1964, 1972, 1976, 1977a, Huhta 1965, 1971, Palmgren \& Biström 1979, Biström \& Väisänen 1988, Heimer \& Nentwig 1991, Koponen 1995, Pajunen et al. 1995), but it has also been fairly abundant in clear-cuts and burnt-overs (Huhta 1965, 1971). It has also been captured in peatlands (e.g. Ledum bogs, Myrica-Molinia bogs, open bogs) (Palm- gren 1972, 1977a) and meadows (Huhta 1971, Palmgren 1977a).

Walckenaeria cuspidata Blackwall, 1833 (Cornicularia cuspidata)

Walckenaeria cuspidata seems to have an affinity for moist habitats with some tree canopy cover or at least taller shrubs (Palmgren 1972, 1976, Heimer \& Nentwig 1991): it has mainly been caught mainly in peatlands with tree or shrub cover (e.g. spruce mires, birch-mixed mires, Ledum bogs with pines, fen-like Alneta, MyricaMolinia bogs, moist depressions with Sphagnum) (Palmgren 1964, 1972, 1976, 1977a). It has also more rarely been collected in open bogs (Palmgren 1972, 1977a), moist and shore meadows (Palmgren 1972, 1977a), medium-moist forests (e.g. MT, mixed forests, coastal Pineta) (Palmgren 1964, 1972, 1977a, Huhta 1965, Biström \& Väisänen 1988, Koponen 1995, 1999, Pajunen et al. 1995), and clear-cuts and burnt-overs (Huhta 1965, 1971).

Walckenaeria dysderoides (Wider, 1834) [Wideria fugax (O. P.-Cambridge, 1871)]

Walckenaeria dysderoides has mainly been encountered in forests (e.g. rocky pine forests, CT, VT, MT, OMT, mixed forests, hazel groves, spruce mires) (Palmgren 1964, 1972, 1977a, Huhta 1965, 1971, Biström \& Väisänen 1988, Koponen 1995, 1999, Pajunen et al. 1995), but it has also been caught quite abundantly in clearcuts and burnt-overs (Huhta 1965, 1971). W. dysderoides has also been collected in bogs (e.g. Ledum bogs, Myrica-Molinia bogs, open bogs) (Palmgren 1972), and medium-moist to moist meadows (Palmgren 1972, 1977a). According to Heimer and Nentwig (1991), it lives within litter and mosses.

Walckenaeria karpinskii (O. P-Cambridge, 1873) (Cornicularia karpinskii, Walckenaeria holmi Millidge, 1983)

Walckenaeria karpinskii has mainly been caught in forests (e.g. VT, MT, HMT, mixed forests, old forests) (Palmgren 1964, 1976, 1977a, Huhta 1971, Palmgren \& Biström 1979, Biström \& Väisänen 1988, Koponen 1995, Pajunen et al. 1995). Huhta $(1965,1971)$ also caught a few individuals 
in clear-cuts. W. karpinskii is a northern species (Palmgren 1977a).

Walckenaeria nudipalpis (Westring, 1851) (Trachynella nudipalpis)

Walckenaeria nudipalpis has been collected in forested to treeless peatlands (e.g. spruce mires, birch-mixed mires, moist depressions, fen-like Alneta, Ledum bogs, Myrica-Molinia bogs, open bogs) (Palmgren 1964, 1972, 1977a, Koponen 1978, 2002a, 2002b, Heimer \& Nentwig 1991, Koponen et al. 2001), medium-moist forests (e.g. VT, MT, mixed forests, old spruce-dominated forests) (Palmgren 1964, 1972, Biström \& Väisänen 1988, Koponen 1995, 1999, Pajunen et al. 1995), and clear-cuts and burnt-overs (Huhta 1971).

Walckenaeria obtusa Blackwall, 1836 (Trachynella obtusa)

Walckenaeria obtusa has been caught in forests (e.g. CT, VT, MT, mixed forests, hazel groves, spruce mires, edges of brooks in forests, moist depressions) (Palmgren 1964, 1972, 1977a, Huhta 1965, 1971, Biström \& Väisänen 1988, Pajunen et al. 1995), open bogs (Palmgren 1972), grass ribbons on small islands (Palmgren 1972), meadows (Huhta 1971), and one individual in a burntover (Huhta 1971). According to Heimer and Nentwig (1991) and Palmgren (1972), it has an affinity for moisture.

Walckenaeria unicornis O. P-Cambridge, 1861 (Cornicularia unicornis)

Walckenaeria unicornis has an affinity for moist habitats (Heimer \& Nentwig 1991): peatlands (e.g. Myrica-Molinia bogs, Ledum bogs) (Palmgren 1972, 1977a, Koponen 1978), moist meadows (Palmgren 1972, 1977a), sandy shores (Palmgren 1964), edges of ditches (Palmgren 1972), small moist depressions among rocks (Palmgren 1972), and fairly moist forests (e.g. a forest fringe at a shore, birch-mixed mires, edges of brooks in forests, Sphagnum in small depressions in forests, fen-like shore Alneta) (Palmgren 1972, 1977a). It has also been caught in old spruce-dominated forests (Koponen 1995), and junipers (Palgmren 1977a).
Walckenaeria vigilax (Blackwall, 1853) (Cornicularia vigilax)

In accordance with Heimer and Nentwig (1991), most of the few findings of Walckenaeria vigilax have been from moist habitats: shores (e.g. sandy shores, heaps of wrack, shore meadows, edges of shore Alneta) (Palmgren 1964, 1972, 1976), bogs (Palmgren 1964, 1976), and grass and leaves in moist sites (Palmgren 1977a). However, Biström and Väisänen (1988) caught it in medium-moist forests (VT, MT).

\section{Zornella cultrigera (L. Koch, 1879)}

Zornella cultrigera has mostly been collected in forests (e.g. VT, MT, mixed forests, overhanging moss in shady scarps) (Palmgren 1964, 1976, 1977a, Huhta 1965, 1971, Palmgren \& Biström 1979, Biström \& Väisänen 1988, Koponen 1995, 1999, Pajunen et al. 1995). It has also been caught in clear-cuts (Huhta 1971), and peatlands (Koponen 1978). Z. cultrigera is a northern species (Palmgren 1977a, Koponen 1999).

\subsection{Liocranidae}

Agroeca brunnea (Blackwall, 1833)

Agroeca brunnea has been found in forests (e.g. CT, VT, coastal Pineta, MT, mixed forests) (Palmgren 1964, 1972, 1977a, Huhta 1965, 1971, Palmgren \& Biström 1979, Biström \& Väisänen 1988, Pajunen et al. 1995), peatlands (e.g. Myrica-Molinia bogs, Ledum bogs with low tree stratum, spruce mires, open bogs) (Palmgren 1972, 1977a, Koponen 1978, 2002b, Koponen et al. 2001), clear-cuts (Huhta 1971), and meadows (e.g. near meadow ditches, moist meadows) (Huhta 1971, Palmgren 1972, 1977a). A. brunnea lives among mosses, leaf litter and bark (Heimer \& Nentwig 1991).

Agroeca proxima (O. P-Cambridge, 1871)

Agroeca proxima has been caught in forests (e.g. CT, VT; rarely OMT) (Huhta 1971, Palmgren 1972, 1977a, Biström \& Väisänen 1988, Heimer \& Nentwig 1991), peatlands [e.g. MyricaMolinia bogs, Calluna bogs, open bogs, Phragmites fens, semi-open depressions of Sphagnum in forests, Alnus swamps, a peat harvesting area; a xerophilic mire species in Kopo- 
nen(1968)] (Palmgren 1943, 1972, 1977a, Koponen 1968, 1979, 2002a, 2002b, Heimer \& Nentwig 1991, Koponen et al. 2001), clear-cuts and burnt-overs (Huhta 1971), and more rarely moist to medium-moist meadows (Palmgren 1972, 1977a). Other habitats listed in Heimer and Nentwig (1991) were dunes.

\subsection{Lycosidae}

Acantholycosa lignaria (Clerck, 1757)

Acantholycosa lignaria typically lives on the bark of dead fallen trees (Palmgren 1939, 1972, 1977a, Holm 1947, Heimer \& Nentwig 1991), with an affinity for dryish light forests (e.g. VT, esker) (Palmgren 1939, Holm 1947, Huhta 1971, Caselius \& Itämies 1993, Pajunen et al. 1995). It has also been caught in Myrtillus-type forests (Biström \& Väisänen 1998), shore meadows (Palmgren 1939), clear-cuts and burnt-overs (Huhta 1971, Itämies \& Ruotsalainen 1985), and fields (Itämies \& Ruotsalainen 1985).

\section{Alopecosa aculeata (Clerck, 1757) (Tarentula aculeata)}

In most Finnish studies Alopecosa aculeata has not been separated from $A$. taeniata. Consequently, the habitat affinity is poorly known (Kronestedt 1990, Immonen \& Itämies1994). A. aculeata has an affinity for dryish light pine stands (e.g. EVT, esker) (Kronestedt 1990, Caselius \& Itämies 1993, Immonen \& Itämies 1994), but it has also been found in open Sphagnum bogs (Kronestedt 1990), sand clearings (Caselius \& Itämies 1993), and waterside forests (Caselius \& Itämies 1993).

\section{Alopecosa inquilina (Clerck, 1757) (Tarentula inquilina)}

Alopecosa inquilina has mostly been caught in light forests, especially VT (Palmgren 1939, 1972, 1977a, Holm 1947, Huhta 1965, 1971, Itämies \& Ruotsalainen 1985, Heimer \& Nentwig 1991, Pajunen et al.1995), but it has also been fairly abundant in clear-cuts (Huhta 1971). Palmgren (1964) captured one individual in a very dry sublapidicol.
Alopecosa pinetorum (Thorell, 1856) (Tarentula pinetorum)

Alopecosa pinetorum has mostly been caught in light coniferous forests (e.g. sparse coniferous forests, open old forests with pine and/or birch or spruce, VT, pine forests of EVT, a narrow strip of ECT; but also MT) (Holm 1947, Palmgren \& Biström 1979, Biström \& Väisänen 1988, Itämies \& Jarva-Kärenlampi 1989, Heimer \& Nentwig 1991, Immonen \& Itämies 1994, Koponen 1995, 1999, Pajunen et al. 1995). It has also been caught in bogs (Heimer \& Nentwig 1991, Immonen \& Itämies 1994) and shores (Immonen \& Itämies 1994).

Alopecosa pulverulenta (Clerck, 1757) (Tarentula pulverulenta)

Alopecosa pulverulenta has an affinity for open habitats, but it has also rarely been found in light forests. The habitat records include dry to moist meadows (Palmgren 1939, 1972, 1977a, Holm 1947, Huhta 1971, Itämies \& Ruotsalainen 1985, Heimer \& Nentwig 1991, Koponen 2000), shore meadows (Caselius \& Itämies 1993), sand shores (Koponen 2000), clear-cuts and burnt-overs (Huhta 1971), treeless skerries (Palmgren 1972), peatlands [e.g. open bogs, Myrica-Molinia bogs, Calluna bogs, Sphagnum fuscum bogs, pine bogs, Phragmites fens, a peat harvesting area; xerophilous mire species in Koponen (1968)] (Koponen 1968, 1978, 1979, 2002a, 2002b, Palmgren 1972, 1977a, Lehtinen et al. 1979, Itämies \& Jarva-Kärenlampi 1989, Koponen et al. 2001), and light coniferous forests (e.g. rocky pine forests, VT, coastal Pineta, shore forests) (Palmgren 1939, 1972, 1977a, Holm 1947, Huhta 1971, Heimer \& Nentwig 1991, Caselius \& Itämies 1993, Pajunen et al.1995).

\section{Alopecosa taeniata (C. L. Koch, 1835)}

There is not much information about the habitat affinity of Alopecosa taeniata, as in most Finnish studies it has not been separated from $A$. aculeata (Kronestedt 1990). It has mainly been caught in forests (mesic forests, waterside forests, fresh coniferous forests, ECT, EVT) (Kronestedt 1990, Caselius \& Itämies 1993, Immonen \& Itämies 1994). It has also been found in gravel shores and open pine bogs (Immonen \& Itämies 1994). However, A taeniata may not be a forest species: 
I collected 900 individuals in clear-cuts, 734 individuals at the edges of $0.09-0.55$ ha uncut retention-tree groups, 200 individuals within the retention-tree groups; prior to logging, I trapped only a total of ten individuals (Matveinen-Huju, unpublished data).

Pardosa amentata (Clerck, 1757) [Lycosa saccata (Linnaeus, 1758)]

Pardosa amentata has mainly been caught in open habitats, such as shores (Palmgren 1939, 1972, Holm 1947, Immonen \& Itämies 1994), moist shore meadows (Palmgren 1972, Caselius \& Itämies 1993), other meadows (Holm 1947, Huhta 1971, Palmgren 1977a), fields (Holm 1947, Itämies \& Ruotsalainen 1985), open peatlands (e.g. Myrica-Molinia bogs, open bogs) (Palmgren 1972, 1977a), bare moist soil partly covered with plants (Palmgren 1977a), and (more rarely) clear-cuts (Huhta 1971). It has also rarely been found in forests: dry pine forests with Cladina, and pine-birch forests (Lehtinen \& Kleemola 1962, Palmgren 1972). According to Heimer and Nentwig (1991), P. amentata lives in moist habitats.

\section{Pardosa fulvipes (Collett, 1876)}

Almost all of the few findings of Pardosa fulvipes have been from open habitats: fields (Holm \& Kronestedt 1970, Lehtinen et al.1979, Itämies \& Ruotsalainen 1985), shores and shore meadows (Holm \& Kronestedt 1970, Lehtinen et al. 1979), and a clearing in a forest (Itämies \& Ruotsalainen 1985). It has also been caught in the grassy slopes of a small brook (Holm \& Kronestedt 1970).

Pardosa hyperborea (Thorell, 1872) (Lycosa hyperborea)

Pardosa hyperborea seems to be confined to more or less open peatlands [e.g. open bogs, Spahgnum fuscum bogs, Calluna bogs, but also pine bogs, Phragmites fens, a peat harvesting area; a hygrophilous mire species in Koponen (1968)] (Palmgren 1939, 1972, 1977a, Holm 1947, Koponen 1968, 1978, 1979, 2002a, 2002b, Itämies \& Jarva-Kärenlampi 1989, Heimer \& Nentwig 1991, Itämies \& Ruotsalainen 1994, Koponen et al. 2001). However, it was also caught it in forests (e.g. pine forests close to bogs) (Itämies \& Jarva-Kärenlampi 1989, Pajunen et al.
1995). One individual has also been found in a clear-cut (Huhta 1971). Other habitat types listed in Heimer and Nentwig (1991) were open forests.

Pardosa lugubris (Walckenaer, 1802) [Lycosa lugubris, Lycosa chleata (Müller, 1764)]

Pardosa lugubris lives both in open habitats and in forests (Heimer \& Nentwig 1991). The habitat records include forests (mainly light ones, such as rocky pine forests, CT, coastal Pineta, VT, EVT, mixed forests, deciduous forests, hazel groves, scarps, but also MT, OMT; rarely spruce mires) (Palmgren 1939, 1972, 1977a, Holm 1947, Huhta 1971, Palmgren \& Biström 1979, Itämies \& Ruotsalainen 1985, Biström \& Väisänen 1988, Itämies \& Jarva-Kärenlampi 1989, Väisänen \& Biström 1990, Caselius \& Itämies 1993, Immonen \& Itämies 1994, Koponen \& Niemelä 1994, Koponen 1995, 1999, Pajunen et al. 1995), dry to moist meadows (Huhta 1971, Palmgren 1972, 1977a), clear-cuts (Huhta 1971), and an edge of a man-made sand field and a dry pine forest (Koponen 2000), shores (Palmgren 1939, 1972), fields (Itämies \& Ruotsalainen 1985), dry sublapidicol (Palmgren 1977a), boulder beds of the feet of cliffs (Palmgren 1977a), and (more rarely) peatlands (e.g. Ledum bogs, open bogs, a peat harvesting area, Alnus swamps) (Palmgren 1972, 1977a, Koponen 1979).

\section{Pardosa paludicola (Clerck, 1757) (Lycosa paludicola)}

Pardosa paludicola has been caught in open and mainly also moist (Heimer \& Nentwig 1991) habitats: peatlands, such as Sphagnum bogs (Lehtinen \& Kleemola 1962, Itämies \& JarvaKärenlampi 1989), moist and shore meadows (also dry to medium-moist ones) (Holm 1947, Palmgren 1939, 1972, 1977a), and other kinds of moist shores (Holm 1947), but less abundantly in sandy shores (Palmgren 1972, Caselius \& Itämies 1993), and fields (Itämies \& Ruotsalainen 1985).

Pardosa palustris (Linnaeus, 1758) [Lycosa palustris, Lycosa tarsalis Thorell, 1856, Pardosa tarsalis (Thorell, 1856)]

Pardosa palustris seems to be an open-habitat species (Heimer \& Nentwig 1991): dry to moist meadows (Palmgren 1939, 1972, 1977a, Holm 
1947, Huhta 1971, Koponen 2000), open grasslands (Palmgren 1939), small skerries (Palmgren 1972), open bogs (Itämies \& Jarva-Kärenlampi 1989, Koponen 2002a), shores (Holm 1947, Palmgren 1972, Koponen 2000), and burnt-overs (Huhta 1971). It has also more rarely been found in forests (Caselius \& Itämies 1993, Pajunen et al. 1995).

Pardosa pullata (Clerck, 1757) (Lycosa pullata) Pardosa pullata has mostly been caught in open habitats: dry to moist meadows (Palmgren 1939, 1972, 1977a, Holm \& Kronestedt 1970, Huhta 1971, Heimer \& Nentwig 1991), clear-cuts and burnt-overs (Huhta 1971), fields (Holm \& Kronestedt 1970, Itämies \& Ruotsalainen 1985, Heimer \& Nentwig 1991), shores (Palmgren 1939, 1972, Holm \& Kronestedt 1970, Heimer \& Nentwig 1991), and open peatlands, such as bogs and fens (Holm 1947, Holm \& Kronestedt 1970, Koponen et al. 2001, Koponen 2002a, 2002b). It has also been caught in tree-covered peatlands (e.g. pine bogs, pine forests on thin peat, small mires in forests) (Palmgren 1939, Itämies \& Jarva-Kärenlampi 1989, Koponen et al. 2001), and light forests (e.g. deciduous forests, eskers) (Palmgren 1939, Caselius \& Itämies 1993, Pajunen et al. 1995). According to Lehtinen and Kleemola (1962) and Koponen (1968), P. pullata lives in moist habitats.

Pardosa riparia (C. L. Koch, 1833) [Lycosa riparia, Lycosa pernix Thorell, 1872, Pardosa pernix (Thorell, 1872)]

According to Holm and Kronestedt (1970) and Heimer and Nentwig (1991), Pardosa riparia lives in meadows in Central Europe, but in open woods in Northern Scandinavia. Most Finnish studies support the view that $P$. riparia is indeed a forest species (e.g. forest edges, open coniferous forests, CIT, ECT, VT, broad-leaved woodlands) (Holm 1947, Lehtinen et al. 1979, Biström \& Väisänen 1988, Itämies \& Jarva-Kärenlampi 1989, Immonen \& Itämies 1994, Pajunen et al. 1995), but it has also been reported as being very abundant in clear-cuts and burnt-overs (Huhta 1971). In Itämies and Ruotsalainen (1985), it was concentrated in open habitats (meadow-like vegetation, fields), but in that study the meadow-like vegetation was at the forest edge zone. It has also been caught in peatlands (e.g. pine bogs, open bogs; even quite abundantly) (Palmgren 1964, 1977a, Koponen et al. 2001).

Pardosa schenkeli Lessert, 1904

One individual of Pardosa schenkeli was caught in a burnt-over by Huhta (1971). According to Heimer and Nentwig (1991), it is a montane species.

Pardosa sphagnicola (Dahl, 1908)

Pardosa sphagnicola seems to be associated with peatlands [e.g. open bogs, Ledum bogs, MyricaMolinia bogs, Alnus swamps, Phragmites fens, Calluna bogs, a peat harvesting area, Sphagnum fuscum bogs, short-sedge fens, Sphagnum in small depressions of semi-open forests; a hygrophilous mire species in Koponen (1968)] (Koponen 1968, 1978, 1979, 2002a, 2002b, Holm \& Kronestedt 1970, Palmgren 1972, 1977a, Lehtinen et al.1979, Itämies \& JarvaKärenlampi 1989, Heimer \& Nentwig 1991, Immonen \& Itämies 1994, Koponen et al. 2001). It has also been caught in CIT (but the trap was located in a crevice of a rock rising steeply from a bog) (Itämies \& Jarva-Kärenlampi 1989), shores (Immonen \& Itämies 1994), waterside meadows (Caselius \& Itämies 1993), and an old burnt-over (Huhta 1971).

Pirata hygrophilus Thorell, 1872

Pirata hygrophilus seems to have an affinity for moist habitats: peaty or otherwise moist sites within forests (e.g. spruce mires, birch-mixed mires, fen-like Alneta, Alnus swamps, Sphagnum in small depressions in forests, edges of brooks in forests) (Palmgren 1939, 1964, 1972, 1977a, Holm 1947, Koponen 1979, Heimer \& Nentwig 1991, Caselius \& Itämies 1993), other kinds of peatlands (e.g. Ledum bogs, Myrica-Molinia bogs, open bogs) (Holm 1947, Palmgren 1964, 1972, 1977a, Koponen 1978, Lehtinen et al. 1979, Biström \& Väisänen 1988, Koponen et al. 2001), and moist meadows and shore meadows (Palmgren 1972, 1977a, Caselius \& Itämies 1993). It has occasionally been found in mediummoist forests (e.g. spruce forests, groves) (Palmgren 1972, 1977a, Pajunen et al. 1995), a stony shore (Caselius \& Itämies 1993), and an old burnt-over (Huhta 1971). 
Pirata piraticus (Clerck, 1757)

Pirata piraticus seems to have an affinity for moist habitats: open peatlands (e.g. MyricaMolinia bogs, Sphagnum bogs, open bogs, quagmires) (Palmgren 1939, 1964, 1972, 1977a, Holm 1947, Lehtinen \& Kleemola 1962, Koponen 1978, 2002b, Lehtinen et al. 1979, Itämies \& Jarva-Kärenlampi 1989, Koponen et al. 2001), moist meadows and shore meadows (Palmgren 1972, Lehtinen et al. 1979, Caselius \& Itämies 1993), shores (Holm 1947, Palmgren 1972, Immonen \& Itämies 1994, Koponen 2000), treeless skerries (Palmgren 1972), Sphagnum in small depressions of forests, and other moist sites within forests (but very rarely spruce mires) (Palmgren 1972, 1977a). A couple of individuals was also caught in MT by Palmgren (1977a). According to Heimer and Nentwig (1991), it lives near standing or slowly flowing water.

\section{Pirata uliginosus (Thorell, 1856)}

Also Pirata uliginosus seems to have an affinity for moisture (Heimer \& Nentwig 1991), because it has mainly been found in peatlands, including forested ones, and peaty sites within forests (e.g. Ledum bogs, Myrica-Molinia bogs, open bogs, Sphagnum fuscum bogs, Calluna bogs, a peat harvesting area, Phragmites fens, Alnus swamps, fen-like Alneta, spruce mires, birch-mixed mires, Sphagnum in small depressions in forests) (Palmgren 1939, 1972, 1977a, Koponen 1968, 1979 , 2002a, 2002b, Lehtinen et al.1979, Itämies \& Jarva-Kärenlampi 1989, Immonen \& Itämies 1994, Koponen et al. 2001). Pajunen et al.(1995) caught it in medium-moist forests.

\section{Trochosa ruricola (De Geer, 1778)}

Trochosa ruricola has been caught in shores (Palmgren 1939, 1972, 1977a, Lehtinen \& Kleemola 1962), and skerries (Palmgren 1972), but also in dry to moist meadows and shore meadows (Palmgren 1939, 1964, 1972, Huhta 1971, Itämies \& Ruotsalainen 1985, Caselius \& Itämies 1993), shore Alneta (Palmgren 1972), fields (Itämies \& Ruotsalainen 1985), and even in forests (Itämies \& Ruotsalainen 1985). According to Holm (1947), T. ruricola lives in dry, sun-exposed habitats, and according to Heimer and Nentwig (1991) in non-shady habitats with medium moisture.
Trochosa spinipalpis (F. O. P-Cambridge, 1895) Trochosa spinipalpis seems to live mainly in peatlands [e.g. Ledum bogs, Myrica-Molinia bogs, open bogs, Sphagnum bogs, Calluna bogs, Phragmites fens, Alnus swamps, a peat harvesting area, quagmires, birch-mixed mires, Sphagnum in small depressions in forests; no findings in spruce mires; a hygrophilous mire species in Koponen (1968)] (Palmgren 1939, 1964, 1972, 1977a, Holm 1947, Lehtinen \& Kleemola 1962, Koponen 1968, 1978, 1979, 2002a, 2002b, Lehtinen et al. 1979, Immonen \& Itämies 1994, Koponen et al. 2001). It has also been collected in meadows (Holm 1947, Huhta 1971, Palmgren 1977a, Heimer \& Nentwig 1991), clear-cuts and burnt-overs (Huhta 1971), borders of a clearing (might have come from a nearby bog area) (Itämies \& Ruotsalainen 1985), shore meadows (Caselius \& Itämies 1993), sandy shores (Caselius \& Itämies 1993), and forests (e.g. sprucepine forest with some traces of marshiness, ECT) (Palmgren 1972, Itämies \& Jarva-Kärenlampi 1989, Caselius \& Itämies 1993, Pajunen et al. 1995).

\section{Trochosa terricola Thorell, 1856}

Trochosa terricola has been caught in light forests (e.g. rocky pine forests, CT, VT, coastal Pineta, mixed forests, hazel groves, overhanging grass in not very shady scarps, forest edges) (Palmgren 1939, 1972, 1977a, Holm 1947, Huhta 1965, 1971, Itämies \& Ruotsalainen 1985, Biström \& Väisänen 1988, Koponen \& Niemelä 1994, Koponen 1995, Pajunen et al. 1995) and in dry to moist meadows (Palmgren 1939, 1972, 1977a, Huhta 1971), and clear-cuts and burntovers (Huhta 1965, 1971, Itämies \& Ruotsalainen 1985). It has also more rarely been found in shady forests, e.g. spruce stands (Huhta 1971, Palmgren 1972, 1977a, Palmgren \& Biström 1979, Pajunen et al. 1995), fields (Palmgren 1939), peatlands (e.g. Calluna bogs, Ledum bogs, Myrica-Molinia bogs) (Palmgren 1939, 1972), dry open sublapidicol (Palmgren 1977a), and shores (Palmgren 1972). However, according to Heimer and Nentwig (1991), it lives in shady habitats with medium moisture. 
Xerolycosa nemoralis (Westring, 1861)

In most studies Xerolycosa nemoralis has been collected in light forests (e.g. a dry polluted pine forest with almost no vegetation, dry pine forests with Cladina, CT, coastal Pineta, mixed forests, hazel groves; a few individuals in MT) (Palmgren 1939, 1972, 1977a, Holm 1947, Lehtinen \& Kleemola 1962, Itämies \& Jarva-Kärenlampi 1989, Heimer \& Nentwig 1991, Koponen \& Niemelä 1994, 1995, Pajunen et al. 1995), but also abundantly in clear-cuts and burnt-overs (Huhta 1971). Koponen (1979) caught it in a peat harvesting area. However, Palmgren (1939) lists meadows as its secondary habitat type, and Huhta (1971) caught one individual in a meadow. According to Koponen and Niemelä (1994), it is a pioneer species.

\subsection{Mimetidae}

Ero furcata (Villers, 1789)

Ero furcata has been caught mainly in forests (e.g. coastal Pineta, CT, VT, MT, mixed forests, spruce mires, hazel groves, junipers) (Huhta 1965, 1971, Palmgren 1972, 1974b, 1977a, Palmgren \& Biström 1979, Biström \& Väisänen 1988, Koponen 1995, Pajunen et al. 1995). It has also been captured in meadows, very rarely dry ones (Palmgren 1972, 1974b, 1977a), clear-cuts and burnt-overs (Huhta 1971), treeless skerries and small islands (Palmgren 1972), and bogs with some cover (e.g. Ledum bogs, Myrica-Molinia bogs; rarely open bogs) (Palmgren 1972, 1974b, 1977a). According to Heimer and Nentwig (1991), E. furcata lives in trees and bushes near the ground.

\subsection{Philodromidae}

Thanatus formicinus (Clerck, 1757)

Thanatus formicinus has been caught in light forests (e.g. rocky pine forests, CT, VT, overhanging grass in not very shady scarps; rarely spruce forests or spruce-mixed forests) (Palmgren 1964, 1972, 1977a, Pajunen et al. 1995), peatlands (e.g. open bogs, Myrica-Molinia bogs) (Palmgren 1972, Koponen 2002b), small islands (Palmgren 1972), a dry meadow (Palmgren 1977a), and clear-cuts and burnt-overs (Huhta 1971). According to Heimer and Nentwig (1991), it lives within mosses in dry habitats.

Tibellus oblongus (Walckenaer, 1802)

Tibellus oblongus lives in sunny habitats (Heimer \& Nentwig 1991): light forests (e.g. rocky pine forests, CT, coastal Pineta, mixed forests, overhanging grass in not very shady scarps, not very closed MT; rarely junipers, pines) (Palmgren 1950, 1972, 1977a), dry to moist meadows (Palmgren 1964, 1950, 1972, 1977a), semi-open grass vegetation on sand (Palmgren 1972), clearcuts (Huhta 1971, Palmgren 1972, 1977a), and peatlands (e.g. Ledum bogs, Myrica-Molinia bogs, open bogs) (Palmgren 1972, 1977a, Koponen 1978).

\subsection{Pisauridae}

Dolomedes fimbriatus (Clerck, 1757)

Dolomedes fimbriatus seems to inhabit moist habitats: peatlands (e.g. Ledum bogs, MyricaMolinia bogs, open bogs, Sphagnum bogs, peaty forests) (Palmgren 1943, 1972, 1977a, Holm 1947, Lehtinen \& Kleemola 1962, Koponen 1968, 2002a, Heimer \& Nentwig 1991, Koponen et al. 2001), moist meadows (Palmgren 1943, 1972, 1977a), and shores (Palmgren 1943). It has also been caught in lower numbers in drier habitats: forests (e.g. VT, MT, branches of spruces) (Palmgren 1972, 1977a, Palmgren \& Biström 1979, Biström \& Väisänen 1998), dry meadows (Palmgren 1972), and roadsides or cleared forests (Palmgren 1977a). According to Palmgren (1943, 1972) and Holm (1947), especially young individuals can be caught in drier habitats.

\subsection{Salticidae}

Euophrys frontalis (Walckenaer, 1802) [Euophrys maculata (Wider, 1834)]

Euophrys frontalis has mainly been collected in light forests (e.g. CT, mixed spruce-pine forest of VT, rocky Pineta, a forest fringe at a shore) (Palmgren 1943, 1972, 1977a, Huhta 1971, Heimer \& Nentwig 1991). It has also been caught in open habitats: Myrica-Molinia bogs in gener- 
ally very dry tussocks (Palmgren 1972), dry to medium-moist meadows (Palmgren 1972, 1977a), and clear-cuts (Huhta 1971). According to Palmgren (1977a), "airy" grasses, or debris intermingled with grasses, seems to be its most favoured habitat.

\section{Evarcha falcata (Clerck, 1757)}

Evarcha falcata has been caught in light forests (e.g. CT, VT, coastal Pineta, rocky pine forests, mixed forests, forest edges, hazel groves, junipers, pines, spruces; rarely MT, HMT, spruce mires) (Lehtinen \& Kleemola 1962, Palmgren 1964, 1972, 1977a, Huhta 1965, 1971, Biström \& Väisänen 1988, Heimer \& Nentwig 1991, Koponen \& Niemelä 1994, Koponen 1995, Pajunen et al. 1995), clear-cuts and burnt-overs (Huhta 1971, Palmgren 1977a), bogs (e.g. Ledum bogs, Myrica-Molinia bogs, open bogs) (Palmgren 1972, 1977a), and dry to very moist meadows (Palmgren 1964, 1972, 1977a). According to Palmgren (1943), E. falcata lives in all kinds of ground vegetation, but it is especially abundant in sunny, dry habitats with Calluna.

\section{Heliophanus dampfi Schenkel, 1923}

Heliophanus dampfi has been caught in bogs (Palmgren 1943, 1972, Heimer \& Nentwig 1991).

\section{Heliophanus dubius C. L. Koch, 1835}

Most of the findings of Heliophanus dubius have been from trees (junipers, pines, spruces, alders in shores, trees in fences) (Palmgren 1943, 1972, 1977a) that were situated mainly in open forests (Palmgren 1972, 1977a). It has also rarely been caught in overhanging grasses of scarps and steep rocky slopes (Palmgren 1977a), roadsides or cleared forests (Palmgren 1977a), and very dry sublapidicol (Palmgren 1964). According to Heimer and Nentwig (1991), however, it lives in the lower vegetation of meadows and forest edges, and in tree stumps.

\section{Neon reticulatus (Blackwall, 1853)}

Neon reticulatus seems to be a forest species (e.g. rocky pine forests, CT, VT, coastal Pineta, MT, mixed forests, spruce mires, birch-mixed mires, rarely hazel groves) (Palmgren 1943, 1964, 1972, 1977a, Lehtinen \& Kleemola 1962, Lehtinen et al. 1979, Palmgren \& Biström 1979, Biström \& Väisänen 1988, Väisänen \& Biström 1990, Koponen 1995), although it has also been collected quite abundantly in peatlands (e.g. spruce mires, birch-mixed mires, Ledum bogs, Myrica-Molinia bogs, open bogs) (Palmgren 1964, 1972, 1977a), and islands and skerries (Palmgren 1972). It has also more rarely been found in dry to moist meadows (Palmgren 1972, 1977a). According to Heimer and Nentwig (1991), N. reticulatus lives within litter and mosses. In Finland, abundant mosses, but also lichens, seem to characterize its typical microhabitat (Palmgren 1943, 1972, 1977a).

\section{Pellenes lapponicus (Sundevall, 1833)}

Pellenes lapponicus has been caught in a burntover (Huhta 1971) and in Empetrum (Palmgren 1943). According to Heimer and Nentwig (1991), it lives within the lower vegetation.

Pseudeuophrys erratica (Walckenaer, 1826) [Euophrys erratica, Pseudeuophrys callida (Walckenaer, 1802)]

Pseudeuophrys erratica has been caught in trees (pines, birches, spruces, oaks) (Palmgren 1943, Koponen 1996). According to Heimer and Nentwig (1991), it lives within rocks and bark.

Salticus cingulatus (Panzer, 1797)

Salticus cingulatus has been caught in trees, e.g. oaks (Palmgren 1943, 1972, Heimer \& Nentwig 1991, Koponen 1996, Koponen et al. 1997), among lichens on rocks (Palmgren 1943, 1972, Lehtinen \& Kleemola 1962) and (more rarely) on walls of houses (Palmgren 1977a, Heimer \& Nentwig 1991), a forest fringe at a shore (Palmgren 1977a), meadows (Palmgren 1977a), under protruding cliff scarps without any taller vegetation (Palmgren 1977a), and a burnt-over (Huhta 1971).

Sibianor aurocinctus (Ohlert, 1865) (Bianor aurocinctus)

Sibianor aurocinctus has been caught in open habitats: dry to moist meadows (Palmgren 1943, 1977a), sandy shores or shore meadows (Palmgren 1943), Myrica-Molinia and open bogs (Palmgren 1972, 1977a), dry fields (Palmgren 1943), and burnt-overs (Huhta 1971). According 
to Heimer and Nentwig (1991), S. aurocinctus lives among litter, mosses and lower vegetation, in dry and warm sites.

\section{Sitticus caricis (Westring, 1861)}

Sitticus caricis seems to have an affinity for moist habitats. It has mostly been caught in peatlands (e.g. Myrica-Molinia bogs, open bogs) (Palmgren 1943, 1972, Lehtinen et al. 1979, Heimer \& Nentwig 1991), but also in moist meadows (Palmgren 1943, 1972), and moist sites within forests (e.g. Sphagnum in small depressions, spruce mires) (Palmgren 1972, 1977a).

\subsection{Sparassidae}

Micrommata virescens (Clerck, 1757) [Micromata roseum (Clerck, 1757), Micrommata viridissima (De Geer, 1778)]

Micrommata virescens is associated with warm and sunny habitats (Heimer \& Nentwig 1991). It has been caught in dry to moist meadows (Palmgren 1964, 1972, 1977a), peatlands (e.g. open bogs, Myrica-Molinia bogs, Ledum bogs) (Palmgren 1972, 1977a), and open forests (e.g. rocky pine forests, overhanging grass in scarps, deciduous groves) (Palmgren 1943, 1964, 1977a).

\subsection{Tetragnathidae}

Metellina mengei (Blackwall, 1870) (Meta mengei)

Metellina mengei has been caught in forests (e.g. VT, a thinned pine forest, coastal Pineta, MT, OMT, spruce mires, mixed forests, hazel groves, deciduous forests; also junipers and spruces, and in Sphagnum) (Huhta 1965, 1971, Palmgren 1972, 1974b, 1977a, Biström \& Väisänen 1988, Heimer \& Nentwig 1991, Pajunen et al. 1995), peatlands, (e.g. in Ledum and Myrica in bogs) (Palmgren 1972, 1974b, 1977a), meadows (Huhta 1971, Palmgren 1974b, 1977a), and roadsides or cleared forests (Palmgren 1977a). Other habitat types listed in Heimer and Nentwig (1991) were gardens.
Metellina merianae (Scopoli, 1763) (Meta merianae)

Metellina merianae has been caught in forests, mostly shady ones (e.g. overhanging mosses of shady rock scarps, hazel groves, spruce-deciduous mixed forests, spruce forests) (Palmgren 1964, 1972, 1974b, 1977a). It has rarely been found within overhanging grasses of meadow ditches (Palmgren 1977a), under protruding cliff scarps without any higher vegetation (Palmgren 1977a), and in cellars (Palmgren 1974b).

Pachygnatha listeri Sundevall, 1830

Pachygnatha listeri has been found in forests (e.g. dense Alneta, Corylus groves, mixed forests, spruce mires; rarely OMT) (Huhta 1965, 1971, Palmgren 1972, 1977a), peatlands (e.g. Ledum bogs, Myrica-Molinia bogs, open bogs), meadows (Huhta 1965, 1971, Palmgren 1972, 1977a), and clear-cuts (Huhta 1965, 1971). According to Palmgren (1972, 1974b) and Heimer and Nentwig (1991), it has an affinity for fairly moist covered habitats.

\subsection{Theridiidae}

Crustulina guttata (Wider, 1834)

Crustulina guttata has been caught in light forests (e.g. CT, VT, coastal Pineta, mixed forests, hazel groves; occasionally spruce forests) (Lehtinen \& Kleemola 1962, Palmgren 1964, 1972, 1974a, 1977a, Huhta 1965, 1971, Palmgren \& Biström 1979, Biström \& Väisänen 1988, Heimer \& Nentwig 1991), treeless islands (Lehtinen \& Kleemola 1962, Palmgren 1972), dry meadows (Palmgren 1972, 1977a), burnt-overs (Huhta 1971), very dry sublapidicol (Palmgren 1964, 1977a), dry open habitats (Lehtinen et al. 1979), and peatlands (e.g. Myrica-Molinia bogs, Ledum bogs, open bogs, moist depressions in Sphagnum) (Palmgren 1972, 1974a, 1977a). According to Palmgren (1972), the essential feature of the typical $C$. guttata habitat seems to be denselyfelted but "airy" vegetation layer near the ground.

Dipoena torva (Thorell, 1875)

Dipoena torva seems to live in trees (junipers, spruces, pines) (Palmgren 1972, 1974a, 1977a). 
According to Palmgren (1974a), modern forestry might have adversely affected it.

\section{Episinus angulatus (Blackwall, 1836)}

According to Palmgren (1974a), Episinus angulatus lives in semi-open habitats, and according to Heimer and Nentwig (1991) in bushes. It has been caught in forests (e.g. CT, VT, MT, mixed forests, hazel groves, spruce mires, a forest fringe at a shore, branches of pines) (Huhta 1971, Palmgren 1972, 1977a), skerries with Pineta or open ones (Palmgren 1972), semi-open grass vegetation on sand (Palmgren 1972), clear-cuts (Huhta 1971), meadows (Huhta 1971, Palmgren 1977a), and peatlands (e.g. Myrica-Molinia bogs, Ledum bogs) (Palmgren 1972, 1977a).

Euryopis flavomaculata (C. L. Koch, 1836) Euryopis flavomaculata has been caught in light forests (e.g. CT, VT, coastal Pineta, rocky pine forests, mixed forests; rarely MT) (Huhta 1971, Palmgren 1972, 1974a, 1977a, Biström \& Väisänen 1988, Heimer \& Nentwig 1991, Pajunen et al. 1995), bogs (e.g. Ledum bogs, MyricaMolinia bogs, open bogs) (Palmgren 1972, 1974a, 1977a, Koponen 2002a), dry and moist meadows (Huhta 1971, Palmgren 1972, 1974a, 1977a), and clear-cuts and burnt-overs (Huhta 1971).

Lasaeola tristis (Hahn, 1833) (Dipoena tristis) Lasaeola tristis has been encountered in pines quite near the ground (Palmgren 1974a, Heimer \& Nentwig 1991), junipers (Palmgren 1977a), field layer vegetation (e.g. in Calluna) (Palmgren 1972, 1974a, 1977a), and peatlands (e.g. MyricaMolinia bogs, open bogs, Ledum bogs, fens) (Palmgren 1972, 1974a, 1977a, Biström \& Väisänen 1988). It has also very rarely been collected within mosses in light forests (Palmgren 1977a).

Neottiura bimaculata (Linnaeus, 1767) (Theridion bimaculatum)

Most of the findings of Neottiura bimaculata have been from meadows (mostly mediummoist, but also dry and moist ones) (Huhta 1971, Palmgren 1972, 1974a, 1977a), and it has also been quite abundantly caught in clear-cuts and burnt-overs (Huhta 1971). It has occurred more rarely in bogs (e.g. Ledum bogs, Myrica-Molinia bogs, open bogs) (Palmgren 1972, 1974a, 1977a), forests (e.g. rocky pine forests, coastal Pineta, mixed forests, MT, spruce mires, hazel groves) (Palmgren 1972, 1974a, 1977a), and sandy shores (Palmgren 1972, Lehtinen et al. 1979). However, according to Heimer and Nentwig (1991), it lives mostly in roadsides.

Robertus arundineti (O. P-Cambridge, 1871)

Robertus arundineti has been caught in different kinds of moist habitats: peatlands, mostly fairly open ones (e.g. Myrica-Molinia bogs, open bogs, Ledum bogs) (Palmgren 1964, 1972, 1977a, Heimer \& Nentwig 1991, Koponen 2002a, 2002b), moist meadows, rarely dry ones (Palmgren 1964, 1972, 1977a, Huhta 1971), and more rarely in peaty and other moist places in forests (e.g. Sphagnum in small depressions within forests, edges of brooks in forests, birch-mixed mires, spruce mires) (Palmgren 1972, 1977a, Heimer \& Nentwig 1991).

\section{Robertus lividus (Blackwall, 1836)}

Robertus lividus has been caught in forests (e.g. rocky pine forests, CT, VT, coastal Pineta, MT, OMT, mixed forests, Alneta, hazel groves, spruce mires; a few even in coniferous trees; not very abundantly in the driest forest types) (Palmgren 1964, 1972, 1974a, 1977a, Huhta 1965, 1971, Palmgren \& Biström 1979, Biström \& Väisänen 1988, Heimer \& Nentwig 1991, Koponen 1995, 1999, Pajunen et al. 1995), clear-cuts and burntovers (Huhta 1965, 1971), peatlands (e.g. Ledum bogs; more rarely Myrica-Molinia bogs, open bogs) (Palmgren 1964, 1972, 1974a, 1977a, Koponen 1978), but more rarely medium-moist to moist meadows (Palmgren 1964, 1972, 1974a, 1977a, Huhta 1971), islands and skerries (Palmgren 1972), and very dry sublapidicol (Palmgren 1964).

\section{Robertus lyrifer Holm, 1939}

Robertus lyrifer has been caught in forests (e.g. a thinned pine stand, a moist mixed forest of birch, pine and spruce) (Huhta 1971, Koponen 1995, Pajunen et al. 1995), and peatlands, such as pine bogs (Palmgren 1974a, Koponen 1978, Lehtinen et al. 1979). 
Robertus scoticus Jackson, 1914

Robertus scoticus has been found in forests (e.g. VT, MT, OMT, HMT, mixed forests, spruce mires, birch-mixed mires; rarely CT) (Palmgren 1964, 1972, 1974a, 1977a, Huhta 1965, 1971, Palmgren \& Biström 1979, Biström \& Väisänen 1988, Väisänen \& Biström 1990, Heimer \& Nentwig 1991, Koponen 1995, Pajunen et al. 1995), peatlands (especially Ledum bogs, more rarely Myrica-Molinia bogs) (Palmgren 1972, 1974a, 1977a, Koponen 1978, Heimer \& Nentwig 1991), more rarely clear-cuts and burnt-overs (Huhta 1965, 1971). One individual has also been caught on a sandy shore (Palmgren 1964).

\section{Steatoda bipunctata (Linnaeus, 1758)}

Steatoda bipunctata has been collected in bark of trees, stems, and trunks (e.g. oaks) (Lehtinen \& Kleemola 1962, Palmgren 1972, 1974a, 1977a, Biström \& Väisänen 1988, Heimer \& Nentwig 1991, Koponen 1996, Koponen et al. 1997), near the ground in forests (e.g. mosses in VT, debris in mixed forest, overhanging mosses of scarps) (Palmgren 1977a), walls and houses (Lehtinen \& Kleemola 1962, Palmgren 1972, 1974a, 1977a, Heimer \& Nentwig 1991), overhanging grasses of meadow ditches (Palmgren 1977a), and rocky habitats (e.g. under protruding cliff scarps without any taller vegetation) (Palmgren 1974a, 1977a, Heimer \& Nentwig 1991).

Steatoda phalerata (Panzer, 1801) (Asagena phalerata)

Steatoda phalerata has been found in peatlands [open bogs, but also Ledum bogs; a xerophilous mire species in Koponen (1968)] (Koponen 1968, Palmgren 1974a, 1977a), dry to moist meadows (Palmgren 1972, 1974a, 1977a), forests (e.g. grass-rich forests, Sphagnum in small depressions) (Palmgren 1974a, 1977a, Pajunen et al. 1995), and clear-cuts (Huhta 1971). According to Heimer and Nentwig (1991), it lives in sunny habitats with sparse vegetation.

Theridion mystaceum L. Koch, 1870 (Theridion neglectum Wiehle, 1952)

Theridion mystaceum has mainly been caught in trees (pines, spruces, junipers, oaks) (Palmgren 1972, 1974a, 1977a, Heimer \& Nentwig 1991,
Koponen 1996). Singletons have been collected in shrubs in fen-like shore Alnetum, soil under cover, and beside a boulder (Palmgren 1972, 1974a).

Theridion sisyphium (Clerck, 1757) [Theridion notatum (Linnaeus, 1758)]

Theridion sisyphium has mostly been collected in coniferous trees (juniper, pine, spruce) (Palmgren 1974a, 1977a) in not densely closed stands (Palmgren 1972), but also in shrubs and dwarf shrubs (Palmgren 1972, 1977a, Heimer \& Nentwig 1991). According to Palmgren (1974a), it lives at 1.5-2.5 m height. It has also been caught in Ledum bogs (Palmgren 1972, 1977a), light forests (e.g. rocky pine forests, coastal Pineta, not very closed MT) (Palmgren 1972, 1977a), and meadows (Palmgren 1964, 1977a).

\subsection{Thomisidae}

Ozyptila atomaria (Panzer, 1801) (Oxyptila atomaria)

Ozyptila atomaria has been caught in light forests (e.g. coastal Pineta, rocky pine forests, CT, VT, pine-birch forests, hazel groves) (Huhta 1971, Palmgren 1972, 1977a), dry to medium-moist meadows (Palmgren 1972, 1977a), clear-cuts and burnt-overs (Huhta 1971), rocky islands (Palmgren 1972), and more rarely peatlands (e.g. Ledum bogs, open bogs) (Palmgren 1977a, Koponen 1978). However, according to Heimer and Nentwig (1991), O. atomaria lives in moist habitats.

Ozyptila praticola (C. L. Koch, 1837) (Oxyptila praticola)

Most of the findings of Ozyptila praticola have been from groves (e.g. litter in hazel groves, oaks) (Palmgren 1950, 1972, Koponen 1996), but also within litter in moist depressions (Palmgren 1972). Also Lehtinen and Kleemola (1962) caught it within leaf litter. It has more rarely been found in forests other than groves (e.g. pine-birch forests, MT, scarps) (Palmgren 1972, 1977a), grassy patches on rocks (Palmgren 1972), meadows (e.g. moist ones, overhanging grass at meadow ditches) (Huhta 1971, Palmgren 1977a), and clear-cuts (Huhta 1971). According to 
Heimer and Nentwig (1991), it lives in different not too dry habitats, under mosses and stones.

Ozyptila trux (Blackwall, 1846) (Oxyptila trux) Ozyptila trux has been caught in forests (e.g. fenlike Alneta, MT, OMT, overhanging mosses of dense scarps, spruce mires, birch-mixed mires, VT; more rarely CT and rocky pine forests) (Palmgren 1950, 1964, 1972, 1977a, Huhta 1965, 1971, Palmgren \& Biström 1979, Biström \& Väisänen 1988, Koponen 1995, Pajunen et al. 1995), peatlands (e.g. Myrica-Molinia bogs, Ledum bogs, spruce mires, birch-mixed mires) (Palmgren 1964, 1972, 1977a, Koponen 1978), medium-moist to moist meadows (rarely dry ones) (Palmgren 1950, 1972, 1977a), and clear-cuts and burnt-overs (Huhta 1965, 1971). According to Heimer and Nentwig (1991), O. trux lives in different 'not too dry' habitats.

Xysticus audax (Schrank, 1803)

Xysticus audax seems to live mainly in trees (e.g. pines, oaks) (Lehtinen et al. 1979, Palmgren 1983, Koponen 1996). It has also been caught near the ground (Palmgren 1983, Koponen \& Niemelä 1994, Pajunen et al. 1995). According to Palmgren (1983), his findings near the ground were probably overwintering individuals. Huhta (1971) caught one individual in a clear-cut.

\section{Xysticus bifasciatus C. L. Koch, 1837}

Xysticus bifasciatus seems to be a meadow species (Palmgren 1950, 1977a). According to Heimer and Nentwig (1991), it lives in lawns and heaths. It has also been caught in forests (VT, spruce-pine forests) (Biström \& Väisänen 1988), Ledum bogs (Palmgren 1977a), and clear-cuts and burnt-overs (Huhta 1971).

\section{Xysticus cristatus (Clerck, 1757)}

Xysticus cristatus has been caught in forests, in coniferous trees and near the ground (e.g. CT, VT, coastal Pineta, MT, OMT, HMT, mixed forests, hazel groves, junipers, pines, spruces) (Lehtinen \& Kleemola 1962, Palmgren 1964, 1972, 1977a, Huhta 1965, Biström \& Väisänen 1988), skerries and islands (Palmgren 1972), dry to moist meadows (Palmgren 1964, 1972, 1977a, 1983), and peatlands (e.g. Ledum bogs, open bogs) (Palmgren 1964, 1972, 1977a, Koponen 1978, 2002a).
According to Heimer and Nentwig (1991), it lives near the ground in lower plants.

Xysticus lineatus (Westring, 1851)

Xysticus lineatus has been caught in peatlands, including peaty sites in forests (e.g. Ledum bogs, birch-mixed mires, Sphagnum in small depressions in forest, open bogs) (Palmgren 1950, 1977a, Heimer \& Nentwig 1991, Koponen 2002b), forests (e.g. VT, fern type deciduousmixed forest) (Huhta 1971, Palmgren 1977a, Pajunen et al. 1995), meadows (dry ones, under heaps of hay in meadow edges) (Palmgren 1977a), and clear-cuts and burnt-overs (Huhta 1971).

Xysticus luctuosus (Blackwall, 1836)

Xysticus luctuosus has been caught in forests (e.g. rocky pine forests, VT, MT, mixed forests, hazel groves, forest edges, junipers, spruce mires) (Palmgren 1950, 1964, 1972, 1977a, Huhta 1971, Palmgren \& Biström 1979, Biström \& Väisänen 1988, Heimer \& Nentwig 1991, Koponen 1995, Pajunen et al. 1995), peatlands (e.g. Ledum bogs, spruce mires) (Palmgren 1950, 1972, 1977a, Koponen 1978), dry to moist meadows (Palmgren 1950, 1964, 1972, 1977a, Huhta 1971), and clearcuts and burnt-overs (Huhta 1971).

Xysticus obscurus Collett, 1877

Xysticus obscurus has mainly been caught in forests (e.g. rocky pine forests, CT, VT, MT, mixed forests, spruce mires) (Huhta 1965, 1971, Palmgren 1972, 1977a, Palmgren \& Biström 1979, Biström \& Väisänen 1988, Koponen 1995, Pajunen et al. 1995). It has also been collected in peatlands (e.g. open bogs, Ledum bogs, spruce mires) (Palmgren 1964, 1977a, Lehtinen et al. 1979). Two individuals were reported in clear-cuts by Huhta $(1965,1971)$.

Xysticus sabulosus (Hahn, 1832)

Xysticus sabulosus has been caught in sandy shores and dunes (Palmgren 1950, 1972, Heimer \& Nentwig 1991, Koponen 2000), CT (Palmgren 1972), and burnt-overs (Huhta 1971). Heimer and Nentwig (1991) mention also heaths. 
Xysticus ulmi (Hahn, 1831)

Xysticus ulmi has been most abundantly caught in dry to moist meadows (Palmgren 1964, 1972, 1977a, Huhta 1971). It has also been found in peatlands (e.g. Myrica-Molinia bogs, open bogs, Ledum bogs; see also forests below) (Palmgren 1972, 1977a, Heimer \& Nentwig 1991), forests (e.g. rocky pine forests, MT, mixed forests, spruce mires, Sphagnum in small depressions, junipers, pines) (Palmgren 1972, 1977a), and clearcuts (Huhta 1971, Palmgren 1977a). Other habitats in Heimer and Nentwig (1991) were shores.

\subsection{Zoridae}

\section{Zora nemoralis (Blackwall, 1861)}

Zora nemoralis has been collected in forests (e.g. rocky pine forests, CT, VT, coastal Pineta, MT, mixed forests, a forest fringe at a shore, overhanging moss and grass in scarps, hazel groves; less abundantly in spruce mires, birch-mixed mires, junipers) (Palmgren 1943, 1964, 1972, 1977a, Huhta 1965, 1971, Palmgren \& Biström 1979, Biström \& Väisänen 1988, Väisänen \& Biström 1990, Koponen 1995, Pajunen et al. 1995), but also somewhat abundantly in clear-cuts and burnt-overs (Huhta 1971). It has more rarely been found in peatlands (e.g. Ledum bogs, MyricaMolinia bogs) (Palmgren 1972, 1977a), dry to moist meadows (Palmgren 1977a), dry open sublapidicol (Palmgren 1977a), and stone walls at the edges of fields (Palmgren 1977a).

\section{Zora spinimana (Sundevall, 1833)}

Also Zora spinimana has mostly been collected in forests (e.g. rocky pine forests, CT, VT, MT, mixed forests, overhanging mosses and grasses of scarps, a forest fringe at a shore, spruce mires, birch-mixed mires, hazel groves, junipers) (Palmgren 1943, 1964, 1972, 1977a, Lehtinen \& Kleemola 1962, Huhta 1965, 1971, Lehtinen et al. 1979, Palmgren \& Biström 1979, Biström \& Väisänen 1998, Koponen 1995, Pajunen et al. 1995), but it has also been found somewhat abundantly in clear-cuts and burnt-overs (Huhta 1965, 1971). It has more rarely been caught in peatlands (e.g. Ledum bogs, Myrica-Molinia bogs, open bogs) (Palmgren 1972, 1977a, Koponen et al. 2001, Koponen 2002a), dry to moist meadows
(Huhta 1971, Palmgren 1972, 1977a), rocky habitats (Palmgren 1964), and very dry sublapidicol (Palmgren 1964).

\section{Discussion}

Although autecological information is essential in ecological studies, it is not easy to find information about it in the literature. Regarding the present review, several matters might cause errors in the classification. Firstly, the numbers of individuals caught have often not been reported in the reviewed studies; consequently, it is difficult to decide whether the habitat type reported in a particular study for a given species was just an occasional one or not. Secondly, the studies have often been carried out in particular types of habitat, some important habitat types for a given species possibly being left out because of the lack of information. Thirdly, only a few of the reviewed publications included several habitat types, and the catching effort varied remarkably, making the decisions about the main habitats of the species difficult. Fourthly, classifying habitats of the reviewed publications may sometimes be difficult because classes are more man-made than real in the nature. Fifthly, in many studies sufficient details about the habitats were not provided, and the decisions in the present paper had to be made based on knowledge about the habitat types in general.

Classifying habitats according to their moisture most likely differed between different authors. Sometimes it was unclear what the authors meant with dry, medium-moist or moist, and Huhta (1971) did not specify it either. My habitatclass boundaries may differ from his. For example, moist forests might belong to class "mediummoist" (forests with forest mosses, e.g. MT) or class "moist" (forests with Sphagnum mosses, e.g. spruce mires) in my classification, and $D$. latifrons (an affinity for shady forests), and $M$. sundevalli (an affinity for both light and shady forests) were classified into the moist habitat class (3) in Huhta (1971), but in my classification they fall into the medium-moist class (2), as the affinity was not for peatlands, but for forests with forest mosses.

My classification also differs from Huhta's 
(1971) for many species in terms of light intensity. Some of the differences are caused only by the clear-cuts; for example, Huhta (1971) classified Z. spinimana as BC2, but I classified it as being $\mathrm{ABC} 12$. For such a species, the habitat class would be $\underline{\mathrm{ABC}} 12$ for studies that include clearcuts, and for other ecological studies it would be $\mathrm{BC} 2$.

Sometimes the reason for the differences in my and Huhta's (1971) classifications might have been caused by differences in classifying habitats. For example, groves might be shady (C) in the middle of summer, although I considered them semi-open (B). For example, because $O$. praticola was found most abundantly in deciduous forests, I classified it as B2, although Huhta (1971) classified it as C3.

Another reason causing differences between my and Huhta's (1971) classification is that I used $25 \%$ of the individuals as a cut-off point. Therefore, my classification might take into account the occurrence in some classes that were not taken into account in Huhta (1971). For example, $B$. alticeps, $H$. insignis, and $T$. alacris were mainly caught in forests, as in Huhta (1971), but as in Palmgren (1977a) more than $25 \%$ of the individuals were caught in meadows, I classified them as indifferent towards light intensity (ABC or $\mathrm{AC}$ ). For $H$. insignis meadows were also mentioned among the main habitats in Palmgren (1972, 1975). Interestingly, meadows were among the main habitats of $B$. alticeps also in Central Europe (Heimer \& Nentwig 1991). Thus, if one wants to use a different cut-off point, the classes would change, for example the class for for $B$. alticeps and $H$. insignis might also be $\mathrm{BC} 2$, and for $T$. alacris $\mathrm{C} 23$.

A similar difference in the cut-off point was with the two Agroeca species. Huhta (1971) classified A. brunnea and A. proxima as $\mathrm{BC} 2$ and $\mathrm{B} 2$, respectively. Because they were caught in open bogs (e.g. Koponen 2002b) and clear-cuts (Huhta 1971), I added the letter A in the habitat classes of these species. They were, however, not as abundant in open habitats as in forested habitats.

There were differences in Huhta's (1971) and my classifications for several species that I classified as having an affinity for both open and semiopen habitats (AB). For example, I classified C. brevis as $\mathrm{AB} 2$ because of the occurrence in meadows (Palmgren 1972, 1976), although Huhta (1971) classified it as B2, and I classified $T$. scabriculus as $\mathrm{AB} 1$ because of the occurrence in lightly forested habitats (Palmgren 1972, 1976, 1977a), although Huhta (1971) classified it as A1.

There were also slight differences for some forest species between Huhta's (1971) and my classification. For example, Huhta (1971) classified $N$. reticulatus as B2, but I classified it as BC23 because of the occurrence in spruce forests and mires (e.g. Palmgren 1972). Huhta (1971) classified E. furcata as $\mathrm{C} 3$, but I classified it as $\mathrm{BC} 23$ because of the occurrence in all kinds of forests, with the exeption of the very dry types (Palmgren 1972, 1974b, 1977a).

There were several species that Huhta (1971) classified as independent of light intensity (D), but I did not. C. sylvaticus, D. pusillus, E. hiemalis, E. falcata, N. clathrata, T. experta, and $Z$. latreillei were not at all or quite rarely caught in shady forests or mires, thus in my classification they were either open habitat species (A) or open to semi-open habitat species (AB). D. pusillus was also found in forests in Central Europe (Heimer \& Nentwig 1991), and in Lithuania in pine bogs (Koponen et al. 2001), thus the class might also be $\mathrm{AB}$ instead of $\mathrm{A}$, or there might be a difference between Central and Northern Europe. $R$. lividus, $R$. scoticus, and $W$. cuspidata were found quite rarely in open habitats (Palmgren 1972 , 1977a), thus I classified them as forest generalists (BC). For R. lividus I added $\underline{\mathrm{A}}$ because it was found quite abundantly in clear-cuts.

There were some species that Huhta (1971) did not classify as independent of light intensity that I did. Because Palmgren (1972) caught $A$. scopigera and $O$. gibbosus in shore and/or fenlike Alneta, Huhta (1971) caught $A$. scopigera in spruce forests, and Palmgren (1977a) caught $O$. gibbosus in "swampy forests", I classified them as $\mathrm{ABC} 23$ and $\mathrm{ABC} 3$, respectively, although Huhta (1971) classified them as A3. As Huhta (1971) based his classification of $O$. gibbosus on British and German studies, there might be differences between them and Finnish studies. Because O. trux was found in open habitats and deciduous forests (e.g. Palmgren 1950, 1972), I classified it as $\mathrm{ABC} 123$, although Huhta (1971) classified it as $\mathrm{C} 3$.

The classification of $W$. antica was not 
straightforward. Heimer and Nentwig (1991) and Palmgren $(1972,1976,1982)$ stated that it lives in dry light habitats, including light forests. However, Huhta (1971) classified it as a forest generalist (BC). Many of the individuals were caught in light forests (B12) (e.g. Palmgren 1982), but not that many in dry open habitats, except for clearcuts (A1) (Huhta 1971). Interestingly, in Koponen (2002b) W. antica was the sixth most abundant species in an open bog (A3). In shady forests (C) it was found more rarely, but in Palmgren (1977a) the abundance exeeded 25\%. Thus, I classified $W$. antica as a generalist in terms of both light intensity and moisture (ABC123).

C. conica, G. omoeda, C. subsultans, and N. peltata were caught mostly in spruces. Therefore, I classified them as shady forest species (C), as Huhta (1971) did, although in Palmgren (1977a) the spruce forests were not of very closed growth. Thus, they could have also been classified as BC. D. pusilla was also caught most abundantly in trees, but Huhta (1971) classified it as an open habitat species (A). Although Heimer and Nentwig (1991) stated that it lives in sunny habitats, only two individuals were caught in open habitats in the Finnish studies.

Huhta (1971) classified $P$. riparia as BC23, but it was $\mathrm{AB} 123$ (might be even AB123) in my classification. There were only a few individuals in shady forests (Pajunen et al. 1995). Huhta (1971) caught it abundantly in clear-cuts and burnt-overs, and Itämies and Ruotsalainen (1985) in meadow-like vegetation. Although it is stated as living in light forests in Scandinavia (Holm \& Kronestedt 1970, Heimer \& Nentwig 1991), in my opinion the open habitats should be added to its habitat range.

For some species there were differences among the Finnish studies and the Central European book (Heimer \& Nentwig 1991). For example, E. atra and E. dentipalpis were in Heimer and Nentwig (1991) generalists, but both in my and Huhta's (1971) classification they were considered as open habitat species. G. murcidum seems to be clearly an open habitat species in the Finnish studies, although Heimer and Nentwig (1991) consider it as a forest species. Huhta (1971) classified $P$. listeri as C3 based on Central European references, and also Heimer and Nentwig (1991) state that it lives in moist shady forests. However, it was only rarely caught in spruce forests or mires in the Finnish studies. It was most abundantly caught in deciduous and mixed forests (Palmgren 1972), but because it was fairly abundant in meadows in Palmgren (1977a), I classified it as AB2.

Of course, the classification presented in this paper is not a final one, as the classes may change when new information is gathered. Furthermore, there are some complicating matters that may confound the classification. For example, the selection of a habitat may vary according to sex and stage of development, and according to the season (Edgar 1971). Further investigation is needed concerning these matters.

Acknowledgements. I thank Susanna Lehvävirta for fruitful discussions, and good comments on an earlier version of the manuscript. Seppo Koponen and an anonymous referee gave comments that helped me to improve the manuscript considerably. Seppo Koponen also helped via email. I also thank Anna Ojala and Jari Niemelä for discussions about the basis of classification, and Diane Alaruikka for checking the grammar of the manuscript. I received funding from The Finnish Biodiversity Research Programme FIBRE, and Maj and Tor Nessling Foundation.

\section{References}

Biström, O. \& Väisänen, R. 1988: Ancient-forest invertebrates of the Pyhän-Häkki national park in Central Finland. - Acta Zool. Fenn. 185: 1-69.

Cajander, A. K. 1949: Forest types and their significance. - Acta For. Fenn. 56: 1-71.

Caselius, R. \& Itämies, J. 1993: The wolf-spider fauna (Araneae, Lycosidae) on an island in the northern Bothnian Bay and on the mainland coast. — Bothnian Bay Reports 6: 3-22.

Edgar, W. D. 1971: The life-cycle, abundance and seasonal movement of the wolf spider, Lycosa (Pardosa) lugubris, in Central Scotland. - J. Anim. Ecol. 40: 303-322.

Foelix, R. F. 1982: Biology of spiders. - Harvard University Press, Cambridge, Massachussetts, and London. $306 \mathrm{pp}$.

Geiger, R. 1965: The climate near the ground. - Harvard University Press, Cambridge, Massachusetts. 611 pp.

Heimer, S. \& Nentwig, W. 1991: Spinnen Mitteleuropas. — Paul Parey, Berlin, Hamburg. 543 pp.

Holm, A. 1947: Svensk spindelfauna 3. Egentliga spindlar. Araneae. Fam. 8-10. Oxycopidae, Lycosidae och Pisauridae. - Entomologiska Föreningen i Stockholm, Stockholm. 48 pp. 
Holm, A. \& Kronestedt, T. 1970: A taxonomic study of the wolf spiders of the Pardosa pullata - group (Araneae, Lycosidae). - Acta Ent. Bohemoslov. 67: 408-428.

Huhta, V. 1965: Ecology of spiders in the soil and litter of Finnish forests. - Ann. Zool. Fenn. 2: 260-308.

Huhta, V. 1971: Succession in the spider communities of the forest floor after clear-cutting and prescribed burning. - Ann. Zool. Fenn. 8: 483-542.

Immonen, K. \& Itämies, J. 1994: Wolf spiders (Araneae, Lycosidae) on four habitats in Kuhmo, Central Finland. - Mem. Soc. F. Fl. Fenn. 70: 87-95.

Itämies, J. \& Jarva-Kärenlampi, M-L. 1989: Wolf spiders (Araneae, Lycosidae) on the bog at Pulkkila, Central Finland. - Mem. Soc. F. Fl. Fenn. 65: 103-108.

Itämies, J. \& Ruotsalainen, M. 1984: Phenology of wolf spiders (Araneae, Lycosidae) at Hämeenkyrö, SW Finland in 1980. — Mem. Soc. F. Fl. Fenn. 60: 145152.

Itämies, J. \& Ruotsalainen, M. 1985: Wolf spiders (Araneae, Lycosidae) in three habitats at Hämeenkyrö, SW Finland. - Mem. Soc. F. Fl. Fenn. 61: 45-54.

Koivula, M. 2001: Carabid beetles (Coleoptera, Carabidae) in boreal managed forests - meso-scale ecological patterns in relation to modern forestry. - $\mathrm{PhD}$ thesis, University of Helsinki.

Koponen, S. 1968: Über die Evertebrata-fauna (Mollusca, Chilopoda, Phalangida, Araneae und Coleoptera) von Hochmooren in Südwest-Häme. - Lounais-Hämeen Luonto 29: 12-22.

Koponen, S. 1978: Kuusamon soiden hämähäkkilajistosta (On the spider fauna of mires in Kuusamo). - Acta Univ. Oul. A 68. Biol. 4: 209-214. [In Finnish with English summary]

Koponen, S. 1979: Differences of spider fauna in natural and man-made habitats in a raised bog. - In: The use of ecological variables in environmental monitoring. The National Swedish Environment Protection Board, Report PM 1151.

Koponen, S. 1995: Ground-living spiders (Araneae) of old forests in eastern Finland. - Mem. Soc. F. Fl. Fenn. 71: $57-62$.

Koponen, S. 1996: Spiders (Araneae) on trunks and large branches of oak (Quercus robur) in SW Finland. Rev. Suisse Zool., vol. hors série: 335-340.

Koponen, S. 1999: Common ground-living spiders in old taiga forests of Finland. - J. Arachnol. 27: 201-204.

Koponen, S. 2000: Spiders (Araneae) on sandy islands in the southwestern archipelago of Finland. - Ekológia (Bratislava) 19 (Suppl. 4): 79-85.

Koponen, S. 2002a: Spider fauna of peat bogs in southwestern Finland. - European Arachnology 2000 (Proc. $19^{\text {th }}$ Eur. Coll. Arachnology, Århus 17-22 July 2000): 267-271.

Koponen, S. 2002b: Ground-living spiders in bogs in northern Europe. - J. Arachnol. 30: 262-267.

Koponen, S. \& Niemelä, P. 1994: Ground-living spiders in a polluted pine forest, SW Finland. - Boll. Acad. Gioenia Sci. Natur. Catania 26 (345): 221-226.

Koponen, S. \& Niemelä, P. 1995: Ground-living arthropods along pollution gradient in boreal pine forest. -
Entomol. Fennica 5: 127-131.

Koponen, S., Rinne, V. \& Clayhills, T. 1997: Arthropods on oak branches in SW Finland, collected by a new trap type. - Entomol. Fennica 3: 177-183.

Koponen, S., Vygandas, R. \& Dapkus, D. 2001: Changes in structure of ground-living spider (Araneae) communities on peatbogs along a transect from Lithuania to Lapland. - Norw. J. Entomol. 48: 167-174.

Kronestedt, T. 1990: Separation of two species standing as Alopecosa aculeata (Clerck) by morphological, behavioural and ecological characters, with remarks on related species in the pulverulenta group (Araneae, Lycosidae). - Zool. Scr. 19: 203-225.

Lehtinen, P. T. \& Kleemola, A. 1962: Studies on the spider fauna of the southwestern archipelago of Finland I. Arch. Soc. Vanamo 16: 97-114.

Lehtinen, P. T., Koponen, S. \& Saaristo, M. 1979: Studies on the spider fauna of the southwestern archipelago of Finland II. The Aland mainland and the island of Eckerö. - Mem. Soc. F. Fl. Fenn. 55: 33-52.

Marusik, Y. M. \& Koponen, S. 2000: Circumpolar diversity of spiders: implications for research, conservation and management. - Ann. Zool. Fenn. 37: 265-269.

Niemelä, J. \& Halme, E. 1992: Habitat associations of carabid beetles in fields and forests on the Åland Islands, SW Finland. - Ecography 15: 3-11.

Niemelä, J., Pajunen, T., Haila, Y., Punttila, P. \& Halme, E. 1994: Seasonal activity of boreal forest-floor spiders (Araneae). - J. Arachnol. 22: 23-31.

Pajunen, T., Haila, Y., Halme, E., Niemelä, J. \& Punttila, P. 1995: Ground-dwelling spiders (Arachnida, Araneae) in fragmented old forests and surrounding managed forests in southern Finland. - Ecography 18: 62-72.

Palmgren, P. 1939: Die Spinnenfauna Finnlands. I. Lycosidae. - Acta Zool. Fenn. 25: 1-86.

Palmgren, P. 1943: Die Spinnenfauna Finnlands. II. Pisauridae, Oxycopidae, Salticidae, Clubionidae, Anyphaenidae, Sparassidae, Ctenidae, Drassidae. - Acta Zool. Fenn. 36: 1-112.

Palmgren, P. 1950: Die Spinnenfauna Finnlands und Ostfennoskandiens. III. Xysticidae und Philodromidae. - Acta Zool. Fenn. 62: 1-43.

Palmgren, P. 1964: Arachnologische bestandesstudien in dem Koli-gebiet, Finnland. - Commentationes Biologicae XXVII. Societas Scientiarum Fennica, Helsinki. 20 pp.

Palmgren, P. 1972: Studies on the spider populations of the surroundings of the Tvärminne zoological station, Finland. - Commentationes Biologicae 52. Societas Scientiarum Fennica, Helsinki. 133 pp.

Palmgren, P. 1974a: Die Spinnenfauna Finnlands und Ostfennoskandiens. V. Theridiidae und Nesticidae. Fauna Fenn. 26: 1-54.

Palmgren, P. 1974b: Die Spinnenfauna Finnlands und Ostfennoskandiens. IV. Argiopidae, Tetragnathidae und Mimetidae. - Fauna Fenn. 24: 1-70.

Palmgren, P. 1975: Die Spinnenfauna Finnlands und Ostfennoskandiens. VI. Linyphiidae 1. - Fauna Fenn. 28: $1-102$.

Palmgren, P. 1976: Die Spinnenfauna Finnlands und Ost- 
fennoskandiens. VII. Linyphiidae 2. - Fauna Fenn. 29: 1-126.

Palmgren, P. 1977a: Studies on spider populations in Mäntyharju, Finland. - Commentationes Biologicae 87. Societas Scientiarum Fennica, Helsinki. 44 pp.

Palmgren, P. 1977b: Die Spinnenfauna Finnlands und Ostfennoskandiens. VIII. Argyronetidae, Agelenidae, Hahniidae, Dictynidae, Amaurobiidae, Titanoecidae, Segestriidae, Pholcidae und Sicariidae. - Fauna Fenn. 30: 1-50.

Palmgren, P. 1982: Ecology of the spiders Walckenaeria (Wideria) alticeps (Denis), new to Finland, and $W .(W$. antica (Wider) (Araneae, Linyphiidae). - Ann. Zool. Fennici 19: 199-200.

Palmgren, P. 1983: Die Philodromus aureolus-Gruppe und die Xysticus cristatus-Gruppe (Araneae) in Finnland. - Ann. Zool. Fenn. 20: 203-206.

Palmgren, P. \& Biström, O. 1979: Populations of Araneae
(Arachnoidea) and Staphylinidae (Coleoptera) on the floor of a primeval forest in Mäntyharju, southern Finland. - Ann. Zool. Fenn. 16: 177-182.

Platnick, N. I. 2003: The world spider catalog, version 4.0. - American Museum of Natural History, online at http://research.amnh.org/entomology/spiders/catalog/index.html.

Saaristo, M. I. 1971: Revision of the genus Maro O. PCambridge (Araneae, Linyphiidae). - Ann. Zool. Fennici 8: 463-482.

Shrader-Frechette, K. S. \& McCoy, E. D. 1993: Method in ecology. Strategies for conservation. - Cambridge University Press. 328 pp.

Väisänen, R. \& Biström, O. 1990: Boreal forest spiders and the preservation of biotic diversity: results from Finnish primeval forests. - Acta Zool. Fennica 190: 373-378. 
Appendix 1. Habitat affinity classes of some Finnish spiders according to light intensity and moisture. The classification applies to the boreal region. $A=$ open habitats, $B=$ semi-open habitats, e.g. light forests, $C=$ shady forests, 1 = dry habitats, 2 = medium-moist habitats, 3 = moist habitats (see text for more details). If the letter or number indicating habitat affinity class is in brackets, the species was found in that kind of a habitat, but the number of individuals found was small compared to the other habitat types (less than $25 \%$ in the studies for which I was able to calculate the percentages). If $A$, or 1 is underlined, the focal species was found in clear-cuts, but not as abundantly in other open or dry habitat types. Thus, the open habitat should be included in the habitat affinity in ecological studies concerning clear-cuts, but not in other studies. A question mark was put in the column "Class", if the number of individuals was $<10$ in the reviewed studies, except in the very clear cases, but the few findings are shown in the columns "Light" and "Moisture". The number of individuals (including juveniles) in the reviewed Finnish studies is shown in the column "N". There is some uncertainty ( $<5$ individuals) in the given numbers, because the numbers of individuals from Palmgren (1977) were calculated from dominance values. The number of individuals was not specified in all studies, which is indicated with a question mark. The classification of Huhta (1971) is shown in the last column for comparison.

\section{Families and species}

\section{Araneidae}

Araneus diadematus

A. nordmanni

A. quadratus

A. sturmi

Cercidia prominens

Cyclosa conica

Gibbaranea omoeda

Hypsosinga sanguinea

\section{Clubionidae}

Clubiona caerulescens

C. kulczynskii

C. lutescens

C. neglecta

C. subsultans

C. subtilis

C. trivialis

\section{Corinnidae}

Phruolithus festivus

Dictynidae

Dictyna arundinacea

D. pusilla

Mastigusa arietina

Gnaphosidae

Drassodes pubescens

Drassyllus praeficus

D. pusillus

Gnaphosa bicolor

G. microps

G. montana

Haplodrassus cognatus

H. moderatus

$H$. signifer

$H$. silvestris

H. soerenseni

Micaria aenea

M. pulicaria

M. silesiaca

Zelotes clivicola

Z. latreillei

\section{Light}

Moisture

(A)B

$\mathrm{BC}$ ?

(1)2(3)

$A(B)$

(A)B(C)

$\mathrm{AB}(\mathrm{C})$

$(A B) C$

(B)C

(A)B(C)

23?

(12)3

(1)2(3)

12(3)

(1) $2(3)$

(1)2(3)

1(23)

$B(C)$

23

$A B C$

(A)B(C)

$A(B)$

(AB)C

$A$

(A)B

AB

(A)B

(A)BC

(A) $\mathrm{C}$

23

(1)23

1(23)

(1)2(3)

(1) 3

1(23)

123

1(2)3

(1) $2(3)$

(1) 2

\begin{tabular}{ll}
$A B(C)$ & $1(2) 3$ \\
$A(B)$ & 12 \\
$A(B)$ & $13 ?$ \\
$A B(C)$ & $12(3)$ \\
\hline$A(B ?)$ & $(1) 3$ \\
$A B$ & 12 \\
$B$ & $2 ?$ \\
$A$ & $(12) 3$ \\
$A B$ & 123 \\
$(A) B$ & $(1) 2$ \\
$A B C$ & $12(3)$ \\
$A B ?$ & $12 ?$ \\
$A B$ & $12(3)$ \\
$A(B)$ & $1(2)$ \\
$A B$ & $1(23)$ \\
$A B ?$ & $123 ?$
\end{tabular}

\section{Class}

$\mathbf{N}$

Huhta 1971

$\begin{array}{lll}\text { B 2 } & 385+? & \text { B3 } \\ ? & 2+? & - \\ \text { A 3 } & 356+? & - \\ \text { B 2 } & 1401+? & - \\ \text { AB 12 } & 107+? & - \\ \text { C 2 } & 387+? & \text { C4 } \\ \text { C 2 } & 297+? & \text { C } \\ \text { B 1 } & 48+? & \text { B2 }\end{array}$

B 23?

?

B 23

A 1

C 2

A 3

B 1

AB 123

B 13

BC 2

C 2?

AB 13

A 12

A 13?

AB 12

A 3

AB 12?

B 2?

A 3

AB 123

$\mathrm{B} 2$ ?

ABC 12

$\mathrm{AB} 12 ?$

AB 12

A 1

AB 1

AB 123?
$14+?$

$8+?$

$128+?$

$38+?$

$704+$ ?

75

$381+?$

$482+?$

$2553+?$

$285+?$

$20+$ ?

$307+?$

$332+?$

$17+$ ?

$437+?$

$34+$ ?

$19+$ ?

$15+?$

24+?

$359+?$

19

$407+?$

44

$80+?$

$10+?$

126

$48+?$
A1

A

?

AB4

$-$

D3

B1

B3

$-$

C

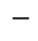

$-$

$-$

C2

B4

A

?

B1

$-$

$-$

B2

?

BC2

A1

A1

A1

B2 


\begin{tabular}{|c|c|c|c|c|c|}
\hline Z. petrensis & $A B ?$ & $1 ?$ & $\mathrm{AB} 1 ?$ & $63+?$ & A1 \\
\hline Z. subterraneus & $A B(C)$ & 12 & AB 12 & $151+?$ & - \\
\hline \multicolumn{6}{|l|}{ Hahniidae } \\
\hline Cryphoeca silvicola & $(A B) C$ & (1)2(3) & C 2 & $871+?$ & $\mathrm{C} 2$ \\
\hline Hahnia nava & $A B$ & $1(23)$ & $A B 1$ & $158+?$ & - \\
\hline H. ononidum & $\underline{A B}(C)$ & 12 & AB 12 & $287+?$ & $\mathrm{BC} 2$ \\
\hline H. pusilla & $\bar{A} B C$ & $(12) 3$ & $\bar{A} B \bar{C} 3$ & $557+?$ & 3 \\
\hline \multicolumn{6}{|l|}{ Linyphiidae } \\
\hline Abacoproeces saltuum & $(\mathrm{A}) \mathrm{B}(\mathrm{C})$ & (1) 2 & B 2 & $92+?$ & $A B$ ? \\
\hline Agnyphantes expunctus & BC? & $2 ?$ & $\mathrm{BC} 2 ?$ & $26+?$ & - \\
\hline Agyneta cauta & $A B C$ & 123 & ABC 123 & $809+?$ & D3 \\
\hline A. conigera & (A)BC & (1)2(3) & $\mathrm{BC} 2$ & $407+?$ & $\mathrm{BC}$ \\
\hline A. olivacea & $\mathrm{BC}$ ? & $2 ?$ & ? & $5+?$ & - \\
\hline A. ramosa & (A)BC & (1)2(3) & BC 2 & $981+?$ & C3 \\
\hline A. subtilis & (A) $\mathrm{BC}$ & 123 & BC 123 & $761+?$ & $\mathrm{BC}$ \\
\hline Allomengea scopigera & $A B C$ & 23 & ABC 23 & $82+?$ & A3 \\
\hline Anguliphantes angulipalpis & (A)BC & (1)2(3) & BC 2 & $148+?$ & $\mathrm{BC} 2$ \\
\hline Asthenargus paganus & BC & 23 & BC 23 & $26+?$ & - \\
\hline Bathyphantes gracilis & $A B(C)$ & $(12) 3$ & $A B 3$ & $269+?$ & A3 \\
\hline B. nigrinus & $A B(C)$ & (1) 23 & AB 23 & $463+?$ & - \\
\hline B. parvulus & $A B$ & 123 & AB 123 & $273+?$ & C3? \\
\hline Bolephthyphantes index & (A)B & $\overline{(12) 3}$ & B 3 & $54+?$ & $\mathrm{BC}$ ? \\
\hline Bolyphantes alticeps & $A B C$ & (1)2(3) & ABC 2 & $396+?$ & BC4 \\
\hline B. luteolus & $A B$ & (1) 23 & AB 23 & $111+?$ & - \\
\hline Centromerus arcanus & $A B C$ & 123 & ABC 123 & $7365+?$ & D3 \\
\hline C. sylvaticus & $A B(C)$ & $\overline{1} 23$ & AB $1 \overline{23}$ & $300+?$ & D3 \\
\hline Ceratinella brevis & $A B(C)$ & (1)2(3) & $A B \overline{2}$ & $347+?$ & B2 \\
\hline C. scabrosa & $B(C)$ & $2(3)$ & B 2? & $38+?$ & - \\
\hline Cnephalocotes obscurus & $A B(C)$ & 123 & AB 123 & $587+?$ & A \\
\hline Dicymbium tibiale & $A B C$ & 123 & ABC 123 & $626+?$ & C3 \\
\hline Diplocentria bidentata & $A B C$ & $12(3)$ & $\mathrm{ABC} 12$ & $1919+?$ & $\mathrm{BC} 2$ \\
\hline D. rectangulata & $\bar{A} B C$ & $\overline{123}$ & $\bar{A} B C \overline{1} 23$ & $218+?$ & $\mathrm{BC} 2$ \\
\hline Diplocephalus latifrons & $(A B) C$ & (1) 2 & $\mathrm{C} 2$ & $402+?$ & $\mathrm{C} 3$ \\
\hline D. picinus & (A)B(C) & (1)2(3) & B 2 & $375+?$ & BC2 \\
\hline Diplostyla concolor & $A B(C)$ & $12(3)$ & $\mathrm{AB} 12$ & $253+?$ & ? \\
\hline Dismodicus bifrons & $A B$ & (1) 23 & $A B \overline{2} 3$ & $173+?$ & A? \\
\hline D. elevatus & (A)BC & (1) 23 & BC 23 & $574+?$ & - \\
\hline Drapetisca socialis & (A) $\mathrm{BC}$ & (1) 2 & BC 2 & $463+?$ & $\mathrm{BC}$ \\
\hline Entelecara congenera & (A) $\mathrm{BC}$ & (1)2(3) & BC 2 & $1814+?$ & - \\
\hline E. erythropus & $A B$ & 2 & ? & $2+?$ & - \\
\hline Erigone atra & $A(B C)$ & $1(2) 3$ & A 13 & $109+?$ & A3 \\
\hline E. dentipalpis & $A(B)$ & 13 & $\mathrm{~A} \overline{1} \overline{3}$ & $311+?$ & A3 \\
\hline Erigonella hiemalis & $A B(C)$ & 123 & $A \bar{B} 123$ & $553+?$ & D3 \\
\hline Gonatium rubellum & (A)BC & (1)2(3) & BC 2 & $105+?$ & $\mathrm{BC} 2$ \\
\hline Gongylidiellum latebricola & $(A B) C$ & (12)3 & C 3 & $320+?$ & 3 \\
\hline G. murcidum & $A(B)$ & (1) 23 & A 23 & $95+?$ & A3 \\
\hline Gongylidium rufipes & $A B(C)$ & (1)2(3) & AB 2 & $1379+?$ & - \\
\hline Helophora insignis & $A B C$ & (1)2(3) & $\mathrm{ABC} 2$ & $814+?$ & $\mathrm{BC} 2$ \\
\hline Hilaira herniosa & $(\underline{A}) B C$ & (1) 23 & BC 23 & $164+?$ & $\mathrm{BC} 3$ \\
\hline Incestophantes kochiellus & $\overrightarrow{\mathrm{BC}}$ & 2 & ? & $8+?$ & - \\
\hline Lepthyphantes antroniensis & (A) $B C$ & (1)2(3) & BC 2 & $244+?$ & $\mathrm{BC} 2$ \\
\hline Lophomma punctatum & $\overrightarrow{A B}$ & (2) 3 & $A B 3$ & $21+?$ & - \\
\hline Macrargus boreus & $(\mathrm{A}) \mathrm{B}(\mathrm{C})$ & (1)2(3) & B 2 & $108+?$ & ? \\
\hline M. carpenteri & $\mathrm{AB}(\mathrm{C})$ & 123 & AB 123 & $605+?$ & A1? \\
\hline M. multesimus & B & 1 & $?$ & 1 & - \\
\hline M. rufus & (A)BC & (1)2(3) & BC 2 & $3823+?$ & $\mathrm{BC} 2$ \\
\hline Maro lehtineni & (A) C & (1) 2 & C 2? & $10+?$ & $?$ \\
\hline M. lepidus & $A B C$ & 3 & $A B C 3$ & $97+?$ & - \\
\hline M. sublestus & (A)BC & (2) 3 & BC 3 & $42+?$ & - \\
\hline Maso sundevalli & $A B C$ & $12(3)$ & ABC 12 & $1738+?$ & $\mathrm{BC} 3$ \\
\hline
\end{tabular}




\begin{tabular}{|c|c|c|c|c|c|}
\hline Meioneta affinis & $A(B)$ & 123 & A 123 & $668+?$ & A3 \\
\hline M. gulosa & $\underline{A}(B C)$ & $1(2)$ & A 1 & $110+?$ & $\mathrm{~A} 1$ \\
\hline M. rurestris & $A B(C)$ & $1(2) 3$ & AB 13 & $56+?$ & A4 \\
\hline Micrargus apertus & $\mathrm{BC}$ & 23 & BC 23? & $21+?$ & - \\
\hline M. herbigradus & $A B C$ & 123 & ABC 123 & $387+?$ & D4 \\
\hline Microlinyphia pusilla & $A(B C)$ & $1(2) 3$ & A 13 & $82+?$ & A \\
\hline Microneta viaria & $(\mathrm{A}) \mathrm{B}(\mathrm{C})$ & (1)2(3) & $\mathrm{BC} 2$ & $479+?$ & $\mathrm{BC} 2$ \\
\hline Minicia marginella & $A(B C)$ & $1(2) 3$ & A 13 & $152+?$ & A3 \\
\hline Minyriolus pusillus & (A) $\mathrm{BC}$ & $12(3)$ & BC 12 & $8372+?$ & $\mathrm{BC} 2$ \\
\hline Moebelia penicillata & $\mathrm{B}(\mathrm{C})$ & $2 ?$ & B 2? & $263+?$ & - \\
\hline Neriene clathrata & $A B(C)$ & (1)2(3) & $A B 2$ & $548+?$ & D2 \\
\hline N. montana & (A)BC? & (1)2? & $\mathrm{BC} 2 ?$ & $211+?$ & - \\
\hline N. peltata & $(A B) C$ & (1)2(3) & C 2 & $787+?$ & C \\
\hline N. radiata & $(\mathrm{A}) \mathrm{B}(\mathrm{C})$ & 123 & B 123 & $98+?$ & - \\
\hline Obscuriphantes obscurus & (A)BC & (1)2(3) & BC 2 & $182+?$ & - \\
\hline Oedothorax apicatus & $\mathrm{A}(\mathrm{B})$ & (1) 3 ? & A 3? & $422+?$ & - \\
\hline O. gibbosus & $A B C$ & (2)3 & ABC 3 & $1553+?$ & A3 \\
\hline O. retusus & $A(B C)$ & (2) 3 & A 3 & $422+?$ & - \\
\hline Oreonetides vaginatus & (A) $\mathrm{BC}$ & (1) 23 & BC 23 & $27+?$ & - \\
\hline Oryphantes angulatus & $A B C$ & (12)3 & $A B C 3$ & $278+?$ & D3 \\
\hline Palliduphantes pallidus & $A B C$ & $12(3)$ & ABC 12 & $120+?$ & C3? \\
\hline Pelecopsis elongata & $(A B) C$ & (1)2(3) & C 2 & $135+?$ & $?$ \\
\hline P. mengei & $(\mathrm{AB}) \mathrm{C}$ & (1) 23 & C 23 & $59+?$ & ? \\
\hline Peponocranium praeceps & $A B ?$ & $3 ?$ & $?$ & 2 & - \\
\hline Pityohyphantes phrygianus & (A)BC & (1)2(3) & BC 2 & $2747+?$ & - \\
\hline Pocadicnemis pumila & $A B(C)$ & 123 & AB 123 & $2312+?$ & A3 \\
\hline Poeciloneta variegata & $(A B) C$ & (1)2? & C 2? & $78+?$ & - \\
\hline Porrhomma campbelli & $\mathrm{C}$ & 3 & $?$ & $?$ & - \\
\hline P. pallidum & $\underline{A}(B) C$ & 123 & AC 123 & $1202+?$ & C3 \\
\hline P. pygmaeum & $\mathrm{AB}$ & (2) 3 & $\bar{A} B \overline{3}$ & $256+?$ & - \\
\hline Savignia frontata & $A(B C)$ & $1(2) 3$ & A 13 & $231+?$ & A3 \\
\hline Scotinotylus evansi & $(\mathrm{A}) \mathrm{B}(\mathrm{C})$ & (1) 2 & B $\overline{2}$ & $176+?$ & AB1-2 \\
\hline Semljicola faustus & $(\overline{A B}) \mathrm{C}$ & (2) 3 & C 3 & $597+?$ & C3 \\
\hline S. latus & $\underline{A C}$ & 12 & $?$ & $2+?$ & - \\
\hline Silometopus incurvatus & $\bar{B}(C)$ & $\overline{12}$ & B 12 & $130+?$ & - \\
\hline S. reussi & A & $13 ?$ & A 13? & $244+?$ & A3 \\
\hline Sisicus apertus & $A B C$ & 123 & ABC 123 & $30+?$ & D3 \\
\hline Stemonyphantes lineatus & $A B C$ & (1)23 & $A B C 23$ & $161+?$ & $?$ \\
\hline Tallusia experta & $A B(C)$ & (12)3 & AB 3 & $166+?$ & D3 \\
\hline Tapinocyba insecta & $A B$ & $12 ?$ & $?$ & $3+?$ & - \\
\hline T. pallens & ABC & $12(3)$ & ABC 12 & $10029+?$ & $\mathrm{BC} 2$ \\
\hline Tapinopa longidens & $\bar{A} B C$ & 12(3) & $\bar{A} B C 12$ & $297+?$ & $?$ \\
\hline Tenuiphantes alacris & $\bar{A}(B) C$ & (1)23 & $\overline{A C} 2 \overline{3}$ & $2232+?$ & C \\
\hline T. cristatus & $(A) B(C)$ & (2) 3 & B 3 & $260+?$ & - \\
\hline T. mengei & $\underline{A B}(C)$ & $12(3)$ & AB 12 & $785+?$ & AB2? \\
\hline T. tenebricola & (A)BC & (1)2(3) & BC 23 & $445+?$ & $\mathrm{C} 2$ \\
\hline Thyreosthenius biovatus & $\mathrm{C}$ & 2 & $?$ & $5+?$ & - \\
\hline T. parasiticus & $(\mathrm{A}) \mathrm{BC}$ ? & $2(3) ?$ & $\mathrm{BC} 2 ?$ & $19+?$ & - \\
\hline Tibioploides arcuatus & (A) $B(C)$ & $12(3)$ & B 12 & $67+?$ & B1-2 \\
\hline Tibioplus diversus & $\overrightarrow{\mathrm{BC}}$ & 2 & $?$ & $3+?$ & C3 \\
\hline Tiso vagans & $A(C)$ & (1)2(3) & A 2 & $316+?$ & - \\
\hline Troxochrota scabra & $A B(C)$ & $12(3)$ & AB 12 & $213+?$ & B1 \\
\hline Troxochrus nasutus & $A C$ & $2 ?$ & $?$ & $4+?$ & 3 \\
\hline T. scabriculus & $A B$ & $1(2)$ & $A B 1$ & $704+?$ & $\mathrm{~A} 1$ \\
\hline Walckenaeria antica & $A B C$ & 123 & ABC 123 & $1376+?$ & $\mathrm{BC}$ \\
\hline W. atrotibialis & $A B C$ & $(12) 3$ & ABC 3 & $85+?$ & D3 \\
\hline W. cucullata & ABC & $12(3)$ & ABC 12 & $854+?$ & C3? \\
\hline W. cuspidata & (A)BC & (12)3 & BC 3 & $284+?$ & D3 \\
\hline W. dysderoides & $A B C$ & 123 & ABC 123 & $558+?$ & B2 \\
\hline W. karpinskii & (A) $\mathrm{BC}$ & (1) 2 & BC 2? & $60+?$ & $\mathrm{C} 3$ \\
\hline
\end{tabular}




W. nudipalpis
W. obtusa
W. unicornis
W. vigilax
Zornella cultrigera
Liocranidae
Agroeca brunnea
A. proxima
Lycosidae
Acantholycosa lignaria
Alopecosa aculeata
A. inquilina
A. pinetorum
A. pulverulenta
A. taeniata
Pardosa amentata
P. fulvipes
P. hyperborea
P. lugubris
P. paludicola
P. palustris
P. pullata
P. riparia
P. schenkeli
P. sphagnicola
Pirata hygrophilus
P. piraticus
P. uliginosus
Trochosa ruricola
T. spinipalpis
T. terricola
Xerolycosa nemoralis
Mimetidae
Ero furcata
Philodromidae
Thanatus formicinus
Tibellus oblongus
Pisauridae
Dolomedes fimbriatus
Salticidae
Euophrys frontalis
Evarcha falcata
Heliophanus dampfi
H. dubius
Neon reticulatus
Pellenes lapponicus
Pseudeuophrys erratica
Salticus cingulatus
Sibianor aurocinctus
Sitticus caricis
Sparassidae
Micrommata virescens
Tetragnathidae
Metellina mengei
M. merianae
Pachygnatha listeri
Theridiidae
Crustulina guttata
Dipoena torva
Episinus angulatus

$\begin{array}{ll}A B C & (\underline{1}) 23 \\ (A) B C & (1) 23 \\ A B(C) & 23 \\ A B(C) ? & (2) 3 \\ (\underline{A}) B C & (1) 2(3) \\ & \\ A B C & 123 \\ A B(C) & \underline{123}\end{array}$

$\begin{array}{ll}(A) B(C) & (1) 2(3) \\ (A) B & 12(3) \\ A B & 12 \\ (A) B(C) & (1) 2(3) \\ A(B) & 123 \\ (A) B C & 12(3) \\ A(B) & (12) 3 \\ A & 23 \\ A(B) & (12) 3 \\ A B(C) & 12(3) \\ A & (2) 3 \\ A(B) & 123 \\ A(B) & 123 \\ A B(C) & 123 \\ A & 1 \\ A B & (12) 3 \\ A B C & (12) 3 \\ A B(C) & (2) 3 \\ A B(C) & 3 \\ A(B) & 12 \\ A B(C) & (12) 3 \\ A B(C) & 12(3) \\ A B & 12\end{array}$

(A)BC

$\mathrm{AB} \quad 1(2) 3$

$\mathrm{AB}(\mathrm{C}) \quad 12(3)$

$\mathrm{AB}(\mathrm{C}) \quad(12) 3$

(A)B 12(3)

$\mathrm{AB}(\mathrm{C}) \quad 123$

$A$ ?

$\begin{array}{ll}\text { (A)B } & (1) 2 \\ (\mathrm{~A}) \mathrm{BC} & (1) 23 \\ \mathrm{AB} ? & 1 ? \\ \mathrm{~B}(\mathrm{C}) ? & 2 ? \\ \mathrm{AB} ? & 12 ?\end{array}$

A (1)23

$\mathrm{AB}(\mathrm{C}) ? \quad 3$

$\mathrm{AB}(\mathrm{C}) \quad 123 ?$

$\mathrm{ABC} \quad(1) 23$

$(\mathrm{AB}) \mathrm{C} \quad 2$ ?

$\mathrm{AB}(\mathrm{C})$

$\mathrm{AB}(\mathrm{C}) \quad 123$

$\mathrm{BC} 2$ ?

(A)B(C) $\quad 123$

$\begin{array}{lll}\text { ABC 23 } & 145+? & \text { D3 } \\ \text { BC 23 } & 84+? & \text { BC3 } \\ \text { AB 23 } & 80+? & - \\ \text { AB 3? } & 12+? & - \\ \text { BC 2 } & 91+? & \text { B2 } \\ & & \\ \text { ABC 123 } & 237+? & \text { BC2 } \\ \text { AB 123 } & 76+? & \text { B2 }\end{array}$

B $2 \quad 17+? \quad$ B2

B 12 265+? -

AB $12 \quad 41+$ ?

B 2 544+? -

A $123 \quad 987+? \quad$ A2

BC 2 161+? -

A $3 \quad 1436+? \quad$ A3

A 23 ? -

A 3 2121+? A3

AB $12 \quad$ 4335+? B2

A 3 74+? -

A $123 \quad 380+? \quad$ A2

A 123 449+? A3

AB $123 \quad 1900+? \quad B C 2-3$

$\begin{array}{lll}? & 1 & \mathrm{~A} 1\end{array}$

AB $3 \quad$ 2640+? A3

$\begin{array}{lll}A B C & 2837+? & \end{array}$

AB $3 \quad 919+?$

AB 3 1386+? -

A $12 \quad 126+? \quad$ A2

AB $3 \quad 591+? \quad$ A3

AB $12 \quad 777+? \quad B 2$

AB $12 \quad 427+? \quad A 1$

BC $23 \quad 132+? \quad$ C3

$\mathrm{AB} 13 \quad 79+? \quad \mathrm{AB}$

AB $12 \quad 278+? \quad A 2$

AB $3 \quad 512+?$

$\begin{array}{lll}\text { B 12 } & 31 & \text { B2 } \\ \text { AB 123 } & 654+? & \text { D4 } \\ ? & 4+? & - \\ \text { B 2 } & 78+? & - \\ \text { BC 23 } & 1547+? & \text { B2 } \\ ? & 2 & ? \\ \text { B 2? } & 13+? & - \\ \text { AB 12? } & 65+? & \text { A1 } \\ \text { A 23 } & 22+? & \text { A } \\ \text { AB 3? } & 64+? & - \\ \text { AB 123 } & 107+? & - \\ \text { ABC 23 } & 357+? & \text { D4 } \\ \text { C 2? } & 55+? & - \\ \text { AB 2 } & 183+? & \text { C3 } \\ \text { AB 123 } & 1370+? & \text { A 1? } \\ \text { BC 2? } & 14+? & - \\ \text { B 123 } & 46+? & ?\end{array}$




Euryopis flavomaculata
Lasaeola tristis
Neottiura bimaculata
Robertus arundineti
R. lividus
R. lyrifer
R. scoticus
Steatoda bipunctata
S. phalerata
Theridion mystaceum
T. sisyphium
Thomisidae
Ozyptila atomaria
O. praticola
O. trux
Xysticus audax
X. bifasciatus
X. cristatus
X. lineatus
X. luctuosus
X. obscurus
X. sabulosus
X. ulmi
Zoridae
Zora nemoralis
Z. spinimana

\begin{tabular}{|c|c|c|c|c|}
\hline $\mathrm{AB}(\mathrm{C})$ & 123 & AB 123 & $263+?$ & B2 \\
\hline$A B(C)$ & 123 & AB 123 & $71+?$ & - \\
\hline$A(B C)$ & $12(3)$ & A 12 & $636+?$ & $A$ \\
\hline$A(B C)$ & (12)3 & $A \overline{3}$ & $504+?$ & A3 \\
\hline$A B C$ & 123 & $\underline{A B C} 123$ & $1024+?$ & D3 \\
\hline $\bar{A} B ?$ & $\overline{2} 3 ?$ & $\bar{?}$ & $4+?$ & A3 \\
\hline (A)BC & (1)23 & BC 23 & $1554+?$ & D3 \\
\hline (A)B & $2 ?$ & B 2? & $83+?$ & - \\
\hline$A(B)$ & 13 & A 13 & $70+?$ & A1 \\
\hline $\mathrm{B}(\mathrm{C}) ?$ & $2(3) ?$ & B 2? & $42+?$ & - \\
\hline$(\mathrm{A}) \mathrm{B}(\mathrm{C})$ & (1)2(3) & B 2 & $416+?$ & - \\
\hline$A B$ & $12(3)$ & AB 12 & $96+?$ & B2 \\
\hline$(\mathrm{A}) \mathrm{B}(\mathrm{C})$ & (1)2(3) & B 2 & $120+?$ & C3 \\
\hline$A B C$ & 123 & $\mathrm{ABC} 123$ & $506+?$ & C3 \\
\hline$(\underline{A}) B C ?$ & $\overline{1} 2 ?$ & BC $1 \overline{2} ?$ & $40+?$ & $?$ \\
\hline $\mathrm{A}(\mathrm{B})$ & $12(3)$ & A 12 & $210+?$ & $\mathrm{~A} 2$ \\
\hline $\mathrm{AB}(\mathrm{C})$ & $12(3)$ & $A B 12$ & $1911+?$ & $?$ \\
\hline$A B$ & $1(2) 3$ & $\mathrm{AB} 13 ?$ & $30+?$ & 3 \\
\hline $\mathrm{AB}(\mathrm{C})$ & $12(3)$ & AB 12 & $168+?$ & $?$ \\
\hline (A)BC & (1)2(3) & BC 2 & $112+?$ & $?$ \\
\hline$A B$ & $12 ?$ & $\mathrm{AB} 12 ?$ & $18+?$ & A1 \\
\hline$A(B C)$ & (1)23 & A 23 & $297+?$ & A3 \\
\hline $\mathrm{ABC}$ & $12(3)$ & $\mathrm{ABC} 12$ & $771+?$ & $\mathrm{BC}$ \\
\hline$\underline{A B C}$ & $12(3)$ & $\underline{A B C} 12$ & $945+?$ & BC2 \\
\hline
\end{tabular}

